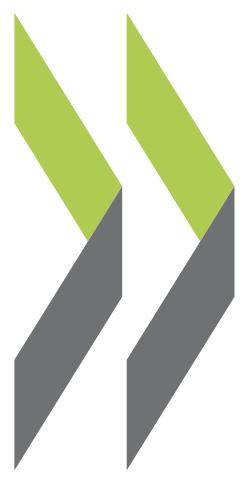

SIGMA Papers No. 10

\title{
Civil Service Pension Schemes
}

\section{OECD}

https://dx.doi.org/10.1787/5kml6g6c4rvl-en 
CIVIL SERVICE PENSION SCHEMES

SIGMA PAPERS: No. 10

ORGANISATION FOR ECONOMIC CO-OPERATION AND DEVELOPMENT

Paris

48826

Document complet disponible sur OLIS dans son format d'origine

Complete document available on OLIS in its original format 


\section{THE SIGMA PROGRAMME}

SIGMA -- Support for Improvement in Governance and Management in Central and Eastern European Countries -- is a joint initiative of the OECD Centre for Co-operation with the Economies in Transition and the European Union's Phare Programme. The initiative supports public administration reform efforts in thirteen countries in transition, and is financed mostly by Phare.

The Organisation for Economic Co-operation and Development is an intergovernmental organisation of 29 democracies with advanced market economies. The Centre channels the Organisation's advice and assistance over a wide range of economic issues to reforming countries in Central and Eastern Europe and the former Soviet Union. Phare provides grant financing to support its partner countries in Central and Eastern Europe to the stage where they are ready to assume the obligations of membership of the European Union.

Phare and SIGMA serve the same countries: Albania, Bosnia-Herzegovina, Bulgaria, the Czech Republic, Estonia, the Former Yugoslav Republic of Macedonia, Hungary, Latvia, Lithuania, Poland, Romania, Slovakia and Slovenia.

Established in 1992, SIGMA works within the OECD's Public Management Service, which provides information and expert analysis on public management to policy-makers and facilitates contact and exchange of experience amongst public sector managers. SIGMA offers beneficiary countries access to a network of experienced public administrators, comparative information, and technical knowledge connected with the Public Management Service.

SIGMA aims to:

- assist beneficiary countries in their search for good governance to improve administrative efficiency and promote adherence of public sector staff to democratic values, ethics and respect of the rule of law;

- help build up indigenous capacities at the central governmental level to face the challenges of internationalisation and of European Union integration plans; and

- support initiatives of the European Union and other donors to assist beneficiary countries in public administration reform and contribute to co-ordination of donor activities.

Throughout its work, the initiative places a high priority on facilitating co-operation among governments. This practice includes providing logistical support to the formation of networks of public administration practitioners in Central and Eastern Europe, and between these practitioners and their counterparts in other democracies.

SIGMA works in five technical areas: the Reform of Public Institutions, Management of Policy-making, Expenditure Management, Management of the Public Service, and Administrative Oversight. In addition, an Information Services Unit disseminates published and on-line materials on public management topics.

\section{Copyright OECD, 1997}

Applications for permission to reproduce or translate all or part of this material should be made to: Head of Publications Service, OECD, 2 rue André-Pascal, 75775 Paris Cedex 16, France.

Views expressed in this publication do not represent official views of the European Commission, OECD Member countries, or the central and eastern European countries participating in the Programme. 


\section{FOREWORD}

This publication ${ }^{1}$ is a tool for designers of new civil service pension schemes in central and eastern Europe. It presents civil service pension schemes in five OECD Member countries and ten central and eastern European countries.

In most central and eastern European countries, people employed in the public administration are covered under common national pension schemes, usually defined in a common pension law. As part of efforts to improve the professionalisation and quality of public administration, countries are defining civil service categories of personnel through civil service legislation. Some countries will introduce specific pension provisions for the public administration employees subject to this legislation. There are at least three obvious reasons for this: to secure the independence of civil servants, to make a public sector career more attractive, and to shift the costs of current remuneration into the future.

In most OECD Member countries, civil servants have separate and specially designed pension schemes. These are either totally independent of the common national pension schemes or complementary to them. Conditions vary between countries and so do principles for financing. In one country there might also be several schemes for various categories of state officials and employees.

"Pay-as-you-go" schemes financed by the annual state budget exist in several OECD Member countries. When they were introduced, national civil services were small and common pension schemes for the working population at large were lacking. Over the last 30 years, the rapid growth of western public services has not had any major impact on pension costs in pay-as-you-go schemes for demographic reasons and, until recently, the financing of pensions has in many countries stayed unchanged. The long-term nature of pension schemes and the strong interest that civil servants and their unions have in keeping them intact has added to the difficulty of changing them.

With changing demography, pensions are becoming a heavy burden on the budget. Pensions imply both considerable running costs and heavy long-term liabilities. That is why many OECD Member countries today are trying to find new solutions to fund the financing costs. Different funding and actuarial techniques can be used to achieve this.

Also available in French under the title "Régimes de pension de la fonction publique". 
Any country that wants to introduce a new pension scheme for civil servants will probably have to find other solutions than a totally independent scheme based on the principle that the state pays the running cost each year from the budget. In addition to the heavy costs and liabilities that a pension scheme imply, there are also other reasons, such as the need for pension rights today to be transferable from one employer to another, from one sector to another or from one country to another to facilitate the mobility of the workforce.

Drafters of Civil Service Laws in Central and Eastern Europe need to take into account certain risks. Without sufficient analysis, pension schemes may create new, considerable, and undetermined annual demands on the state budget, as well as a contingent liability for the state of a considerable and, yet again, undetermined magnitude.

Through this publication, SIGMA seeks to highlight the complexity and long-term nature of a civil service pension scheme, as well as to clarify the running costs and liabilities implied. The objective is also to promote recognition of all considerations necessary for designing a modern pension scheme, and to make clear different methods for acquiring rights and for funding.

The publication's first chapter provides a general description and analysis of pension systems for civil servants. It introduces the basics of a pension system and the relations between the three pillars in any modern, "western" occupational pension scheme. This chapter can be recommended to persons wishing to orient themselves and to gain a clear understanding of the complicated substance, relations and types of costs contained in a pension scheme. The chapter is based on the Issues Paper presented at a SIGMA Multi-Country Seminar held in Tallinn 4-5 December 1995. The other chapters are for the most part also based on papers presented and discussed at that seminar. It should be noted that the descriptions provided in the ten country papers date from 1995. As the reform of common pension schemes is on the agenda in several central and eastern European countries, changes may have occurred since then which are not reflected in these papers.

Staffan Synnerström

Senior Counsellor

February 1997

\author{
SIGMA-OECD \\ 2, rue André-Pascal \\ 75775 Paris Cedex 16, France \\ Tel (33.1) 45.24.79.00 or 45.24.13.94 \\ Fax (33.1) 45.24.13.00 \\ e-mail: sigma.contact@oecd.org \\ http://www.oecd.org/puma/sigmaweb
}




\section{TABLE OF CONTENTS}

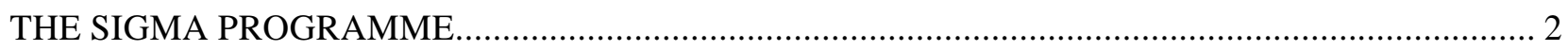

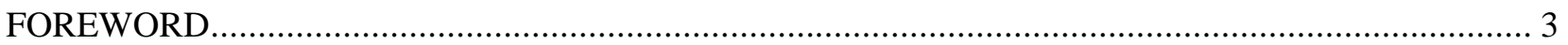

CHAPTER 1 PENSION SYSTEMS FOR CIVIL SERVANTS BY STAFFAN EKEBRAND...................11

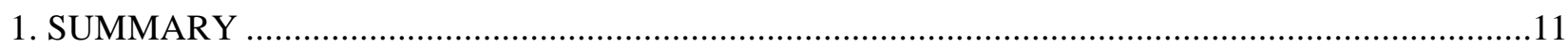

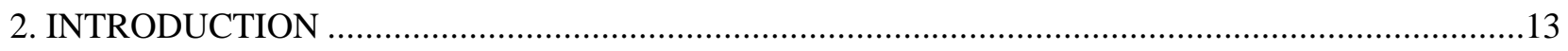

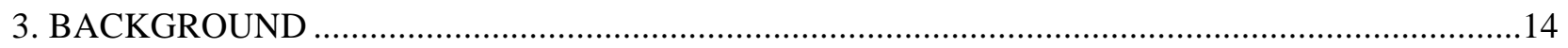

3.1 Pension Systems in Western Europe — An Overview .............................................................14

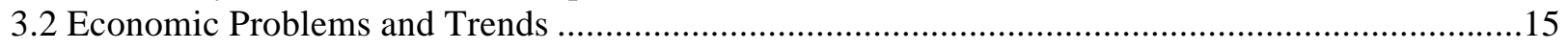

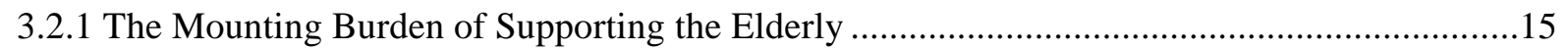

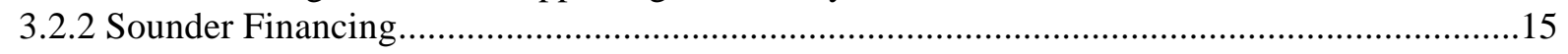

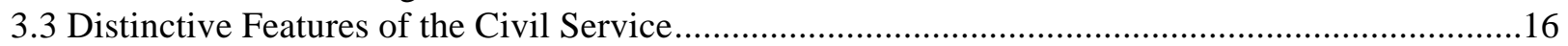

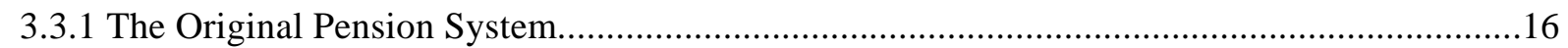

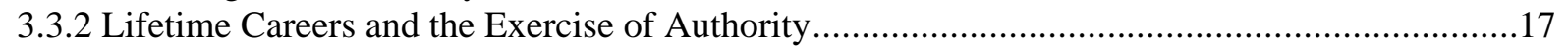

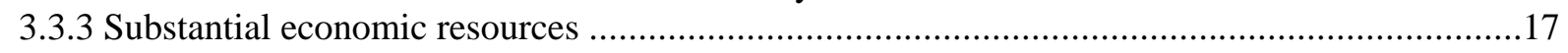

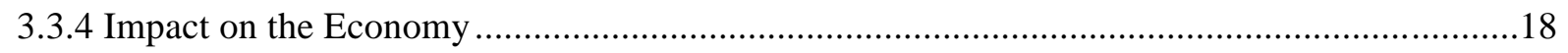

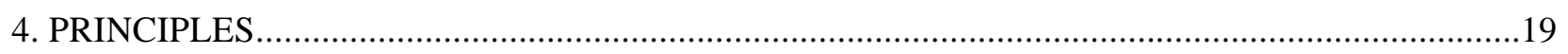

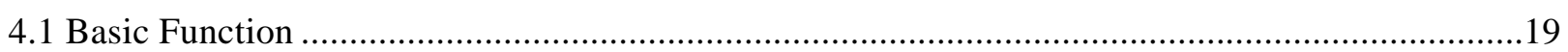

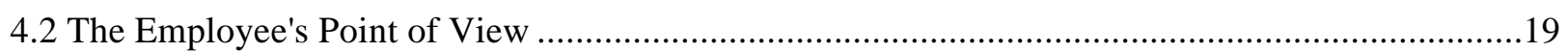

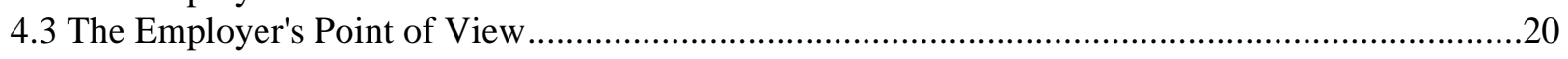

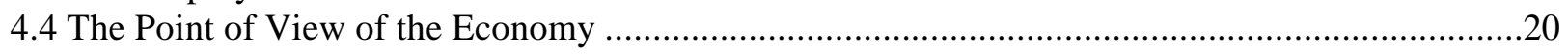

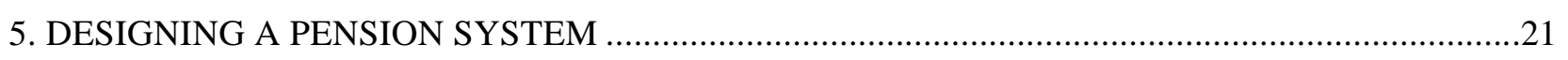

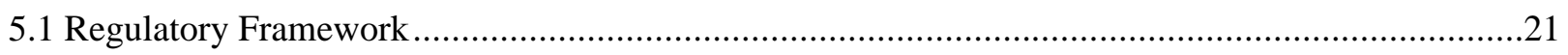

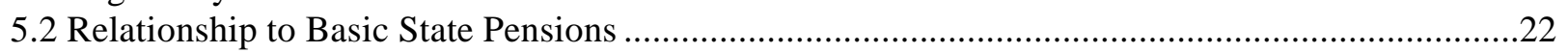

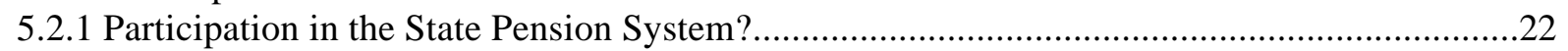

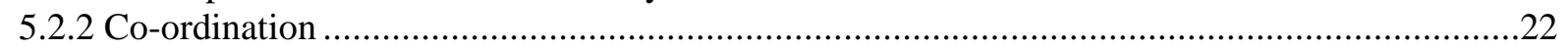

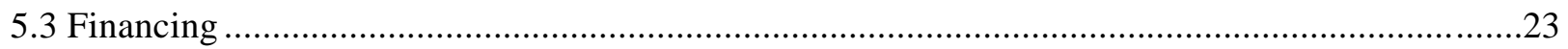

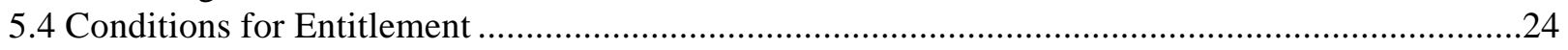

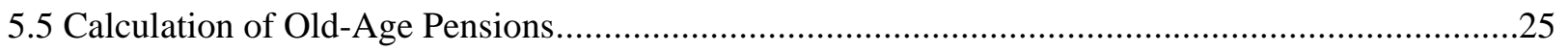

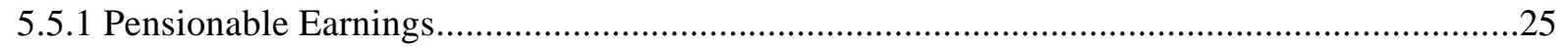

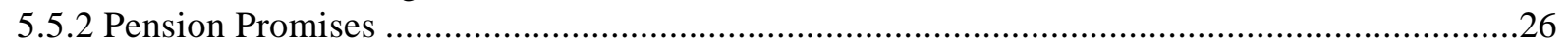

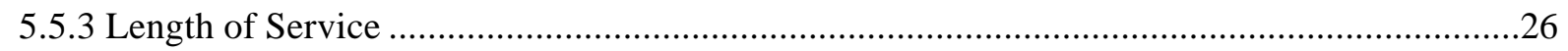

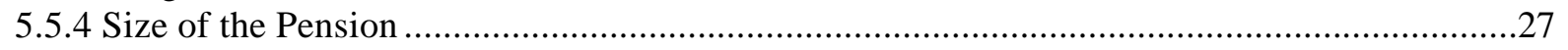

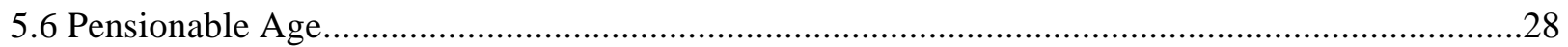

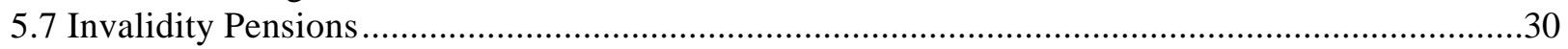

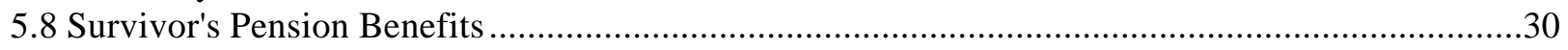

5.9 Commencement of Old-Age Pension Payments .......................................................................... 


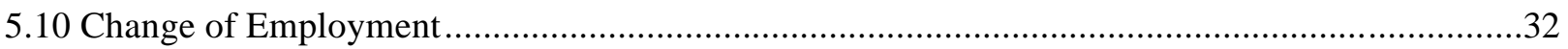

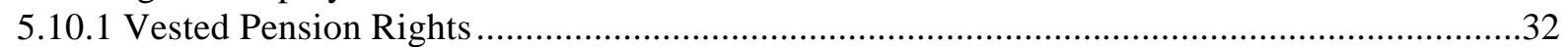

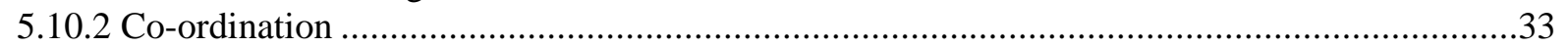

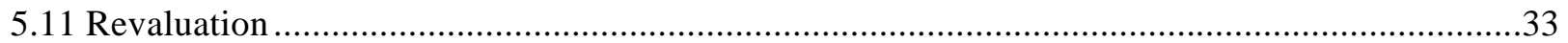

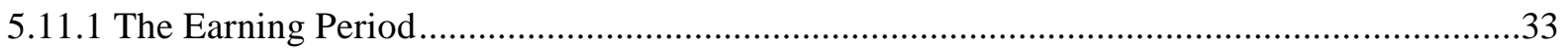

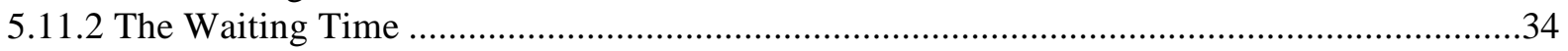

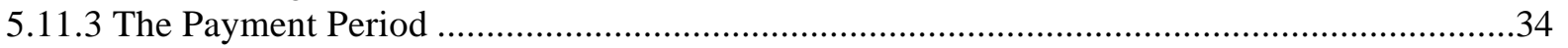

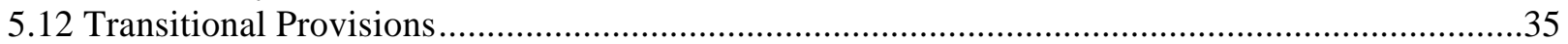

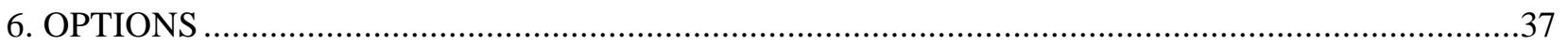

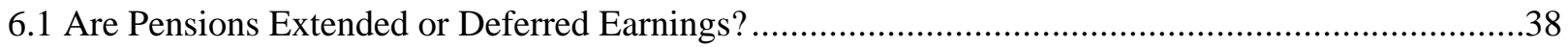

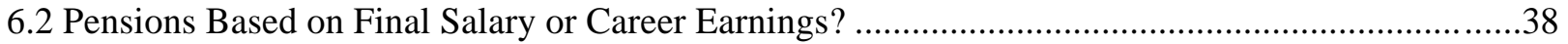

6.3 Benefit-Defined or Contribution-Defined Pension Promises? ......................................................39

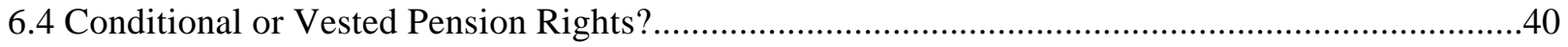

6.5 Gross or Net Co-ordination with State Basic Pensions? ................................................................

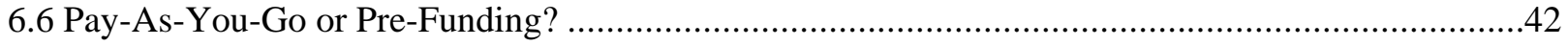

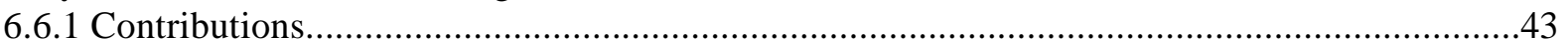

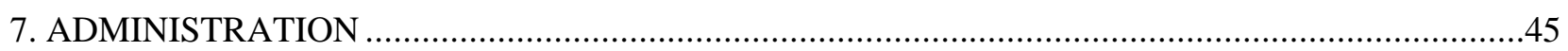

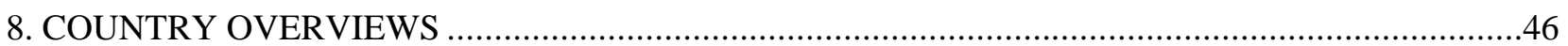

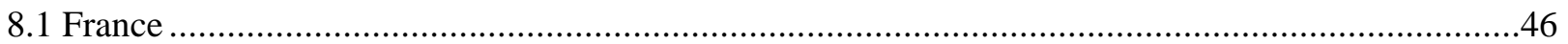

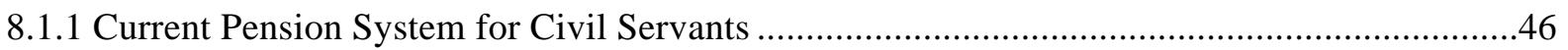

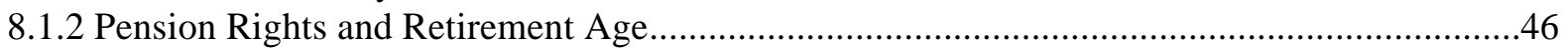

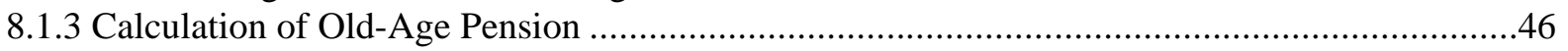

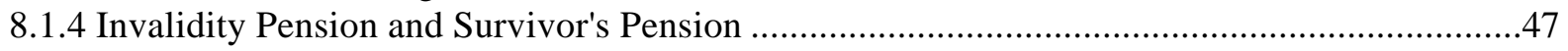

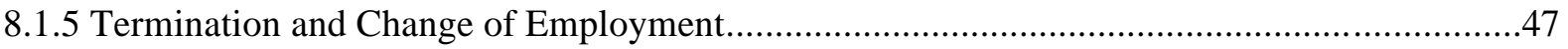

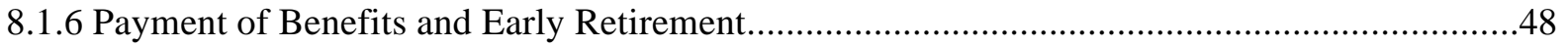

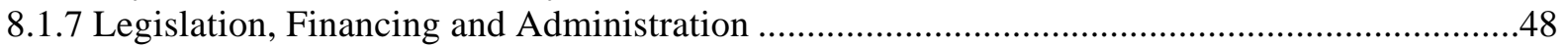

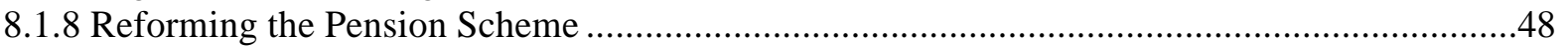

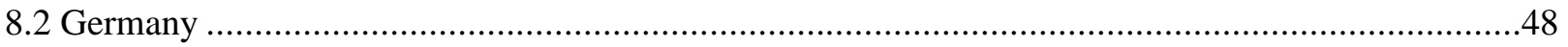

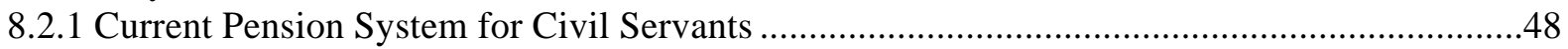

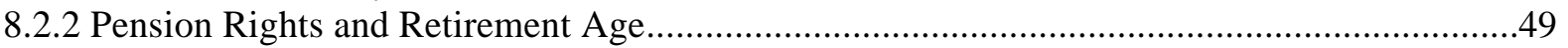

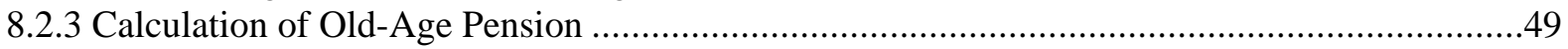

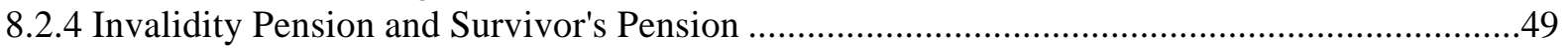

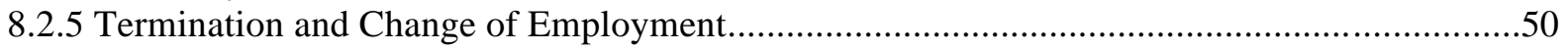

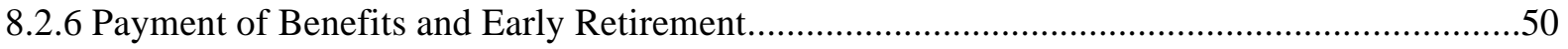

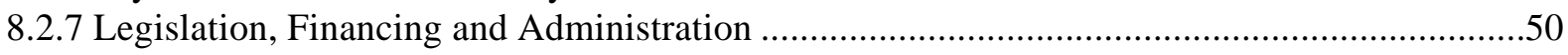

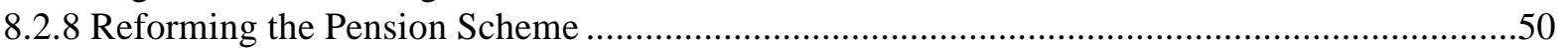

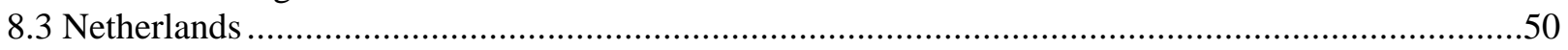

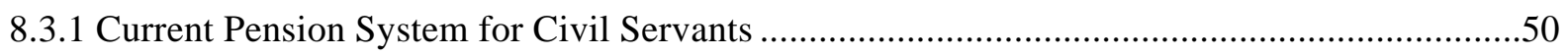

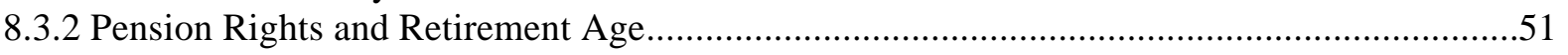

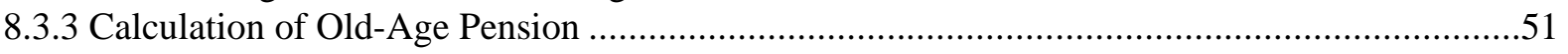

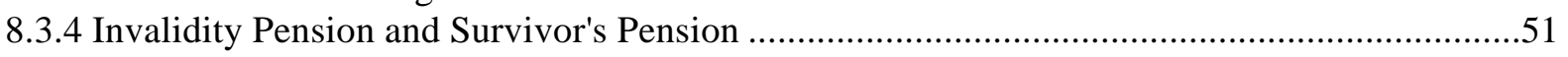

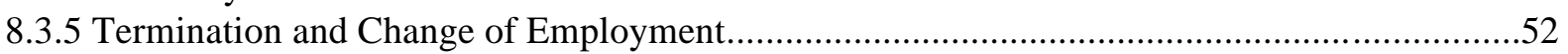

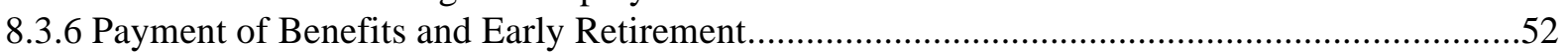

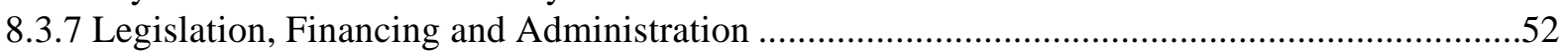

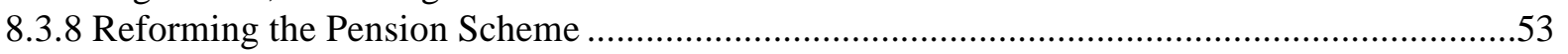

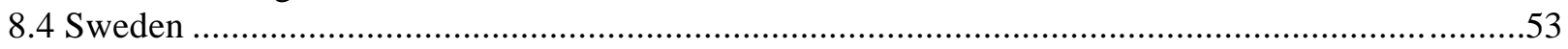

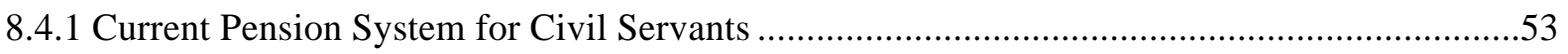


8.4.2 Pension Rights and Retirement Age. .53

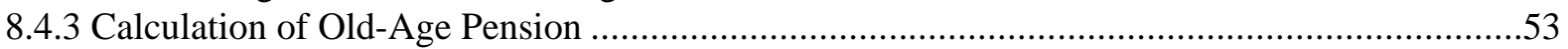

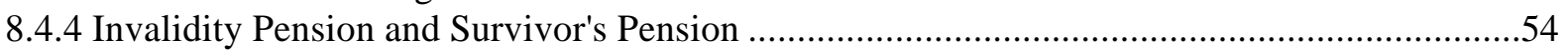

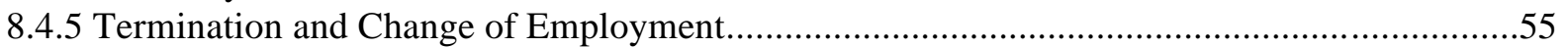

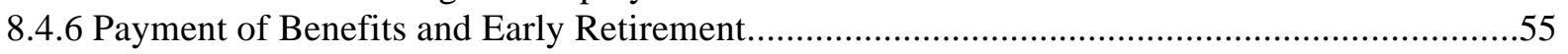

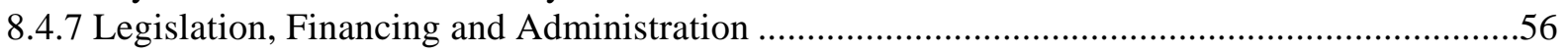

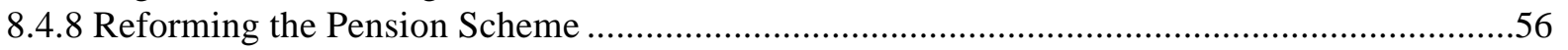

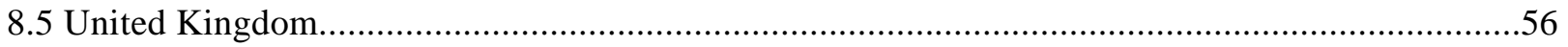

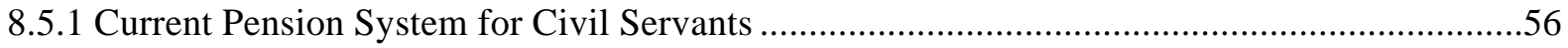

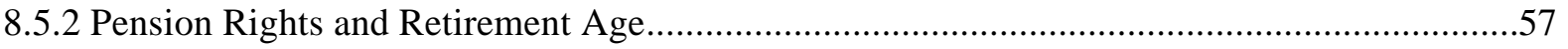

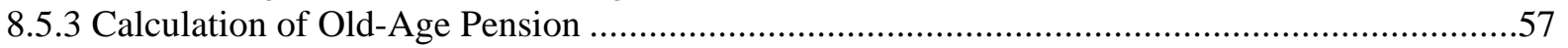

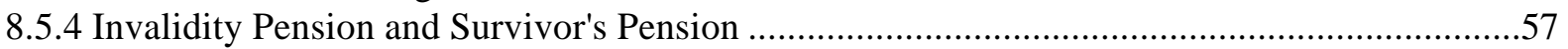

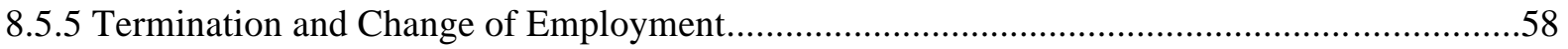

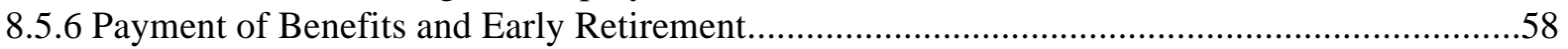

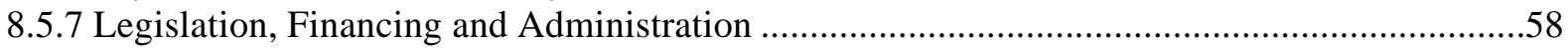

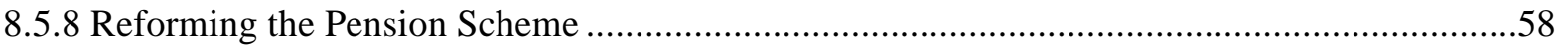

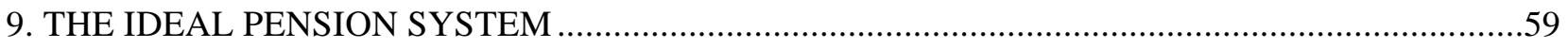

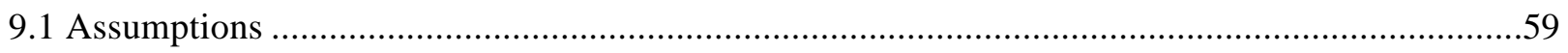

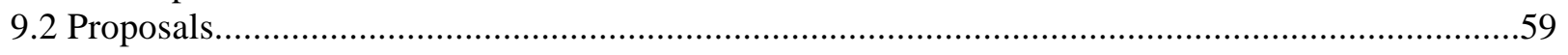

CHAPTER 2 PROTECTING THE EARLY LEAVER BY DOUGLAS ANDERSON .............................63

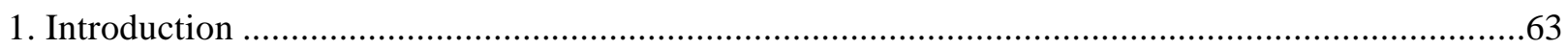

2. Benefits on Voluntarily Leaving Employment Before Retirement ................................................63

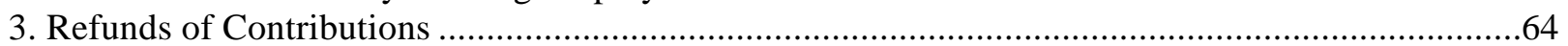

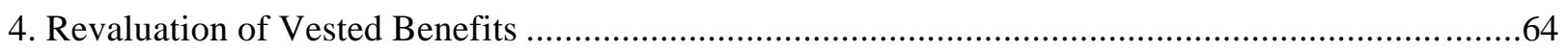

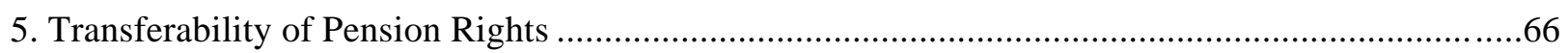

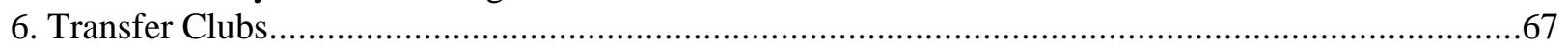

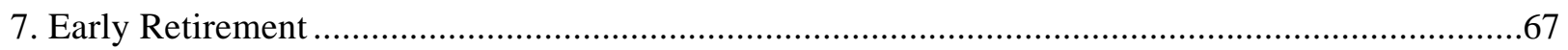

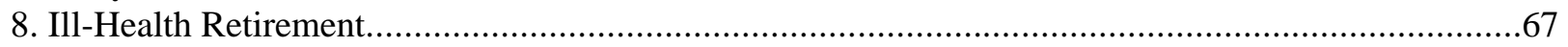

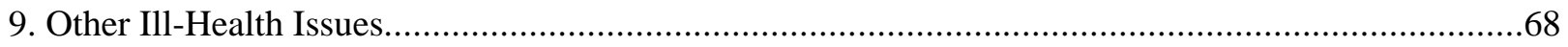

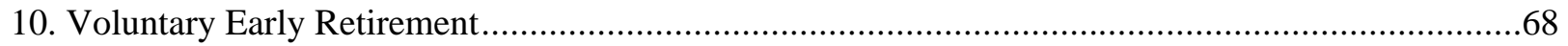

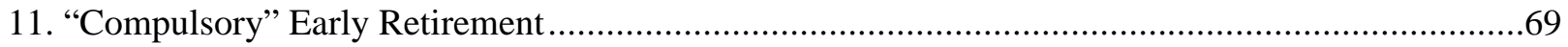

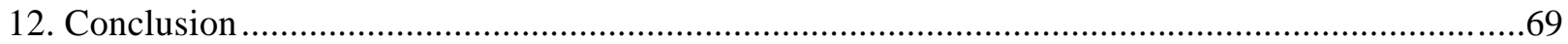

CHAPTER 3 THE TRUE COST OF EARLY RETIREMENT SCHEMES BY DOUGLAS ANDERSON.71

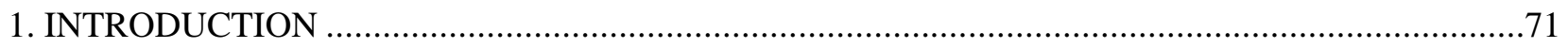

2. EARLY RETIREMENTS VERSUS LUMP SUM COMPENSATION: CASH FLOW IMPLICATIONS

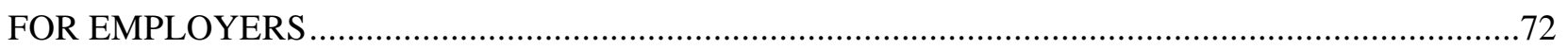

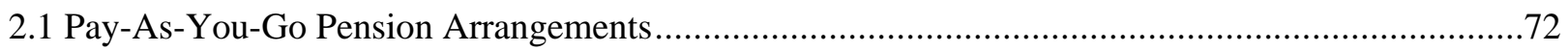

2.2 So Why Are Early Retirement Schemes So Popular? ...................................................................

2.3 Option 1. Lump Sum Compensation Payment …….....................................................................

2.4 Option 2. Enhanced Early Retirement................................................................. 73

3. CAPITALISED COST OF EARLY RETIREMENTS: METHODOLOGY AND ASSUMPTIONS .....75

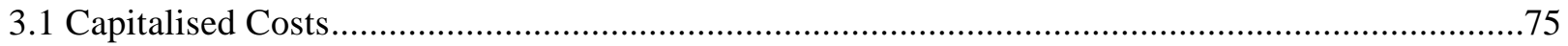

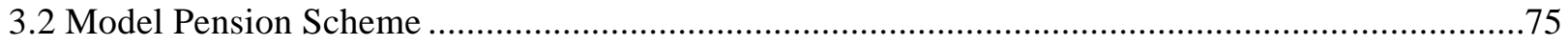

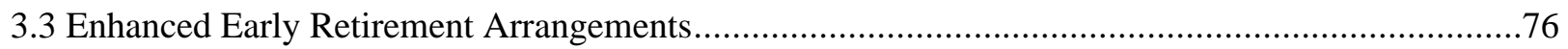




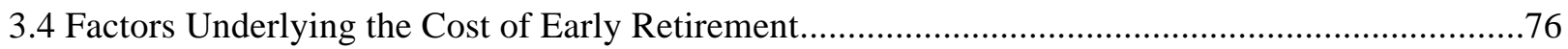

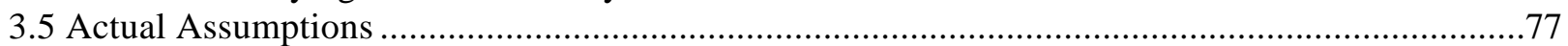

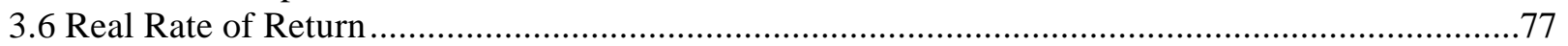

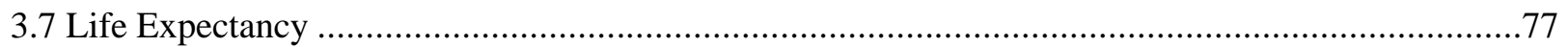

4. CAPITALISED COST OF EARLY RETIREMENTS: RESULTS ……..........................................78

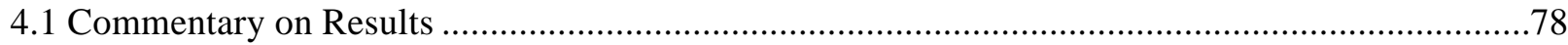

4.2 Capitalised Cost of Early Retirement Terms -- Normal Retirement Age 60.................................79

4.3 Capitalised Cost of Early Retirement Terms -- Normal Retirement Age 65...................................80

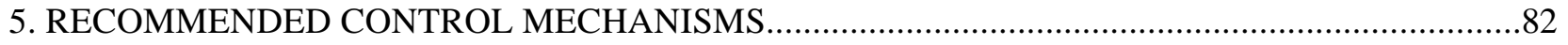

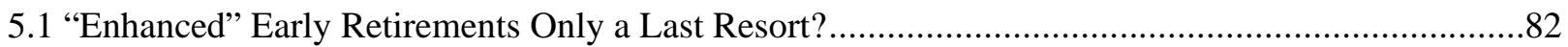

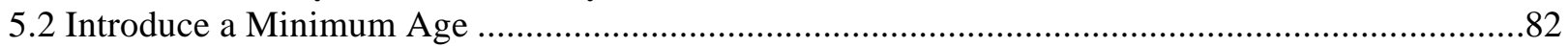

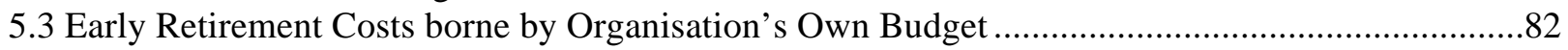

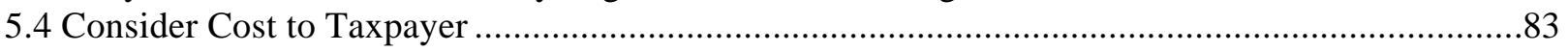

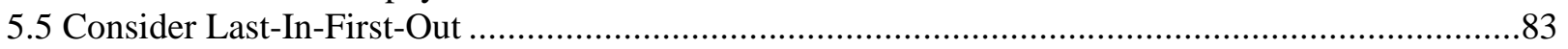

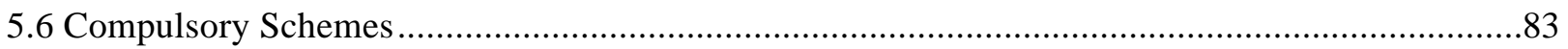

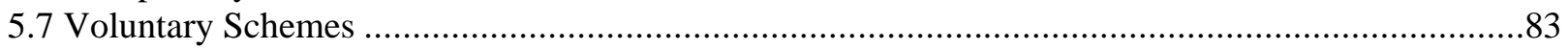

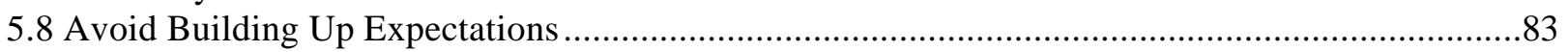

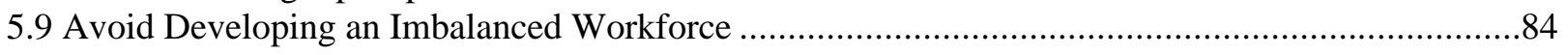

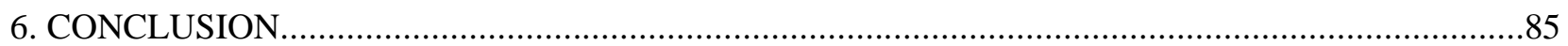

CHAPTER 4 REFORMING PENSION SCHEMES, IMPLEMENTATION AND TRANSITIONAL

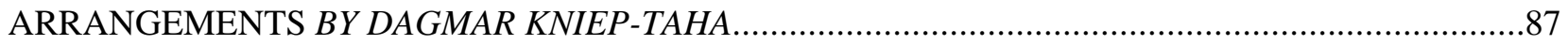

CHAPTER 5 NATIONAL PENSION SCHEMES IN TEN CENTRAL AND EASTERN EUROPEAN

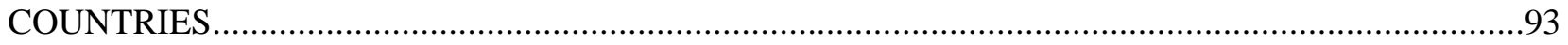

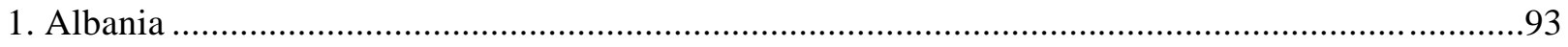

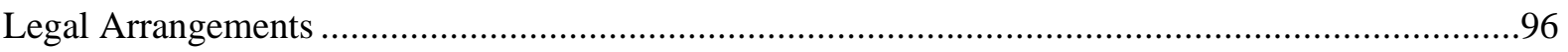

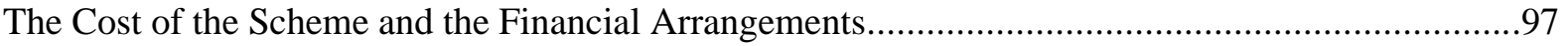

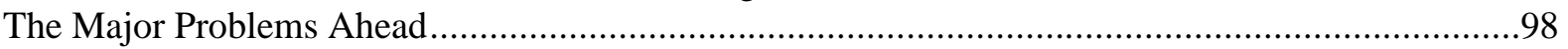

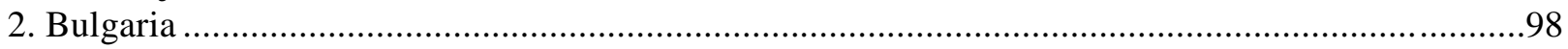

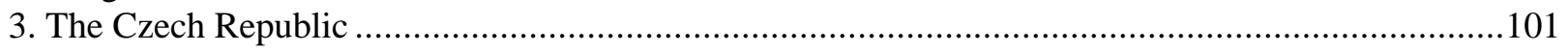

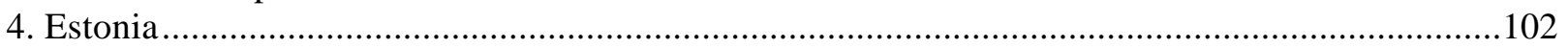

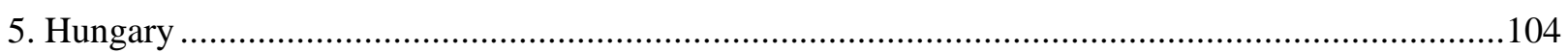

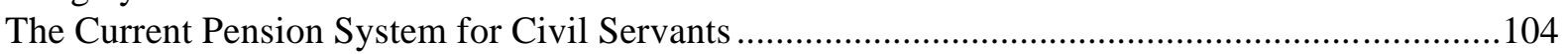

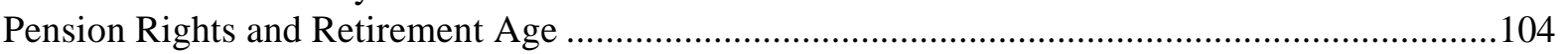

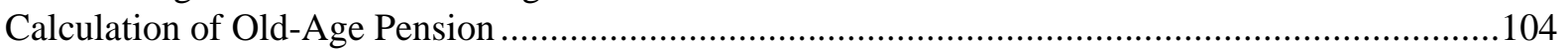

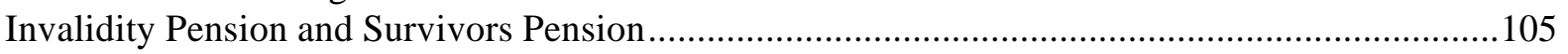

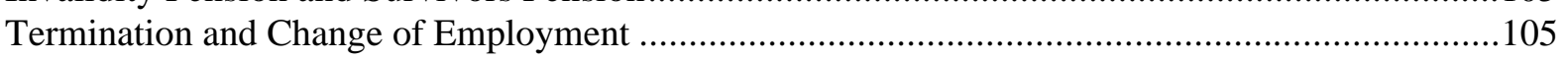

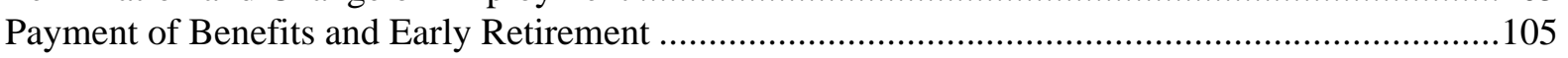

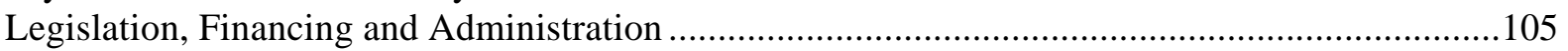

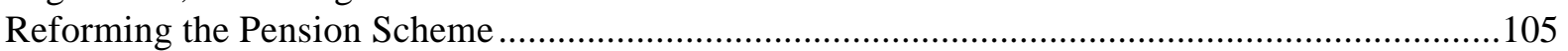

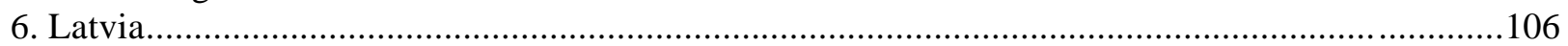

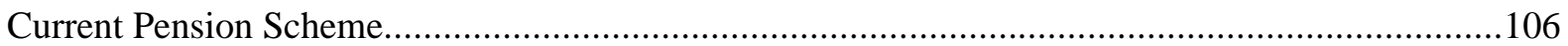

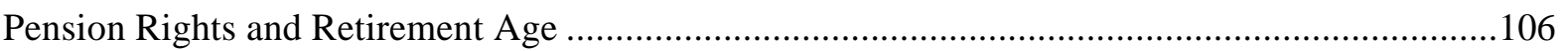

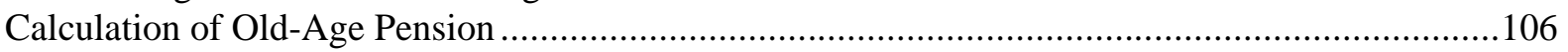

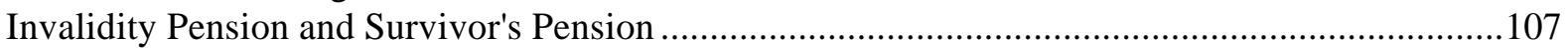

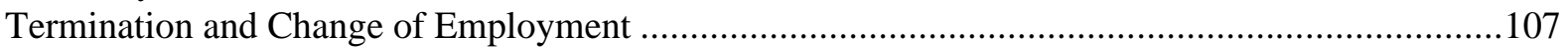




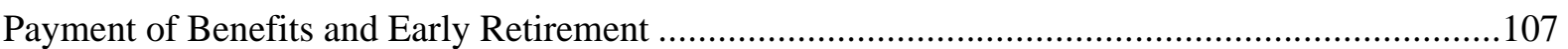

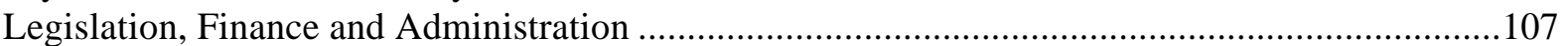

Problems of Creating a New Civil Service Pension Scheme ........................................................108

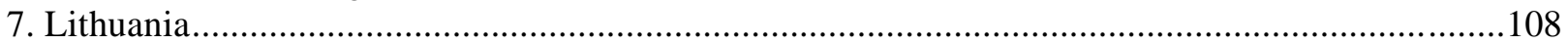

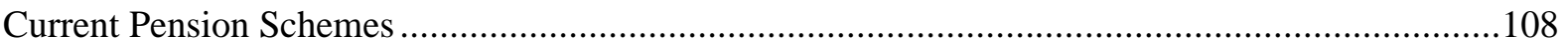

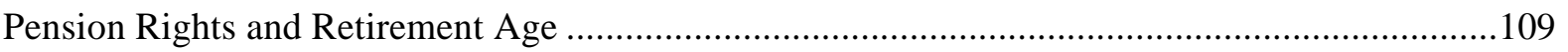

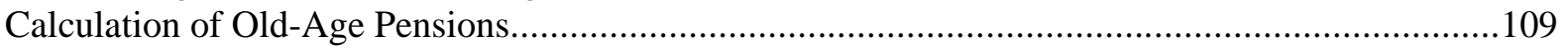

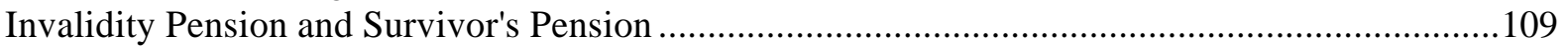

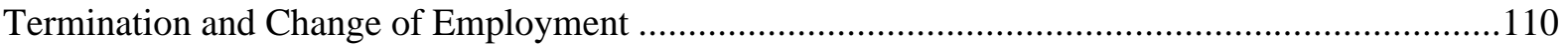

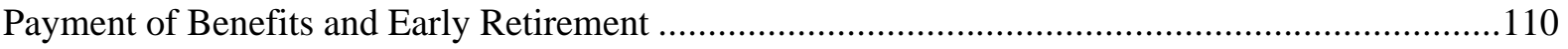

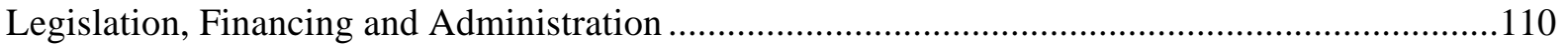

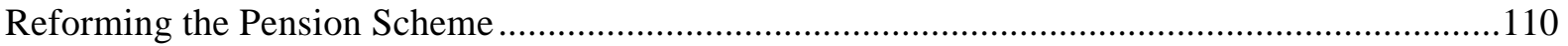

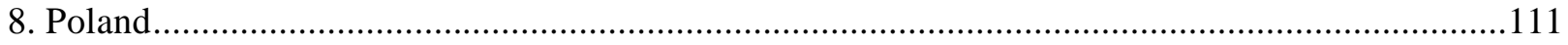

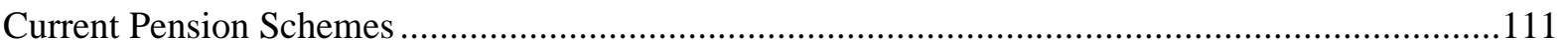

Organisation and Financing of Pensions in the Employees System ............................................111

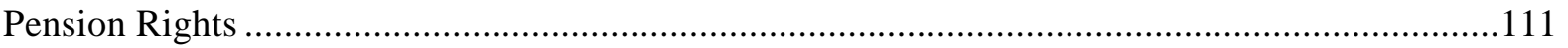

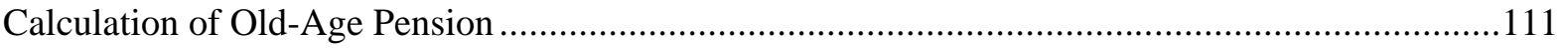

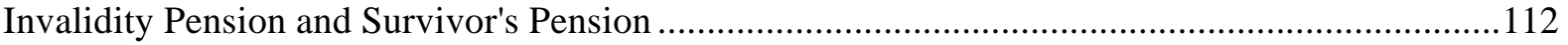

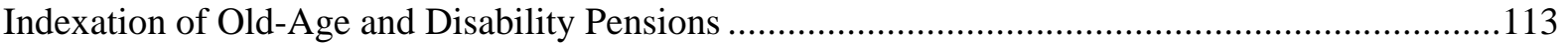

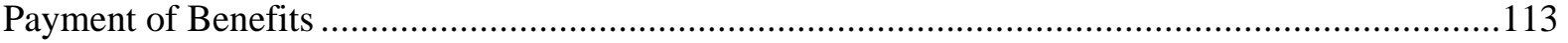

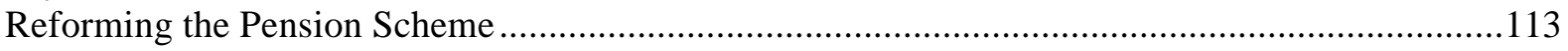

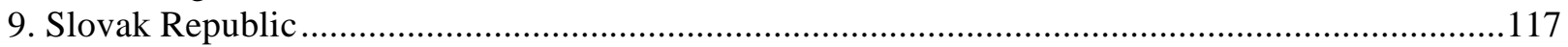

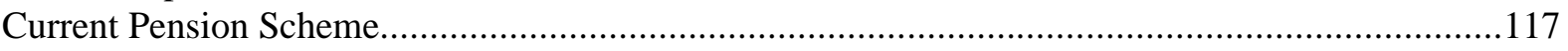

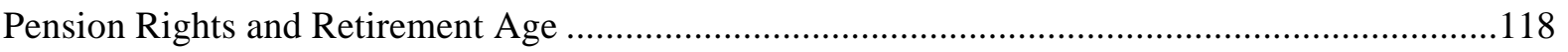

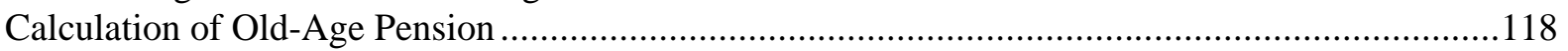

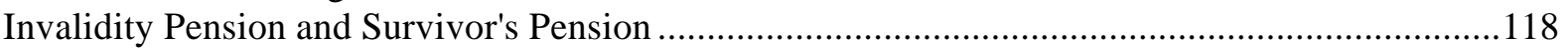

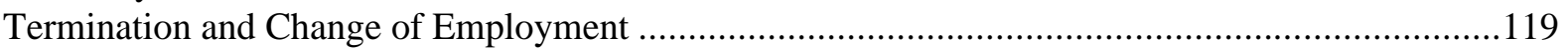

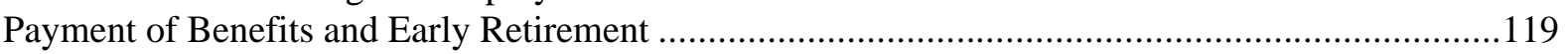

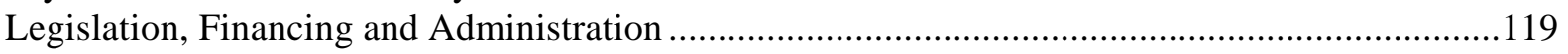

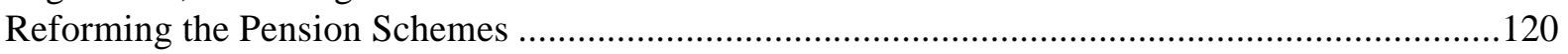

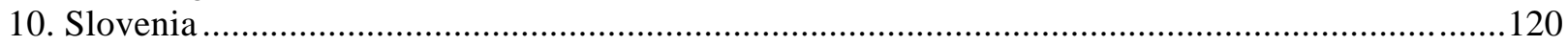




\section{CHAPTER 1 PENSION SYSTEMS FOR CIVIL SERVANTS BY STAFFAN EKEBRAND}

\section{SUMMARY}

The purpose of this Paper is to give an account of various kinds of pension systems for civil servants and to present a discussion of alternatives.

Generally speaking, pension promises represent extremely long-term commitments. Pension systems designed today may affect benefits paid out in the middle of the next century.

For historical and other reasons the pension schemes applied in Western European countries vary considerably. By and large, however, the problems are the same. According to current estimates, the burden on the active population of supporting pensioners will double in the next 50 years. To meet this challenge, pension benefits are being reduced and future pensions are being pre-funded to a greater extent than is the case today.

In many ways occupational pensions in the public sector have a unique history. Public sector employers were the first to provide economic security in the form of pensions for their employees when they were no longer able to support themselves. In some respects this sector has a special relationship with its employees, apart from having substantial financial resources.

It is argued that public sector pension schemes should be designed with a view to stability, security and flexibility. They should also be fair and simple to understand and administer, and there should be an obvious connection between earnings and pensions.

The various aspects of designing a pension scheme for civil servants are dealt with at length, in particular the regulatory framework, the design of pension schemes and their relationship to state basic pensions. They may be financed by a pay-as-you-go system or by pre-funding, which is rare in the public sector. The main factors determining the calculation of old-age pensions are pensionable earnings, the nature of the pension promise, the importance attached to the employment career and the size of the pension.

Pensionable age is an important factor in the system, and one which touches on many conflicting interests. Apart from old-age pensions an occupational pension scheme should also provide invalidity pensions and survivor's pensions. An employee's entitlement to benefits is established when his employment comes to an end. Several options are open when it comes to drawing old-age pension. Where an employee has changed jobs there is a risk of his not receiving the pension to which he considers himself entitled. It is important to establish rules that ensure that the value of the pension does not diminish during the years of retirement. Finally, there is a discussion of the transitional provisions that may be necessary when pension schemes are reformed or new schemes introduced.

Pension Board.

The author is Deputy General-Director of the Swedish National Government Employee Salaries and 
A number of key terms are used in this Paper to describe the design of a pension scheme. The options chosen are crucial to the functioning of the scheme. The links between them become clear when answers are given to the following six questions. Should pensions to be regarded as extended or deferred earnings? Should they be based on final salary or career earnings? Should pension promises be benefit-defined or contribution-defined? Should pension rights be conditional or vested? Should co-ordination with basic pensions take place in accordance with the gross or net co-ordination model? Should pensions be financed by means of a pay-as-you-go system or by pre-funding?

This discussion is followed by a brief description of civil service pension systems in France, Germany, the Netherlands, Sweden and the United Kingdom. The Paper concludes with a description of the main features of an ideal pension system. Two old-age pensions based on career earnings are proposed, one benefit-defined and financed by state employers under a pay-as-you-go system and one contribution-defined, funded by employees' contributions to an independent pension fund. The contribution-defined old-age pension offers flexibility as regards the age from which pensions can be claimed, the protection of survivors and supplementary personal pension savings. 


\section{INTRODUCTION}

The object of an occupational pension system is to provide income security in old age, in the event of permanent disability and in the event of death. The purpose of the system is to guarantee retirement benefits to employees who have a working career of 40 years or more behind them. A person entering the labour market in 1995 at the age of 20 will reach pensionable age in 2040 or thereabouts and may expect to be a pensioner for 20 years or more after that. The pension system currently in force may thus affect the financial status of the providers of pensions and those entitled to pensions during a large part of the next century.

Such a long time frame calls for great caution in drafting the rules on pension benefits and deciding on the financing technique. Western Europe offers a variety of solutions in this respect, depending on who has made the pension promises and who are entitled to pension benefits and on the economic, social and political conditions in general.

This Paper presents the problems that must be solved, the demands that should be met and the options available in the design of pension systems for civil servants. The description applies to the situation in Western Europe and should be useful as a guide to the design of pension systems for civil servants in Central and Eastern European countries. Naturally, the fact that the author's frame of reference is Swedish may have influenced the text in parts.

Limiting the discussion of pension systems to Western Europe does not mean that conditions and experience in other parts of the world are considered irrelevant. On the contrary, there are several countries outside Europe where innovative and well-designed pension systems are now being established.

By way of introduction there is a concise presentation of various types of pension system and related problems and trends, with particular reference to conditions in the civil service. There follows a discussion of the requirements that should be met by a pension system for civil servants, the various components of which are described in chapter 4 . The most important options in designing such a system are discussed, and this discussion is followed by a brief description of the solutions adopted in five Western European countries. The Paper concludes with a presentation of the ideal pension system.

The main focus of the Paper is on a discussion of technical matters. 


\section{BACKGROUND}

\subsection{Pension Systems in Western Europe - An Overview}

The provisions made to support pensioners vary considerably from one country to another, depending on the coverage offered by the country's social security and basic state pension systems. In some countries, pensions are largely financed by pre-funding, while in others they are financed primarily by public non-funded pension systems. In addition, in some countries the state provides benefits, often subject to means tests, which are not classed as pensions at all, or support for the elderly is provided in the form of goods and services, either free of charge or at subsidised prices.

Pensions are sometimes described in terms of a three-tier system, where the first tier represents universal, statutory basic state pension systems, the second supplementary occupational pension systems and the third personal pension insurance and other savings. These three tiers are largely interdependent, indeed so much so that it would be more accurate to talk about three segments of one and the same tier than three separate tiers. Even if the relative size of each system varies considerably between Western European countries, it may be assumed that individuals in similar circumstances want them to deliver the same living standards. The differences in individuals' expectations of living standards as pensioners in relation to previous income appear to be much smaller than the differences in the design and structure of the Western European systems that provide the pension benefits.

In all Western European countries the social security system provides a statutory basic pension that is financed on a year-by-year basis via the budget by means of contributions or taxes. This form of financing, without pre-funding, is known as a pay-as-you-go system. The rules vary, but in most countries pension rights are established on the basis of the number of years during which contributions have been paid in during the employee's active career and of their size. In some countries the right to a basic pension depends on the period of residence in the country.

Supplementary occupational pension systems vary greatly from one country to another. Their contribution to overall social security varies considerably, depending on various factors which will not be discussed here. By and large, however, the size of this contribution is related to the level of statutory protection, although recipients cannot always expect their occupational pension to compensate for the vacuum left by statutory protection. To raise and to provide an adequate replacement income, occupational pension systems are normally subject to favourable legislation, in particular favourable tax treatment.

There is no clear demarcation line between the first tier and the second. In some countries, such as France, the supplementary occupational pension is to all intents and purposes a first-tier pension, since it is financed by a pay-as-you-go system with compulsory participation above a certain level of earnings. In Spain and Italy there are virtually no supplementary systems. In many other countries, such as Germany, the Netherlands and the United Kingdom, occupational pension systems are financed by various forms of pre-funding.

Participation in a pension system may vary from selected groups working for a single employer to the country's entire workforce, who are covered by comprehensive collective agreements providing for a compulsory pension system. Pension systems may apply to a whole sector of the labour market, for example the public sector, or they may be limited to certain professions. As regards the public sector, at least a part of it, such as the civil service, may not only have its own occupational pension system but also 
be excluded from the basic state pension system. This is the case in Germany and France. In the United Kingdom, civil servants can opt for systems other than the civil service pension system.

The long-term nature of pension promises means that sound financing is crucial to the stability and security of the pension system. Basically, there are two main financing techniques, i.e. pre-funding and pay-as-you-go, as well as several variations and combinations of these techniques. The chief difference between them lies in the periodization of pension costs. The pre-funding arrangements normally applied in a certain country are usually those encouraged - sometimes even prescribed - or discouraged by the authorities. Pay-as-you-go is typical of the first-tier statutory pension system, but is not very often used for second-tier occupational pensions.

The substantial differences existing between the solutions adopted by different countries are largely attributable to historical causes. Economic, social and political differences of today are of course also significant factors.

\subsection{Economic Problems and Trends}

\subsubsection{The Mounting Burden of Supporting the Elderly}

In the last 30 years the birth-rate in Western Europe has fallen from about 2.6 to just over 1.5, which is considerably lower than the rate necessary to sustain a stable population. With increasing life expectancy, the age structure will therefore undergo dramatic changes. Estimates indicate that the burden of supporting the elderly, expressed as the number of old-age pensioners in relation to the active population (those aged 65 or over as a percentage of the number of people in the age group 15-64), is expected to double from just over 20 per cent in 1990 to over 40 per cent in 2040, assuming a net immigration of 250000 per year. These figures do not of course tell the whole truth about the support burden, since they do not take into account other relevant factors such as open and concealed unemployment, the percentage of children and adolescents and the percentage of women in the labour market. Furthermore, the situation varies greatly from one country to another.

Nevertheless, this trend is alarming. Total payments to old-age pensioners from the three-tier system in the European Union are estimated at over 10 per cent of GDP. All other things being equal, this trend will, in the next 50 years, make it necessary to double expenditure on old-age pensions to 20 per cent and the financial demands on the system will increase accordingly. If account is also taken of the probable increase in the real value of pensions and the fact that old people account for a large proportion of expenditure on health, the potential redistribution of income and expenditure from the working population to old-age pensioners assumes very substantial proportions.

\subsubsection{Sounder Financing}

An overwhelming proportion of pensions in Western Europe today consist of statutory basic pensions financed on a pay-as-you-go basis by transferring income from the active population to pensioners. In the light of the mounting burden of supporting the elderly, this is liable to put these pension systems in jeopardy, since, to maintain a financial balance, they must either increase their revenues or reduce the benefits paid out. Revenues can be increased by raising taxes, including payroll taxes. Meeting pension obligations by increasing the budget deficit and the national debt cannot, of course, be regarded as a feasible option. The other alternative, reducing pension benefits, involves either lowering benefit levels or raising the pensionable age. 
This situation has focused attention on pensions. In several countries more or less radical reforms of the national statutory pension system are being planned or have already been implemented. The general view is that a larger proportion of pensions should be financed by pre-funding or other forms of provision for future pension payments. This applies even more to supplementary occupational pension systems. There is a growing understanding that the connection between savings, the national debt and economic growth is crucial to economic development. Without going further into these issues, which lie outside the subject of this Paper, it may be noted that the financing of pensions is the subject of growing attention on account of the repercussions on the national economy as a whole. It may be noted furthermore that industrialised countries in other parts of the world face problems and trends that are similar to those described above.

The issues discussed here are of an economic nature. The perspectives differ somewhat when it comes to occupational pension systems for specific sectors of the labour market, but the problems are broadly the same. They are important factors which should be given careful consideration in the design of pension systems.

\subsection{Distinctive Features of the Civil Service}

The factors determining the structure of occupational pension systems vary to some extent from one sector of the labour market to another. The public sector, in particular, is a special case, and it may be argued that it demands a special occupational pension system.

\subsubsection{The Original Pension System}

It is worth pointing out that today's statutory basic state pensions and occupational pensions both derive from the public sector occupational pension system. The state was the first employer to assume responsibility for supporting its employees and their survivors by developing systems for old-age, invalidity and survivor's pensions. This development has followed two main lines. These pensions have either been regarded as extended, albeit reduced, earnings, to be paid for out of the national budget in the same way as wages for public employees. Employees who were public officials during their working careers have been treated as such after their active careers too. According to the other way of thinking, pensions were regarded as deferred earnings. Pension societies were set up and savings invested to support the members in their old age. Pre-funding is based to a greater or lesser extent on actuarial principles. In most countries the first principle has become the norm in financing pensions for civil servants. The reason for this is probably that it is a convenient way of improving pension conditions even for those who have not qualified for them, together with the fact that it has been economically feasible - via the budget - to do this. In practice, the "extended earnings" principle has won the day, despite the fact that nowadays the general view, at least in theory, is that pensions should be thought of as "deferred earnings".

The idea of supporting the old, the sick and surviving widows and children by pensions spread gradually from the public sector to other sectors, and was implemented by building up the three-tier system described above. Various kinds of occupational pension systems were created in various sectors for certain categories of employees. The process was encouraged, in particular, by the creation of favourable conditions for the financing of pensions, above all preferential tax treatment. When small groups of employees were assured security in their old age, demands were raised for statutory basic pension systems that would bring similar benefits to the majority, at least of the working population. Pensions emerged as an element of social security programmes. Since civil servants already had the right to a pension from the state, and usually on much better terms, it was natural in most countries to exclude them from the social 
security pension system. For employees in the private sector the process was naturally rather different. Here the obligation rested on the employers, where necessary, to supplement the statutory pension by providing adequate support for their former employees and their survivors.

Naturally, this description does not hold good for all countries, but it gives a historical explanation of why civil service pension systems often differ from other occupational pension systems.

\subsubsection{Lifetime Careers and the Exercise of Authority}

The rules governing public service differ greatly from those governing relationships between employers and employees in the private sector. Private sector employers must generate profits. The regulations applying to civil servants deal with the rights and obligations imposed on them by society. The situation for civil servants differs from that of other employees in that they exercise public authority, with the sacrifices and demands on loyalty etc. which this entails. In return, the state assumes responsibility for supporting civil servants up to the end of their lives. Those who join the civil service do so on the assumption that it will provide them with a lifetime career. Their terms of employment involve sacrifices in the form of (often not very high) pay levels established in a grade structure, but also offer the advantage of secure employment and a good pension.

Whether this description is correct and relevant today varies greatly from one country to another, but when pension systems for civil servants were introduced in Western Europe it was undoubtedly so. Germany and France are examples of countries where this is still the case, while in Sweden it has scarcely any relevance at all. Attitudes to the public sector and the position of civil servants have greatly influenced the design of civil service pension systems.

\subsubsection{Substantial economic resources}

Where the state is the employer, the costs and the financing of pensions do not have the same priority as for private employers, since the state's economic resources are of a completely different order. The cost of civil service pensions is small compared with the national budget as a whole. Should these costs rise sharply, the state can always increase revenue by raising taxes. The state's power to levy taxes is one of the reasons why it has usually been considered unnecessary in the public sector to secure pensions by pre-funding.

Since these pensions - to a very large extent - are financed by a pay-as-you-go system, it is difficult to identify the real costs. Are the costs incurred when pensions are paid out or when they are earned? The answer depends on the basic approach, i.e. whether pensions are regarded as extended earnings or deferred earnings. Ambivalence in this respect is not conducive to cost-consciousness, and it is not always considered necessary to make cost estimates.

Where costs are not the focus of attention, the benefits are. This is probably the main reason why civil service pensions are normally benefit-defined and not contribution-defined. It is the size of the benefit that is defined in the pension scheme and not the size of the contribution. Contributions - costs - are regarded merely as a consequence of the benefits and indeed rather a vague consequence. Occupational pensions in the private sector, and also basic state pensions, present an entirely different picture.

This somewhat superficial view of pension costs is also due to the fact that, unlike the situation in the private sector, there are no owners with an obvious interest in holding back costs. Nor is it always clear who represents the employer. Those who frame the rules have every reason to make them as 
favourable as possible. This is one aspect of the special relationship between employers and employees in the public sector which has already been mentioned.

Thanks to the economic strength represented by the national budget, it seems unnecessary to make pre-funding arrangements for civil service pensions, and this in its turn means that the pension system is, paradoxically, vulnerable to political decisions to erode it.

\subsubsection{Impact on the Economy}

Because of the resources available to the public sector for the financing of its employees' pensions, special restraint is called for. It must be taken into account that other sectors may feel that pension benefits that are considered normal in the civil service should also apply in the rest of the labour market. Since the pension levels for civil servants thus tend to become the general norm, they make a disproportionate economic impact in relation to the number of employees in that sector. For this reason too the state as employer must accept greater economic responsibility than private employers, who are only responsible for the economy of their own company. 


\section{PRINCIPLES}

Civil service pension systems vary considerably from one country to another. Although this Paper is not concerned with any particular national system, it is necessary, in the interests of a meaningful discussion, to establish certain general principles that cut across specific national structures.

\subsection{Basic Function}

Without analysing the basic function of a pension system in detail, the purpose of such a system should evidently be to provide economic security when the individual is no longer able to support himself as before. The pension system fulfils this function by distributing income evenly over the individual's life-cycle, as well as distributing income between individuals.

The employee saves (defers) part of his income for a later period in life. If pensions are financed by a pay-as-you-go system, which does not provide for any savings, the individual's income is distributed by means of a "social contract" (the pension system) under which the younger generation agrees to support its elders in return for the expectation of receiving the same benefits from the next generation.

The individual insures himself against the risks arising within a certain collective, "the risk" of a longer than average life, the risk of disablement before reaching pensionable age and the risk of dying and leaving unsupported dependants. Distribution between individuals can also be based on distributional policies. Certain groups are awarded higher pensions than their contributions would justify from a strictly actuarial point of view. For example, women usually receive the same pension as men (in the same income bracket) despite the fact that their lives as pensioners are on average about 20 per cent longer.

The means used to redistribute incomes consist of old-age pensions, invalidity pensions and survivor's pensions. The principles that should be applied to the design and financing of these benefits in the case of civil servants are mentioned below. Since there are three parties with an interest in the system, the principles are mentioned from their respective points of view: the employee's, the employer's and society's (the economy).

\subsection{The Employee's Point of View}

Pensioners should have a reasonable and constant real income when they are no longer able to support themselves as before.

An employee who retires early should not lose the pension rights that he assumes he has earned.

The pension conditions should be, and should be perceived to be, fair in comparison with other groups belonging to the system and with other labour market pension schemes. 
There should be a certain amount of flexibility, so that employees can adapt their pension to their particular situation.

The pension system should be credible, stable and secure, i.e. there should not be any likelihood of changes in the rules leading to the loss of accrued pension rights. The stability and security of the system should be enhanced by a sustainable financing system.

The pension system should be simple and easy to understand and assure predictable pensions, so that the recipient knows what benefits he is entitled to and can take the necessary steps to ensure that he receives them.

The pension system should be prudently administered, and the registration of data should be subject to stringent security procedures.

\subsection{The Employer's Point of View}

Pensions must be financed in such a way as to ensure reasonable and predictable costs.

It should be possible to identify costs and their origin.

The pension system should ensure that there is a clear relationship between performance, as measured by earnings, and pensions.

The system must be sufficiently flexible to adjust to economic, demographic and other changes in the state sector.

It should not be possible to improve pension benefits by means of manipulations on the part of the employee or the institution where he is employed.

The pension conditions should facilitate recruitment to the civil service.

The system should be transparent and easy to understand.

The system should be simple and cheap to administer.

The pension system should be prudently administered, and the registration of data should be subject to stringent security procedures.

\subsection{The Point of View of the Economy}

The pension system should encourage savings and work, both directly and indirectly by influencing other occupational pension systems.

The pension system should not be an obstacle to labour mobility.

Employers and employees should give careful consideration to the objectives that they wish to achieve with their pension schemes. The above criteria may seem like a wish list, but they serve a purpose as benchmarks against which alternative system designs can be tested. 


\section{DESIGNING A PENSION SYSTEM}

Designing a pension system is a difficult task. It raises issues of a very long-term nature that are of great economic importance both to those making the benefit commitment and to those entitled to the pension. There can be no doubt that it is much easier to introduce and improve benefits than to reduce or abolish them. Great caution is therefore essential. The consequences and precise nature of any new promises must be carefully considered.

This section will deal with the essential components of any pension system. In Section 6 below ("Options") there will be a discussion of the central issues and the advantages and disadvantages of the various alternatives.

\subsection{Regulatory Framework}

An employee's pension benefits are part of his conditions of employment. They are set forth in a so-called pension scheme. In the case of civil servants, the conditions of employment and related pension schemes often form part of their service regulations. The conditions of employment may also be kept separate from these regulations in order to emphasise the special nature of remunerations, pensions and other benefits to the employee.

In view of the far-reaching financial commitment involved in a pension promise, pension schemes for civil servants often have the formal status of an Act of Parliament. Detailed rules of minor economic importance are usually adopted by the Government.

Although the conditions are formally laid down in regulations issued by the employer - the state - there should be a structure enabling employees to influence them prior to their adoption. A transparent method of ensuring the participation of the employees is to arrange for the pension scheme to be the subject of a collective agreement. Whether this is possible or appropriate naturally depends on the labour laws and the labour market in the public sector. It is also important that there should be a close connection between the party or parties who will bear the costs of the pension scheme and those who decide on its content.

Regardless of whether the pension scheme is governed by statutory provisions or a collective agreement, it should be exhaustive. The rules applying to the pension system as a whole, both with respect to benefits and financing, should be included. It is not possible to go into detail in this connection, but all the issues dealt with in Sections 5.2 - 5.12 should be covered. It may be practical to issue purely administrative rules separately from the pension scheme itself.

Lastly, it must be emphasised that rules should be formulated in such a way as to be readily understandable. The effort put into producing a simple and well-structured text is eminently worthwhile, both from the point of view of those who need information about their pension rights and of those whose task it is to administer and develop the rules. 


\section{Relationship to Basic State Pensions}

Most countries have some kind of statutory state basic pension, at least for the working population. These pensions are often flat-rate, but they may also be earnings-related. The length of employment or residence in the country are often relevant to the size of state pensions.

\subsubsection{Participation in the State Pension System?}

The question arises whether civil servants should be included in the state pension system and be covered, in addition, by a supplementary occupational pension system, or whether they should be excluded from the state pension, but have a pension system of their own. This matter has already been discussed in the historical overview, where it was mentioned that in many cases civil servants have their own pension system that pays out all their pension benefits.

It is impossible to generalise about what is the best solution. This is best decided by the historical background and the specific national context.

The main advantage of segregating a civil service pension system from the basic pension system is perhaps that such a system is simpler, since the two systems do not have to be co-ordinated. Co-ordination poses a number of problems, a subject which will be dealt with shortly.

While it may be simpler to design a separate pension system to meet the special needs of civil servants, it is not always possible to disregard the basic state pension system entirely, since that system often guarantees a basic or minimum pension. Consequently, the civil service pension scheme should include corresponding conditions that guarantee at least equivalent benefits. This makes it necessary to include distributional features that blur the relationship between performance, as measured by earnings, and pensions. In other words, it is obviously an advantage if the social dimension can be left to the basic pension system and the civil service pension system can be designed as a supplementary system whose only object is to provide a pension in relation to earnings.

Labour mobility is facilitated if civil servants belong to the same statutory pension system as other employees. Where this is the case, problems connected with the co-ordination - or lack of co-ordination - of pension rights acquired elsewhere only affect the supplementary occupational pension system, i.e. that particular proportion of the overall pension. It is also easier to compare pension conditions for civil servants with those for private sector employees if they are both covered by the same basic system.

It may also be an advantage if civil servants enjoy the same social security benefits as other citizens. It is difficult to explain why they should be exempt from rules that they themselves impose. Any cutbacks adopted in the basic pension system should affect all citizens. Naturally, the same applies to improvements. There is no really objective reason why civil servants should be given special treatment in this respect.

\subsubsection{Co-ordination}

If civil servants are to be covered by two pension systems, one providing basic pensions and the other supplementary pensions, rules must be laid down for the necessary co-ordination of these systems. There are two fundamentally different models. In one of these the occupational pension is calculated as a gross amount from which the amount paid out as a basic pension is deducted. If the occupational pension 
is reduced due to insufficient length of service, the basic pension deduction should be reduced correspondingly. In the other model, the occupational pension is calculated net in relation to the basic pension. The net amount is determined on the basis of an assumed general basic pension level. Both models involve complications, which will be dealt with later.

\subsection{Financing}

Sound financing is a crucial element of a credible, stable and secure occupational pension system. The all-important task of financing pensions can be formulated as follows.

The employer's pension obligation represents a promise to the employee of future pension payments. Meeting this obligation will, when the time comes, entail costs for pension payments. These pension costs must be financed in some way. Capital must always be available, and if the employer has not previously made provision for pension payments, the capital must be paid in by the time the pension payments fall due. Pension costs can be financed in two different ways, either by a pay-as-you-go system or by pre-funding.

In a pay-as-you-go system the pension amounts are paid for on a continuous basis as they fall due. No funding takes place and no capital is set aside for future pension payments. For the system to be acceptable, the employer must have a reliable, long-term source of income to cover the costs. The Government's right to collect taxes normally represents adequate security.

If the collective that is covered by the pension scheme provides the system with revenue by paying some kind of contribution, it must be stable, in particular its age structure. The system must be balanced. If the number of pensioners increases at the expense of the number of active members, it may be exposed to great strain.

Pre-funding means that provision is made for future pension payments. The funds allocated for this purpose, together with the interest earned on them, constitute the pension capital which is subsequently drawn on when pensions are paid out. The allocations should be determined in such a way as to ensure that the capital is sufficient to cover the estimated pension payments. This is done on the basis of assumptions about future interest rates, life expectancy and expenses. These actuarial rules, must be based on assumptions that are sufficiently conservative to ensure that, even in unfavourable circumstances, the pension capital will be sufficient for the promised pension payments. Consequently, this capital usually generates a surplus that can be used either to raise pensions or to reduce the allocations.

Special measures must be taken to ensure that pre-funded pension obligations can be met when pensions fall due. These measures depend on the requirements laid down by national legislation. Such rules may be included in provisions relating to civil law and tax law. The classic instrument that, to some extent, is used in virtually all countries to secure pension capital is pension insurance, which means that the employer entrusts the fulfilment of his obligations to an insurer in return for the premium for this service demanded by the latter.

Various kinds of independent pension funds are another alternative. The employer allocates resources to these funds for future pension payments. Normally, he does not renounce responsibility for meeting his pension obligations, but he can demand compensation from the funds for pensions paid out. Sometimes employers retain the pension capital in their own business by allocating reserves to a special 
account in the balance sheet destined exclusively for pension purposes. To be credible, these reserves must be secured by credit insurance or a government guarantee.

The two techniques for financing pension costs are described above in their purest forms. Obviously, various modifications are possible and do occur. Pay-as-you-go systems are often combined with a buffer fund to equalise costs over time. This eliminates sharp variations in current expenditure due to sudden fluctuations in pension payments. However, such a system must not be mistaken for a secured pre-funding system; it is still a pay-as-you-go system.

It is possible to combine these techniques by providing the necessary pension capital only when pension payments commence. This may be appropriate where it is impossible to know in advance whether certain benefits will actually be paid out or not. The method is of course also possible where it is possible to calculate the risk of payment. However, in that case the employer will take out insurance, provided either by himself or by a separate insurer.

Another variation is to finance part of the pension by a pay-as-you-go system and part by pre-funding. The simplest way to do this is to divide the pension into two separate benefits. These benefits can vary and thus complement each other. Obviously, different kinds of benefits may require different financing techniques, a subject which will be discussed later.

\section{$5.4 \quad$ Conditions for Entitlement}

All pension schemes include rules about minimum requirements that must be met by employees to be eligible for pension rights, e.g. a minimum age, a minimum employment career or certain service requirements in the case of rights related to a specific benefit. A complicated system may impose a large number of requirements for various situations, while a simple system will minimise the number of requirements. Naturally, the latter system is preferable as long as simplicity is not achieved at the expense of unacceptable costs and benefits.

If civil servants are excluded from the state pension system and receive the whole of their pension from their own pension scheme, it is natural to make comparisons with the terms of the state pension scheme. Civil servants should not be less favourably treated than if they were covered by the state pension system.

The most elementary requirement is the minimum age when a civil servant can join the pension scheme. Where it has been considered necessary to lay down such a requirement, it is usually about 18-20 years. The need to establish such a requirement is decided by the other conditions that must be fulfilled for membership. Membership of the scheme does not of course imply entitlement to all rights from the start. For example, it may be reasonable to provide entitlement to invalidity pensions and survivor's pension from an earlier age than that from which entitlement for old-age pensions starts to be acquired. The question of the minimum qualifying age for entitlement to an old-age pension should be covered by the rules for calculating pensions and pension rights for employees who leave their employer early or take early retirement.

Pension schemes always include a definition of the kind of service that entitles employees to join the system, i.e. the scheme has a certain sphere of application. Apart from such definitions, certain categories of part-time employment are usually excluded from pension rights, e.g. employment on an hourly basis and employment amounting to less than 40 or 50 per cent of full-time employment. In some countries, further conditions apply to membership even in the case of service covered by the definition. In 
the case of fixed-term appointments, a vesting requirement (a minimum period of qualification for entitlement to certain rights) of six months or more is often stipulated. Such requirements may sometimes also apply to permanent appointments.

This section deals with the conditions for membership of a pension scheme. The conditions for entitlement to the various benefits provided by the scheme will be discussed under the respective benefits. In conclusion, it should be emphasised once again that a system with different minimum ages and other qualification requirements for pension benefits is highly impractical. Apart from creating confusion, the differences in conditions cannot always be justified on objective grounds.

\subsection{Calculation of Old-Age Pensions}

In Western Europe there are as many ways of calculating civil service pensions as there are pension schemes. Some of them are described in brief in Section 8 ("Country Overviews"). This section contains a general discussion of the calculation of old-age pensions in accordance with various models.

\subsubsection{Pensionable Earnings}

The size of an occupational pension normally depends on the employee's earnings and the length of his employment career. A close examination of the earnings that determine the pension reveals that two contrasting principles are applied. In the public sector pensions are usually calculated on the basis of final pre-retirement earnings (final salary). This may mean the salary at the point of retirement, the salary that the employee has had for at least one year, the average earnings during the last five years prior to retirement or some other of the countless variations on this theme.

Where pensions are based on earnings over a period of one year or more, the employee's salary at the start of this period must be considered in relation to the salary levels applying at the end of the period. In a grade structure it is natural to base the calculation on the relevant salary levels at the end of the period. In the case of an individual salary system, an index must be applied either to salaries or to inflation. Where indexation of pension payments occurs, it may be appropriate to adjust the earnings on which the pension is based in accordance with the same index.

It may be necessary to limit the possibility of receiving a higher pension on the basis of a pay rise immediately prior to retirement. Unless the higher pension increases the costs carried by the party who is responsible for the pay rise, there is an obvious risk, where wage-setting is not subject to strict control, of manipulation of the system.

Another question is whether and how any salary supplements and other variable salary components should be taken into account. It may be appropriate in such cases to take into account a longer period than for the fixed salary.

The other principle applied to pensionable earnings is that of career earnings, i.e. all the pay received by the employee during his career. This principle eliminates some of the problems connected with the final salary principle. However, indexation or some other form of revaluation is necessary. Since the period taken into account here is considerably longer, the revaluation of previous earnings should not be related to salary scales. Salary scales may be altered many times during a 40 -year employment career, and this would require transitional solutions in each case. Instead, revaluation should be effected either by 
indexation or by awarding bonuses, depending on the precise nature of the pension promise and the method of financing it.

\subsubsection{Pension Promises}

Employers' pension promises are based on one of two principles. The traditional practice in the case of occupational pensions is for the employer to promise employees a specified benefit, usually related to earnings, subject to a qualifying period of $30-40$ years for a full pension; i.e. the pension is benefit-defined. The employer must then make the necessary provisions or contributions to ensure that the promise will be fulfilled. The size of the benefit is thus always defined in the pension scheme. However, the cost of the contributions is an uncertain factor. They cannot be predicted with any certainty, which is unsatisfactory from the employer's point of view. With the pay-as-you-go system this is not always considered a problem, but it undoubtedly involves less control of costs and less cost-consciousness. The problem can be met by making actuarial cost estimates, even though these are not necessary for financing purposes.

The other principle involves the promise of a specified premium or contribution, often a percentage of the employee's earnings; i.e. the pension is contribution-defined. In accordance with this principle the benefit amount depends on the amount that has been contributed to the system and normally the bonuses that have been awarded, mainly out of the surplus generated by capital management. In this case it is the benefit amount that cannot be predicted. At the same time, it is an advantage for the employer to know the size of his contribution and thus the costs connected with the pensions. The disadvantage for the employee of not being able to predict the size of his pension is not very significant provided that he is given regular information on the status of his pension entitlement.

It must be added that it is possible, and perhaps also desirable, to combine the two principles. This helps to cancel out the advantages and disadvantages of each system. Pension schemes combining both principles provide two sets of old-age pensions.

\subsubsection{Length of Service}

As has already been mentioned, the employment career is normally relevant to the size of the pension. Where the career earnings principle is applied, the length of employment is reflected automatically in the employee's total pensionable earnings. The length of service as such is irrelevant to the calculation of the pension.

In the case of final salary-related pensions, a length of service coefficient or some similar coefficient must be calculated. The qualification requirement for a full pension is often 40 years of service. Where this total is not attained, the pension is reduced correspondingly by multiplying the amount by a length of service coefficient. If the qualification requirement for a full pension is 40 years and the actual number of years of service is 30 , this coefficient will be 0.75 and the pension will be reduced accordingly.

In some pension schemes the accrued pension is expressed, not by a coefficient, but in terms of a percentage of pensionable earnings each year. If, for example, a full pension corresponds to 70 per cent of pensionable earnings and the qualifying period is 35 years, this means that 2 per cent of pensionable earnings accrues each year until the maximum pension level has been attained. These calculations can be refined and made more complicated by weighting, e.g. awarding 2.4 per cent for each of the first 15 years and 1.7 per cent for the last 20 years. 
The minimum employment career for a full pension is 35-40 years in most countries, but periods of 30 and 45 years also occur. The career requirement for a full pension is obviously related to the number of years between the minimum age at the start of the qualifying period and pensionable age. There has been a trend in recent years towards reducing pension costs by increasing the length of the qualifying period for a full pension.

Another factor in calculating the length of service is the rules relating to leave of absence. These may take into account the reasons for, and the length of, such absence. Another problem is part-time employment. As a rule, calculations should not be made too complicated by excessively detailed rules. Another sound principle is that part-time employment should either affect the calculation of the length of service or of pensionable earnings, but not both. In the case of final salary-related pensions, there is always a risk of an employee being awarded a higher or lower pension than what might seem reasonable. The employee may, for example, work part-time for most of his career, but start working full-time on reaching the age when pensionable earnings start to be taken into account, thus receiving a full pension on the basis of a full-time salary. Conversely, an employee who first works full-time and then starts working part-time would only receive half the full amount. Such effects can be eliminated by laying down strict rules on leave of absence and employees' working hours.

If employment is terminated prior to pensionable age due to retirement on an invalidity pension or death, the remaining years up to pensionable age should be included — at least to some extent - in the length of service for the purpose of calculating old-age pensions.

\subsubsection{Size of the Pension}

In a benefit-defined system the size of a pension is usually established as a certain percentage of pensionable earnings. It can also be calculated as a flat-rate amount, although this method is hardly ever used in connection with occupational pension systems. However, a combination of these systems may be appropriate as a means of achieving a partial redistribution of pensions from high-paid to low-paid employees. Many systems include rules on minimum pensions. The need for such rules depends, in particular, on the extent to which the basic state pension system fulfils such a function and the relationship between the occupational pension and the state pension.

Pension levels vary greatly between different countries in Western Europe, from 50 to 100 per cent of final salary, including basic pensions where applicable. It is difficult to make comparisons between countries, since pensions are not the only factor affecting pensioners' standards. In countries where pension contributions are made by the employee, he ceases to pay the contribution when he becomes a pensioner. Sometimes, pension income is subject to more favourable tax treatment than wage income. Pensioners may receive social security benefits or have lower living costs due to subsidised travel etc. Obviously, these factors vary greatly from one country to another.

Apart from these reservations, a normal pension level for civil servants in Western Europe is about 75-80 per cent of final salary. However, as was mentioned, this does not necessarily mean that the income levels of these employees falls by 20-25 per cent upon retirement. A sound general principle in establishing pension levels should be that pensions should not exceed those that would be chosen by employees under a voluntary system, assuming that they do not underestimate their need of pension protection. If pensions are regarded as deferred earnings, it is natural to ask what percentage of the earnings the individual employee is prepared to set aside for his pension. This obviously varies, and some scope should be left for supplementing pensions by personal pension insurance policies. The need of 
national savings is another argument for providing such scope. However, occupational pensions should always ensure an adequate level of income.

Naturally, it is not always necessary, nor even desirable, for pension levels in all income brackets to be the same. Where civil servants are also covered by the state pension system, their income from that system should, depending on whether the gross or net co-ordination model is applied, be taken into account. The result may be a lower supplementary pension level in low income brackets. Lower pension levels may also be justified at the other end of the income scale. If the pensionable age in the basic pension system is higher than in the supplementary occupational pension scheme, it may also be necessary to allow a higher pension level under this scheme for the first few years, since no basic pension is payable during that period.

In some countries the pensioner's family situation, either during his active career or during retirement, may have a bearing on the size of his total pension. Where this is not taken into account in the basic pension system, supplements for wives and children or some other form of favourable treatment may be included in civil service pension schemes. The pension rules should take account of the relevant pay conditions.

The size of pensions in a contribution-defined system depends, as mentioned above, on how much has been paid into the system and on how the pension capital has been managed. In pension schemes contributions are normally fixed as a certain percentage of pensionable earnings. The percentage rate may vary in different income brackets for the same reason as the benefit levels in a benefit-defined system.

The benefit amount cannot be deduced from the scheme. It depends on a variety of factors, e.g. the size of the contributions and the period during which they are paid in, the capital inherited from those members of the collective who have died and the surplus generated by capital management. Employees are best served by favourable rules for the management of pension funds and professional fund operation. Pension capital is converted into monthly pension payments on the basis of assumptions about future interest rates, life expectancy and expenses, i.e. actuarial factors. Although women live 4-5 years longer than men, this is normally not taken into account, and the result is a substantial transfer of pension capital from men to women.

For employees to have an idea of the size of their pension under a contribution-defined system, they must be given regular information at least about the pension rights they have earned at any given time.

\subsection{Pensionable Age}

The right to pension benefits usually depends on the fulfilment of certain conditions. Rules may be laid down about a minimum period during which an employee must be a member of the pension scheme (vesting requirement) and there may also be rules laying down a certain minimum age for entitlement to old-age pensions.

Pensionable age may mean two different things. One is a right for the employee to retire at a certain age, from which date the old-age pension is immediately paid out. The other is an obligation for employees to retire at a certain age. Sometimes these two ages coincide, but in many schemes for civil servants the obligation to retire may apply as much as five years later than the right to do so. A variation on this theme is the right to early retirement from a certain age in return for a specific reduction of the pension. This reduction may be marginal, or it may be calculated in accordance with strict actuarial 
principles. In some schemes it is also possible to defer pensions, the value of which is correspondingly increased. These variations fall within the concept of flexible pensionable age.

Apart from the right or obligation to retire at a certain age, there is also an age from which payment of an old-age pension is calculated to commence. From an actuarial point of view all old-age pensions are calculated on the assumption that payment of the pension will commence from a given age. It is obviously important to determine this age where the pensionable age is flexible.

In most countries in Western Europe the pensionable age for civil servants is 60 as regards the right to retire and 65 as regards the obligation to do so. This flexibility takes into account varying individual needs when it comes to retirement. In some countries the pensionable age is lower for certain professional categories due to the fact that their work is regarded as particularly demanding or to special considerations, such as security. Examples of professional categories in the public sector where this principle is applied are military officers, policemen, firemen, engine drivers, air traffic controllers and teachers. In these cases the right to a pension is often related both to age -50 or $55-$ and a minimum number of years of service. Differences in pensionable age between men and women scarcely occur any more.

To establish a reasonable and fair pensionable age is a difficult undertaking and there are no generally accepted principles for how it should be done. Many conflicting interests are at stake. On the one hand, certain professional categories claim the right to a lower pensionable age on account of hard physical work, which is difficult for employers to assess, while employers need to be able to retire staff they no longer need on account of their age, particularly in certain fields. On the other hand, employees are keen to remain at work as long as they find it rewarding and, above all, a high pensionable age is economically desirable to employers. Last but not least, employees want fair and equal treatment regardless of individual differences.

In addition to these conflicting interests, the situation is complicated by the fact that working life is undergoing a process of rapid change, and this applies also to the special needs of certain professional categories. Another factor to be taken into account in this connection is the pensionable age in the basic state pension system and the rest of the labour market. Whether or not civil servants are covered by state pensions, it is an advantage if the pensionable age is the same in both systems, at least for the broad majority.

In view of all the above factors, it is not easy to find a satisfactory solution to this issue. Whatever pensionable age is decided on, some people will retire too late and some too soon. However, economic realities limit the scope for manoeuvre. Lowering the pensionable age by one year not only means that pensions are paid out for one extra year, but also that the necessary pension capital accrues for one year less. It is therefore important to make actuarial calculations of the costs and give them careful consideration in establishing the pensionable age.

The problem of redundancy is often solved by retiring older staff on a pension. On no account should the pensionable age be lowered. Instead, temporary and special measures should be taken when it is necessary to allow early retirement, assuming that the economic situation permits this. Pensionable age must be established on the basis of a retirement age that is both desirable and sustainable.

There is a noticeable trend in many countries towards solving the problem of rising pension costs by raising the pensionable age. In view of the steady increase in life expectancy, this appears to be a reasonable course. 


\section{Invalidity Pensions}

An occupational pension scheme normally includes rules on invalidity pensions. Alternatively, these rules may be incorporated in the health insurance system. An invalidity benefit paid up to pensionable age to a former employee who has retired on account of permanent disability should, however, be regarded as a pension.

Basically, there are two ways of designing an invalidity pension. One way is to design a pure risk benefit which does not require pre-funding. This means that an employee who terminates his employment forgoes the right to an invalidity pension in the event of disablement. Under this system invalidity pensions cannot be earned. The second way includes a saving component, which means that an invalidity pension is earned in the same way as an old-age pension. Following early retirement, the employee is entitled to an invalidity pension amounting to the proportion of a full pension for which he is qualified at the time of retirement.

As with old-age pensions, conditions should be laid down for entitlement to an invalidity pension. Often, there are rules on qualifying periods. The problem of deciding whether the disability is permanent or not is a medical matter which will not be discussed here. It is also necessary to lay down rules determining whether the pension will be terminated if the recipient starts work again.

It is wise to make a clear distinction between invalidity pensions on medical grounds and early retirement pensions granted on account of redundancy. Redundancy benefits may be justified in specific situations, but they should not form a regular part of a pension scheme. When a redundancy situation arises in a certain area, an early retirement pension should be granted by a separate decision, which should also specify how it is to be financed.

The method of calculating invalidity pensions depends on how old-age pensions are calculated. If they constitute benefit-defined promises based on final salary, it is natural that invalidity pensions should be calculated in a similar manner. Often, the recipient is compensated for early retirement, so that the period up to pensionable age is taken into account, wholly or in part, for pension purposes as if he had remained at work. In principle, the same applies to contribution-defined old-age pension promises, where invalidity pensions are usually also benefit-defined.

There may also be justification for establishing a higher level for invalidity pensions than for old-age pensions. At the same time, it is perhaps more important than in the case of old-age pensions not to risk establishing a level that is too high in relation to the employee's salary. The individual should always have an economic incentive to work.

The simplest way to finance invalidity pensions for civil servants is to use the same technique as for old-age pensions. Even in the case of pre-funding, the risk should be taken by the employer, preferably with the costs calculated as a risk premium. It is of course also possible to insure against this risk.

\subsection{Survivor's Pension Benefits}

Occupational pension systems should include some form of survivor's pension to be complete. The pattern of employment varies greatly from one country to another and consequently the need for and extent of survivor's pensions. If women work to the same extent as men, the main need for survivor's pensions is in the form of children's pensions. Survivor's pensions for adults are now usually provided both in the form of widow's and in the form of widower's pensions. A divorced spouse may also be 
entitled to a survivor's pension, as well as a survivor who has cohabited with the deceased without being married.

Survivor's pensions are usually shared between the beneficiaries in accordance with a plan established in the pension scheme, which often means that the benefits encroach on each other. The length of time during which the pension is paid out varies, in particular, depending on who the beneficiary is. Children's pensions are usually not paid after the age of 19 or 20 and survivor's pensions for adults not if the beneficiary remarries.

Like invalidity pensions, survivor's pensions are a risk benefit which may or may not include an element of saving. Usually, funds for survivor's benefits are allocated for those who retire early on the same conditions as for old-age pensioners. If old-age pensions are pre-funded, the same financing method should apply to survivor's pensions. They should also be secured in the same way as old-age pensions, unless they represent a pure risk benefit.

A survivor's pension for a sole beneficiary is usually calculated as a certain percentage 50-60 per cent - of an old-age pension. If the employee dies while he is still in service, it is the old-age pension successively earned up to pensionable age that is taken into account. Alternatively, a survivor's pension may be fixed at a flat rate and payable during a limited period, e.g. five years.

In the case of contribution-defined pre-funded old-age pension promises, another alternative exists: the pension capital set aside for the old-age pension may be paid out to the survivor.

Very often there is also an occupational group life insurance policy as well as a survivor's pension. This may entitle the survivor to a flat-rate amount, such as one year's normal salary, payable in the event of death. The amount may diminish with the age of the insured employee and be zero by the time he reaches pensionable age.

\subsection{Commencement of Old-Age Pension Payments}

A benefit-defined old-age pension is paid out in the form of a life annuity from the date when pensionable age is attained. If payment commences on some other date, this should naturally affect the amount paid out. Assuming constant costs, the payment out of a fully funded system of a pension from another date will necessitate an actuarial recalculation of the pension amount. In a pay-as-you-go system a standardised reduction or increase may be made to allow for early or deferred payment of the old-age pension. The pension to be paid out is the amount that has accrued at the time of payment; in the event of early retirement, therefore, a certain period remains to be earned up to pensionable age. If the employer is prepared to bear the costs, the amount by which the pension is reduced can of course be smaller than it should be according to strictly actuarial principles. Such cases may be regarded as instances of flexible pensionable age.

In the case of a contribution-defined pension promise the size of the pension depends directly on the amount of pension capital set aside, as well as the age from which the pension is to be paid out. This may justify greater flexibility as regards payment. The beneficiary may be in need of a higher benefit during his first few years as a pensioner. He should, to some extent, be entitled to choose the length of time during which payment is made, e.g. five or ten years or the rest of his life. However, steps should be taken to ensure that the beneficiary will be paid a sufficient amount for the rest of his life so as not to become destitute and dependent on public assistance. 
It may be mentioned in this connection that old-age pensions are sometimes combined with a lump sum paid out when the beneficiary reaches pensionable age. The rationale behind this is that the new situation in which the pensioner finds himself requires a special increment.

Therefore, pension schemes should include rules laying down the date from which an old-age pension may be paid out, at the earliest and at the latest. They should also include rules on the recalculation of pensions. If it is possible to draw part of the pension for a limited period, this should also be regulated.

It is worthwhile repeating at this point that early retirement pensions granted on grounds of redundancy or for other non-medical reasons are not to be confused with the early retirement pension payments referred to above. Such pensions should be kept separate from benefits under pension schemes. Special rules should be issued when the need arises. Otherwise there is a risk of confusing cost centres and control will be lost.

\subsection{Change of Employment}

Under many pension schemes employees who terminate their employment risk losing the pension benefits to which they assume they are entitled. For this reason an employee who wishes to change jobs may not do so for fear of losing pension benefits. Such pension conditions are an obstacle to labour mobility.

\subsubsection{Vested Pension Rights}

It is necessary at this juncture to discuss the question of vested pension benefits. Where entitlement is dependent on one or more conditions, the benefit is conditional. In the absence of such conditions it is said to be a vested benefit. This concept may vary from one country to another, but it is nevertheless appropriate to discuss it in connection with the calculation and revaluation of benefits in the event of termination of their employment. A benefit whose value can be eroded can hardly be considered a vested benefit in the proper sense.

The vesting requirement for civil servants' entitlement to old-age pensions varies in Western Europe from a few months of service to as much as fifteen years. Until this vesting requirement is completed, the old-age pension is conditional in the sense that an employee who leaves his employment before the end of this period is not entitled to a pension. This does not necessarily mean that he is not entitled to some other benefit, of less value, such as a lump-sum severance payment.

Another condition that exists in some schemes is the requirement that employees must remain in service until they attain pensionable age, or some other age near pensionable age, to be entitled to pension benefits. In such cases termination of employment involves the loss of pension rights. This may seem unfair, but where the conditional benefit relates to a certain profession or appointment the loss of entitlement may be justified. For example, it is hard to see why an air traffic controller, with a pensionable age of 60 instead of the normal 65, who voluntarily leaves before the age of 60 should receive his accrued old-age pension between the age of 60 and 65. Therefore, his old-age pension before the age of 65 may be conditional, but not, of course, his pension from the age of 65 .

Making accrued pension entitlement subject to conditions is one way for employers to keep their employees. This phenomenon is a serious obstacle to labour mobility, and in some countries legislation has been enacted in order to limits the scope for conditional pension rights. Efforts are also being made by 
the European Union to eliminate obstacles to mobility, including restrictions on the stipulation of conditional pension rights.

\subsubsection{Co-ordination}

Even where pension rights are not strictly conditional, the way pensions are calculated and the fact, in some schemes, that pension benefits are not revalued in the event of termination of employment may deter employees from changing jobs. This applies primarily to benefits based on final salary. To solve this problem it may be necessary to include rules in the pension scheme requiring co-ordination with other occupational pension rights. Co-ordination can be organised on the following lines.

Previous service years can be taken into account for a pension under the pension scheme applicable to the new appointment and the accrued pension benefit be incorporated into the pension. This assumes that both schemes represent the same value. Where this is not the case, the accrued years of service should be recalculated with reference to the difference in value. Where the final salary principle applies, co-ordination tends to place a disproportionate amount of the cost on the last employer, and consequently the system should be based on mutual agreement between the two pension schemes. The methods used to integrate accrued pension rights may vary. Pension capital can be transferred when the employee takes up his new post or the accrued benefit can be paid into the latter system when the pension is due. Another method is to reduce the pension by the amount paid out for the accrued benefit.

The possibility of co-ordinating pension rights earned under different pension schemes is an important factor in facilitating labour mobility and recruiting qualified staff. However, the co-ordination rules are often complicated and it is difficult to conclude agreements about them and even more difficult to alter such agreements. The rules are also difficult for employees to understand. One great advantage of contribution-defined promises and pensions based on career earnings is that such systems do not require co-ordination. Each employer is responsible for his share of the final pension, without having to take into account any accrued pension rights. Such a pension scheme still does not, however, eliminate the difficulty of recruiting a person who is covered by another scheme with conditional benefits.

\section{$5.11 \quad$ Revaluation}

The extremely long-term nature of pension obligations makes the issue of revaluation exceptionally important both to employees and employers. This applies particularly to countries with high inflation, or rather in times of high inflation, since a fifty-year time frame involves great uncertainty about the future. The question whether and how the value of accrued pension rights should be revalued before and during the period of payment should therefore be explicitly regulated in the pension scheme.

There are three phases in which this issue is relevant: the earning period, the payment period and possibly the waiting time between these two periods.

\subsubsection{The Earning Period}

In the case of pensions based on final salary the accrued pension right is raised during the term of employment to the same extent as the employee's salary. If his salary is reduced, the value of his pension right is reduced accordingly. 
For pensions based on career earnings the situation is different. If the pension promise is benefit-defined, special rules must explain how accrued pension rights are to be revalued. There are two possible models. In the first, the general raise is decided each year, preferably in conjunction with the review of salaries. In the other model pension rights are raised each year by an index related to price or wage trends or a mixture of the two. The index model is the most appropriate for this phase, where the employee is still with his original employer.

Contribution-defined pensions financed by pay-as-you-go systems are treated in the same manner. If, however, pensions are fully funded, the accrued pension rights are raised each year by the surplus generated by capital management and the insurance elements. In that case employees benefit greatly from prudent and professional management. Rules on investment of the capital and the fund managers are therefore essential components of the pension scheme.

\subsubsection{The Waiting Time}

If an employee terminates his employment before his pension is due, there is a period prior to the payment of this pension which often has an adverse effect on the value of the earned benefit. Benefit-defined pensions based on final salary are not designed for early leavers. Where this happens nevertheless, it seems to be considered legitimate in some quarters, if not to cancel the pension right, at least to erode its value. Revaluation may have to wait until the time comes for payment of the earned benefit. Once again, this hampers labour mobility.

The alternative is of course to ensure that any decision on the revaluation of accrued pension rights during the earning period applies also to the interval between termination of employment and the commencement of pension payments. As regards pensions based on final salary, special rules are only necessary with respect to this interval, since the value of the pension rises automatically during the earning period.

In the case of pre-funded contribution-defined pensions, the same is true during the waiting time as during the earning period. The revaluation of accrued pension rights depends on the surplus generated.

\subsubsection{The Payment Period}

When it comes to the payment phase, there is a fundamental difference between pre-funded contribution-defined pensions and other pensions. In the former case the employer has discharged his obligations by paying the contributions. The employee who retires is entitled to the accrued surplus, but also accepts the risk that the surplus will be less than he had reason to expect. With benefit-defined pensions the beneficiary receives the amount promised in the scheme, neither more nor less. The employer bears the risk of the costs being higher - or the chance that they will be lower - than he had estimated.

The pension scheme should contain rules on revaluation of benefits during the payment phase. In the case of fully-funded contribution-defined pensions these rules will apply to management of the funds paid in. In other cases the rules should not tie pensions to automatic indexation, at least not unless the index is related to economic development. Otherwise pensioners' living standards during negative real wage trends may rise disproportionately compared with those of the working population. Where pensions are financed under a pay-as-you-go system, which means that they are paid for by those in employment, there is a risk of this creating tension between the generations. It may even lead to cancellation of the "generation contract". The normal method is therefore to revalue pensions once a year, preferably in accordance with principles laid down in the scheme. 


\subsection{Transitional Provisions}

When a new pension scheme is introduced it is necessary to establish transitional rules for the phase-out of the previous provisions and the introduction of new ones. The same applies when pension conditions are altered. Depending on the rate at which change is to take place, such transitional rules may apply for anything between a few months and several decades. Conflicting interests are at stake. Those who stand to gain from the change will obviously want to introduce it as fast as possible; conversely, those who lose by it will want to wait as long as possible before it takes effect. An extreme course is to let the new pension scheme apply only to those who enter employment after the scheme has taken effect. Sometimes this is considered the only way of introducing changes for the worse.

The real problem connected with new or improved benefits is the question of finance. If pre-funding is the technique adopted, it will take a long time, possibly 40 years, before a reform has matured. To achieve a speedier process it is necessary to set aside larger amounts during a transitional period. On the other hand, a pay-as-you-go system allows improved conditions, e.g. a 10 per cent rise in pension levels for all employees, to be introduced overnight. The effect on costs, i.e. for payment of the pensions, only becomes apparent much later; indeed the full effect is not felt until about 40 years after introduction of the reform. In other words, pay-as-you-go systems do not encourage a proper review of proposed increases in benefits.

Conversely, when changes for the worse are introduced, the savings made in a pre-funded scheme are hardly noticeable for the scheme-members at first. Employees can rest assured that the amount that has accrued at a given time will not be taken away from them. Only the pension earned after that time will be reduced. Non-funded benefits, however, are liable to disappear immediately if the economic situation makes cuts necessary. The chance of actually receiving a promised pension on reaching pensionable age is obviously much greater if the pension is pre-funded than if it is financed by a pay-as-you-go system.

The question of financing should be given careful consideration when transitional rules for a new pension scheme or improvements of an existing scheme are formulated. It is important that the public should have confidence in the readiness and ability of the employer, i.e. the state, to meet its pension obligations even if a pension scheme is financed under a pay-as-you-go system. The introduction of new benefits and the phase-out of old ones should therefore take place gradually, particularly if these changes are for the worse. If it is not considered desirable for the new benefits to accrue at the normal (slow) rate, the qualifying period can be shortened by taking into account a specified employment period retroactively. Another method, which is applicable where benefits are based on final salary, is to require a shorter earning period for a transitional generation than that normally required for a full pension.

If a new pension scheme is financed by a contributory pay-as-you-go system, the system will not normally require all contributions (based on the employees) during the first few years or decades to finance payments. In that case it is important not to treat the contributions made as income in the national budget that can be used for purposes other than pensions. They should be earmarked for use as a buffer against future fluctuations in contribution revenues and the pensioner population.

Another aspect of transitional rules is that it is wise not to apply parallel pension conditions for too long. It is understandable if the introduction of a reform is accompanied by a guarantee that benefits will not be lower than those provided under the previous conditions. An alternative is to give employees the option of retaining the old conditions or opting for the new ones. This is not a satisfactory solution, since it is liable to be costly and difficult to administer. If a cautious transition to new conditions is 
desirable, it is better to let the previous conditions continue to apply to all employees over a certain age, e.g. those with not more than five years remaining until pensionable age.

To sum up, the possibility of speedily implementing a pension reform that is offered by pay-as-you-go systems should be used with discretion. Pension promises must be fulfilled and the pensions which employees have earned under the rules previously in force must by respected as far as possible; as a matter of principle, reforms should only apply to the period after their entry into force. With pre-funding this occurs automatically. If a speedy introduction of new rules is considered desirable, higher contributions should be paid during a transitional period. 


\section{OPTIONS}

In this Paper pensions are described with reference to certain key terms. Section 6.5 describes two models for co-ordinating supplementary occupational pensions with benefits under the state basic pension system, gross co-ordination and net co-ordination. In Section 6.6 financing is described in terms of pay-as-you-go systems or pre-funding. In Section 6.2/6.3, which deals with the calculation of pensions, the terms final salary and career earnings are used in connection with pensionable earnings and the terms benefit-defined and contribution-defined in connection with pension promises. Lastly, Section 6.4 deals with the issue of conditional or vested pension rights. The time has come to put these terms into perspective. Since they are related to each other in various ways, it is practical in this context to focus on their implications and to discuss the most natural and effective combinations between them.

Pensions may be regarded either as deferred earnings or extended earnings. The structure of a pension has a logical relationship with the principle on which it is based. The following diagram illustrates the relationships between the terms mentioned above.

\section{Key Pension Terms}

\begin{tabular}{|l|l|l|}
\hline Financing: & Pay-as-you-go & Pre-funding \\
\hline $\begin{array}{l}\text { Co-ordination with basic } \\
\text { pensions: }\end{array}$ & Gross/Net & Net \\
\hline Pension rights: & Conditional & Vested \\
\hline Pension promises: & Benefit-defined & Contribution-defined \\
\hline Pensionable earnings: & Final salary & Career earnings \\
\hline View of occupational pensions: & Extended earnings & Deferred earnings \\
\hline
\end{tabular}

The diagram should be read from the bottom up. The prevailing view of occupational pensions is the foundation on which the pension system should rest. It should decide the choice of pension system and determine its whole structure.

The structure of pension schemes will be discussed here mainly in theoretical terms, although it must be said that designing a pension system in reality is complicated by existing systems and the difficulty of changing them. in Section 4.

The implications of the various alternatives should be checked against the principles established 


\subsection{Are Pensions Extended or Deferred Earnings?}

The basic approach to occupational pensions will determine the structure of the system. This approach will partly depend on attitudes to employment. Should the employer, especially the last employer, accept far-reaching responsibility for providing for his employees? Does the employer expect the employee to remain with him for life? If so, pensions may be regarded as extended earnings. Or is employment considered temporary, even though it may last a long time, and does the employer only accept responsibility for the actual term of employment? Is it up to the employee to ensure that his overall pension is sufficient to support him when he reaches pensionable age? In that case, it is natural to think of pensions as deferred earnings.

Attitudes to the public sector and the position of civil servants are relevant in this connection. This matter was discussed in Section 3.3, "Distinctive Features of the Civil Service". Should the pension scheme be designed only for the target group concerned, or should there be a common approach to all national occupational pensions? A common approach is obviously preferable from the point of view of labour mobility, since otherwise pension provisions may be an obstacle to mobility.

There is a long-term global trend, stronger in some places than others, towards greater labour mobility. Employees change jobs more often, even across national borders. It is expected that in the future they will alternate between work, training and other activities more than is the case today. Conditions of employment are likely to be less rigid, and ties to the employer looser.

\subsection{Pensions Based on Final Salary or Career Earnings?}

The question whether pensionable earnings should be based on the employee's final salary or his career earnings should be decided by one's basic view of the function of pensions. In practice it is not always so simple. Nevertheless, the fact that real life is full of contradictions should not prevent one from aiming for a logical approach.

According to the diagram, if pensions are regarded as extended earnings, then it is natural to base pensionable earnings on final salary. Since the pension level is related to the employee's earnings immediately prior to retirement, this guarantees a standard of living similar to the one he had at the end of his career.

If pensions are thought of as deferred earnings, then pensions should be based on the employee's career earnings. An employee's work contribution earlier in his career should have the same value when it comes to calculating his pension as his final salary. There is an obvious correlation in this approach between earnings as a reward for the employee's performance and his future pension. Where the pension is based on final salary, the employee's earnings during most of his professional career are irrelevant.

The final salary principle favours those whose careers offer a high salary during the final phase. Their pensions will be higher in relation to their career earnings than for those whose salary does not change very much throughout their professional careers. This approach raises questions as to the fairness of the system. Do the careerist and the employee whose input diminishes towards the end of his career get equal treatment, and what about the employer who must pay the cost of raising the careerist's pension at the end of his career and the employer who may not have any costs at all, since the other employee's pension has already been paid for? 
There is also a risk that the final salary principle may encourage manipulation of an employee's earnings for the purpose of achieving an excessively high pension. Conversely, the principle makes it impossible to wind down prior to retirement, even if both the employer and the employee might consider this desirable.

Naturally, the disadvantages of basing pensions on final salary can be offset by rules laid down in the pension scheme. Other conditions of employment may also play their part. In the public sector, in particular, salary scales and a statutory promotion system may eliminate the possibility of manipulation. It is, however, unfortunate that such rules should be necessary to ensure that the pension system works.

Calculating pensions on the basis of final salary is an obstacle to labour mobility. Employees must ask themselves whether they stand to lose by changing from one system to another. Agreements on complicated co-ordination rules must be concluded between various occupational pension schemes to prevent adverse effects on mobility. Where the principle of career earnings is applied, each employer is responsible for his share of the employee's overall pension regardless of the rights he has earned previously.

Insofar as it is possible to detect a trend in attitudes to pensionable earnings, it is from final salary to career earnings.

\subsection{Benefit-Defined or Contribution-Defined Pension Promises?}

Pension promises based on final salary can only be benefit-defined, and the benefit amount is specified in the pension scheme. As can be seen from the diagram, pensions based on career earnings can be both benefit- and contribution-defined. In most cases, however, such pensions are contribution-defined, and the size of the contribution is specified in the pension scheme.

A distinctive feature of benefit-defined pension promises is that the final cost cannot be predicted. Complicated actuarial calculations, based on uncertain assumptions, are necessary if the benefits are to be pre-funded or if appropriate contributions are to be paid during the earning period. Employees do not need to worry about the financing, since it is the employer who bears the risk of the costs being higher than estimated. On the other hand, the employer also benefits from any surplus generated by capital management. In practice, however, it may not be agreement on who the pension capital belongs to.

If employers and employees are to share pension costs under a benefit-defined system, the employees' contributions must necessarily be an approximation. In other words, it is not possible to fix the employees' contribution at, say, one-third of the real costs. Since individual contributions are a common feature of pension systems for civil servants, it must be emphasised that statements about the proportion of costs represented by these contributions cannot be accurate. This makes it difficult to justify changes in individual contributions on objective grounds.

It is no easy matter in terms of costs to the employer or benefits to the employee to promise employees a specific future pension where this is based on future final salary. Such promises also extend over a very long period, which creates considerable resistance to change. Since a certain proportion of the pension has always been earned at any given time, it is difficult to change the promise in a way that is both reasonable and fair. Changes for the worse, however reasonable and necessary they may be, may justifiably be described as a breach of promise. The problem of changing pension conditions is particularly obvious in a pre-funding system, but it also arises where a pay-as-you-go system is applied. 
These problems do not occur where benefit-defined promises are based on career earnings. Such a promise may be formulated as follows: the employee earns a pension of $1 / 40$ of 70 per cent of annual pay between the age of 25 and 65 , or 1.75 per cent of his earnings per year. The difficulty of calculating costs in this case is limited to actuarial calculations of the contribution and to ensuring revaluation of accrued pension benefits. The conditions can be changed without risk of a breach of promise since the pension level - e.g. 1.75 per cent - can be changed in such a way as only to relate to future earnings. This makes it easier to implement necessary changes.

The main feature of contribution-defined promises is the uncertainty of the benefit amount. The cost, however, is given from the start and is final the moment the contribution is paid in, at least if the pension is pre-funded. The main requirement in a contribution-defined pension scheme is to ensure revaluation or growth of the pension funds, in particular up to the time when the pension falls due.

The natural way to finance contribution-defined pension promises is by pre-funding. As a rule, any surplus generated by the fund management falls to the employees, who thus benefit from prudent and professional management. The employer may want to invest the pension capital in his own business. Rules on investment of the funds and the appointment of fund managers or trustees, as well as decisions concerning bonus awards, are therefore essential elements of the pension scheme. The employees, as well as the employer, are represented on the board of the pension fund or of the insurer who manages the pension capital. Another alternative is to let employees decide individually where their pension savings should be invested. In that case the number of alternatives should be limited, so as to avoid the risk of pension savings being dissipated in risky investments or by high costs.

Where the scheme is financed under a pay-as-you-go system, the (notional) reserve must be revalued by regular decisions or by relating it to a price or wage index etc. With this financing technique the employer's costs are only known when the pension is paid out, even though the promise is contribution-defined.

As shown by the diagram, contribution-defined promises are based on career earnings; final salary can only be a basis for benefit-defined pension promises. The previous remarks about the career earnings principle therefore also apply to contribution-defined pension promises. This system makes the connection between performance, as measured by earnings, and pensions very clear and thus directly encourages work. It imposes unambiguous responsibility on the individual for his own pension situation, especially if the capital is invested. At the same time, this makes it necessary to issue regular, simple and comprehensible information to employees on the status of their pension earnings.

There is at present a noticeable trend towards contribution-defined pension promises.

\subsection{Conditional or Vested Pension Rights?}

According to the diagram, conditional pension rights are only possible in the case of benefit-defined promises based on final salary. In fact, there is no obstacle to conditional pension rights in other cases, but they do not easily fit into the framework of contribution-defined promises or other benefits based on career earnings.

There is very little justification for conditional pension rights. A short vesting requirement at the start of an employee's career might possibly simplify administration by making it unnecessary to calculate and pay small amounts to employees who are only employed for a short period. A longer vesting requirement would make employees less inclined to change jobs and would thus be an obstacle to labour 
mobility. The main reason for such requirements is probably economic; employers save money by not having to pay pension benefits to those who are only employed for a short period.

Nor can conditional rights be justified in cases of termination of employment, unless pension rights are related to a low pensionable age laid down for a certain appointment. However, employees should in no circumstances lose accrued old-age pension rights that fall due upon commencement of the normal pensionable age. Such insecure pension rights are both unfair and indefensible. Nevertheless, they help employers to keep qualified — and not so qualified — staff, although once again they are an obstacle to labour mobility.

A special case of conditional rights occurs where the value of a benefit received on termination of employment is lower than the proportion of his old-age pension for which the employee is qualified. The benefit may have been calculated in accordance with unduly stringent principles or may not have been revalued. Employers have many ways of discriminating against early leavers.

The simplest way of financing conditional pension rights is by a pay-as-you-go system. Pre-funding is not advisable, at least not until the time for payment arrives and the benefit vests.

\subsection{Gross or Net Co-ordination with State Basic Pensions?}

The first decision to be taken as regards basic state pensions is whether civil servants should be covered by such pensions at all. In many countries they are not covered by the state pension system, but only by an occupational pension. This issue has been discussed already. The structure of the occupational pension system is irrelevant. There is, however, a connection between the model used for co-ordination with basic pensions, if any, and pensionable earnings. A pension based on career earnings can scarcely be co-ordinated with a basic pension based on the gross co-ordination model, especially not if it is contribution-defined.

The implication of the gross co-ordination model is that the basic pension system is irrelevant to civil service pensions. Both improvements and changes for the worse in the basic pension are neutralised, which from the employer's point of view is an advantage in good times and a disadvantage in bad ones. Obviously, for employees it is the other way round. Changes in the basic pension system only affect civil servants' pensions when their system is correspondingly adjusted.

Another problem of the gross co-ordination model may be that the pension amounts received by employees under a supplementary pension vary between individuals depending on the amount deducted on account of the basic pension. The larger the differentials in the basic pension system and the more differences there are in the methods of calculating the two pensions, the greater is the risk of variation. In principle there is nothing to prevent the supplementary pension falling to zero after the basic pension is deducted, unless the method of calculation eliminates this possibility. However, if the gross occupational pension amount is perceived as the only pension promise, this is not necessarily a problem.

Even if individual variations in the size of pensions are not a problem in themselves, they cause problems when it comes to calculating pension costs for the individual employee during the earning period. The size of the pension benefit is not known until payments commence. This means in its turn that accurate pre-funding in accordance with direct actuarial principles is impossible. Therefore, the most appropriate technique for financing gross pensions is a pay-as-you-go system. 
The net co-ordination model works the other way round. Changes in basic pensions take effect immediately. The calculation of occupational pensions depends on how basic pensions are calculated and on the amounts fixed. Obviously, the occupational pension levels depend on the proportion of the (fictitious) total pension accounted for by the basic pension system.

Since the size of the pension is known during the qualifying period, it is possible to calculate costs and the best financing technique is probably pre-funding.

If the state pension system is changed to such an extent that the level of benefits in the supplementary system must be lowered or raised, the net co-ordination model may pose a problem. Part of the occupational pension must be replaced by the state pension or vice versa. Such an adjustment may have to be carried out gradually. With the gross co-ordination model this is simpler, since adjustment is automatic. The gross level can remain the same and the changed state pension will account for a larger or smaller proportion of the total pension, as the case may be.

Apart from the aspects discussed above, it must be said that the gross co-ordination model is much more difficult to apply, in terms of regulation and administration, than the net co-ordination model. Rules must be laid down for calculation of the individual amounts to be deducted and procedures established for the collection of individual data on basic state pensions.

\subsection{Pay-As-You-Go or Pre-Funding?}

The financing of pensions was one of the main subjects of Sections 6.1 and 6.2. For historical reasons, and simply because the state is in a position to promise pensions without pre-funding, most countries finance civil service pensions by means of a pay-as-you-go system. This reflects a view of pensions as extended earnings. However, the trend in Western Europe today is towards an increasing element of pre-funding even for civil service pensions.

Pay-as-you-go systems offer several short-term advantages, since costs do not have to be paid as they arise but can be deferred until later. Where a new pension scheme is to be introduced, it may be tempting to implement it at a faster rate than would be possible if it was fully funded. The same applies when it is decided to improve pension conditions, in which case pay-as-you-go systems can award the older generation benefits for which they have not qualified.

Once a pay-as-you-go system has been established, changing over to a pre-funding system puts a great strain on the economy. For more than a generation the system will be burdened with two sets of costs, i.e. the cost of paying out pensions and the cost of allocating funds for future payments.

Another short-term advantage of pay-as-you-go systems is that it is simpler to change pension conditions and benefits, and their effect is immediate. The financing system presents no obstacle. This applies not only to improvements, but also to changes for the worse. Under such a system a stroke of the pen can deprive employees of benefits that they believed they had earned. The situation is quite different with pre-funding systems. These systems are more stable and more likely to deliver on their promises.

This is an important aspect of the choice between financing techniques that is not always given the attention it deserves. When the state promises new benefits to its employees they are naturally inclined to believe that it will deliver them. However, experience has shown that this is not always the case and future changes in today's pension schemes, which in many cases are generous, will of necessity, on account of the increased burden on the active population, involve changes for the worse. 
Benefit-defined promises of gross benefits are best financed by a pay-as-you-go system, since the benefit amounts following deduction of the basic pension are unknown throughout the qualifying period. The same applies to conditional pension rights. Pre-funding is not to be recommended since no payment may ever have to be made.

\subsubsection{Contributions}

Pre-funded pensions automatically sharpen cost-consciousness. Changes in pension conditions entail immediate consequences for those who have to bear the costs. Pre-funding has a sound restraining influence on pensions in the best sense.

The opposite is true of pay-as-you-go systems. Improved benefits only affect costs at a much later date. It is, however, quite possible even with a pay-as-you-go system to calculate the costs incurred by active employees in qualifying for pension benefits and to charge these costs to the employer. The correct technique is to calculate and account for the employer's total pension obligations as a debt to present and past employees. This debt should be calculated in accordance with actuarial principles at the capitalised present value of accrued pension benefits. The costs will then be a function of changes in pension liabilities. This procedure is appropriate where the state is the employer. It has the added advantage that the state's total pension liabilities to its present and past employees are known and can be recorded.

The fundamental difference between pre-funding and the pay-as-you-go system described above, where pension obligations are calculated, is that in a pre-funding system the pension capital is irrevocably destined for the pensions in question. Under a pay-as-you-go system, regardless of whether or not there is a buffer fund or (proforma) booked reserve, those entitled to pensions have no guarantee that they will receive the benefits to which they consider themselves entitled. Their best guarantee is if the pension capital is invested in the non-state sector and they themselves have a say in its management. There are several examples in Western Europe of pension funds or similar institutions where capital reserved for civil servants' pension schemes is managed by representatives of both employers and employees. If it is considered important for reasons of public finance, the rules on investment can stipulate that a specified proportion of the pension capital must be invested in government securities.

Irrespective of the method used to calculate pension costs, it is an advantage if they are charged to the institution in which those who are covered by the pension scheme are employed. This will make those who are responsible for this department more cost-conscious and ensure that costs are kept down. The natural procedure is to charge the pension costs to the same budget as wages. The budget should be debited with a pension contribution corresponding to the allocations or calculated costs referred to above.

Civil servants often pay a half or one-third of their own pension costs. If they are excluded from the state basic pension system and those covered by that system pay individual contributions, then civil servants should also pay similar contributions to the civil service pension scheme. In the interests of comparison, it is an advantage if similar principles are applied in both the private and public sectors. Individual contributions calculated in accordance with actuarial principles have the added advantage of making employees aware of the actual costs. 
In the case of contribution-defined promises, pension contributions are an integral part of the system. Therefore the obvious course is to invest the contributions in a fund, but it is also possible to record accrued pension rights in proforma accounts. A pre-funding system can be combined with voluntary savings within the institution that is responsible for managing the fund. Whether or not this is worthwhile depends on the size of the pensions, but also on the existence of any other personal pension savings schemes on favourable terms. The advantage of voluntary savings schemes managed by the same institution is that they should provide simple savings arrangements that offer a satisfactory and assured yield at low cost. 


\section{ADMINISTRATION}

The administration of occupational pensions depends on the design of the pension scheme. Generally, it consists in collecting and registering data on pensionable earnings, calculating contributions and benefits, regulating and fixing benefits, collecting contributions and accounting for contributions and pension assets. The calculations may involve actuarial methods. In the case of pre-funded pensions there is also the task of managing the pension capital. In addition, administrators usually have the task of informing members of pension conditions and supplying appropriate information to individuals. Administrative details vary considerably depending on whether pension promises are benefit- or contribution-defined, whether benefits are based on final salary or career earnings and whether they are financed by pre-funding or by a pay-as-you-go system.

It is impossible to generalise about which solution is simplest to administer, it depends on the specific mix of options chosen. For example, contribution-defined promises are simple to administer, but that also goes for benefit-defined pensions based on final salary and financed by a pay-as-you-go system. However, administration in these cases is completely different. The former is basically traditional pension savings, while the latter only requires calculations to be made when pension payments commence.

The administration of civil service pensions should preferably be the responsibility of a central body. This body should be responsible to those who decide on the pension conditions and should be independent of the institutions where the civil servants are employed. Central administration ensures legal certainty and equal treatment. Modern information technology makes it possible to deal with large volumes rationally and reliably. This is particularly important when new pension schemes are introduced.

Capital management, where this occurs, should not be the responsibility of the administration. If pension capital is set aside for contribution-defined pensions, its management is crucial to the benefit amounts that can be paid out. Those who are entitled to the benefits should therefore have a say, or at least some control over, capital management. This matter has already been discussed elsewhere. 


\section{COUNTRY OVERVIEWS}

Here follows a brief description of civil service pension systems in five Western European countries. This selection has not been made because the systems in these countries are regarded as examples of particular excellence. They all have a long history and would probably look different today if thorough reforms were possible. There are other systems in other countries, both inside and outside Europe, especially those designed recently, which are equally interesting, if not more so.

\subsection{France}

\subsubsection{Current Pension System for Civil Servants}

Civil servants (les fonctionnaires) in France are not covered by any of the basic state pension schemes, as are other public employees. The special scheme for civil servants - and military officers called le Code des Pensions Civiles et Militaires de retraite (CPCM), is therefore also a basic scheme. Special provisions for military officers will not be accounted for in this outline about civil servants.

Public employees without civil servant status are covered by a special supplementary scheme, IRCANTEC, which is very similar to the arrangements in the private sector, AGIRC and ARRCO.

Both public sector schemes are compulsory within their respective range.

\subsubsection{Pension Rights and Retirement Age}

It takes a civil servant 15 years of service, at the latest by retirement age, before he is qualified for CPCM old-age pension benefits. There is no time requirement for invalidity pension. If the servant does not satisfy said requirement he is covered by the state basic pension scheme and the supplementary IRCANTEC.

The general retirement age is 60 , but it is possible to stay in service until the age of 65 .

\subsubsection{Calculation of Old-Age Pension}

The state's pension promise to its civil servants is defined as a benefit. The calculation basis is final salary, i.e. the basic salary grade and step, excluding bonuses and other individual indemnities, that has been continuously paid for at least six months for the employment in question before its termination.

Bonus and indemnities represent 20 per cent on average of the total remuneration. Since these earnings are not considered for the CPCM pension there is a considerable investment in private retirement funds, some of them managed by public servant unions. 
CPCM pension is earned at the rate of 2 per cent of final salary per service year up to a maximum of 37.5 years. That makes a full pension benefit of 75 per cent of final salary. In some cases, due to family situation or nature of service, bonuses are given in the form of extra years that raises the pension to a maximum of 80 per cent.

It is not possible to take earlier employments covered by other pension schemes into account, with some exceptions regarding the public sector. Neither is it possible to make a transfer of pension rights into the CPCM scheme.

Since the CPCM scheme is a basic scheme, it contains conditions for a minimum pension. If the employee has served for 25 years or more, the benefit is set at FF 64000 per year. If the service time is $15-25$ years the minimum benefit is equal to 4 per cent of this amount per service year.

The pension provisions for the rest of the public sector, the general state scheme and IRCANTEC, constitute an interesting comparison. The calculation basis is presently the best 12 years (indexed), but each new calendar-year will add another year until the best 25 years will be the basis in 2008 - more of career earnings than last salary.

\subsubsection{Invalidity Pension and Survivor's Pension}

Civil servants are entitled to invalidity pensions by the CPCM scheme regardless of age and years of service. The benefit is calculated in the same way as the old-age pension, which means that only years of effective service are considered. If the invalidity is the result of a service activity, a life annuity is paid out.

The CPCM pension scheme provides survivor's pension to widows/widowers, when married at least two years prior to the end of service or having a child between them, and to children up to age 21 . The widow's pension is equal to 50 per cent of the old-age pension to which the deceased was entitled. In case of remarriage or cohabitation, the widow's pension is annulled. The widower's pension requires that the widower has reached the age of 60 . The calculation is done the same way as the calculation of the widow's pension, but there are certain limitations to the benefit amount. The orphan's pension amounts to 10 per cent of the old-age pension.

\subsubsection{Termination and Change of Employment}

If the civil servant leaves before he has served for 15 years, his pension rights will be transferred and calculated according to the state basic scheme and to the IRCANTEC. If he has served for 15 years and leaves before retirement age, he will be entitled to a deferred pension to be paid from the age of 60. If the servant has an "active" status (se next passage) he will receive the deferred pension from age 55 . The value of the pension rights is preserved by the same linkage to public sector salaries as applies to benefits under payment.

It is not possible - and for that matter probably not desirable - for a former civil servant to have his CPCM pension rights transferred to another pension scheme. 


\subsection{6}

\section{Payment of Benefits and Early Retirement}

Personnel with "active" status, i.e. whose work is particularly risky or gives rise to exceptional strain and fatigue (police, custom officers, teachers etc.), may retire with an immediate pension at the age of 55 .

Female civil servants who are mothers of three children may retire as soon as they have fulfilled 15 service years, irrespective of age.

The CPCM pension benefits are automatically upgraded at the same time as the salaries for active staff are revised. Salary negotiations thus affect pensioners just as well as active staff.

\subsubsection{Legislation, Financing and Administration}

Pension systems for public servants are guaranteed by the French Constitution. The CPCM scheme for civil servants is issued by law and based on the notion of extended earnings from the state budget.

The scheme is financed directly by the state budget by taxes, with no funding for future benefit payments. The civil servant pays a contribution of 7.85 per cent of his gross salary, which is not affected by the pension expenditures. It is seen as a general budget resource. This means that the present situation with reductions in public service personnel makes the pension costs appear as an increased burden on the budget. The total cost of the CPCM scheme for civil servants is estimated at 33 per cent of the salary amount.

The pensions of civil servants are treated by the pensions department in each ministry or administration and paid out by the French Treasury through its Pension Service, located in Nantes. The responsibility for rules and regulations lies with the Ministry of Public Service, Direction Générale de l'Administration et de la Fonction Publique (DGAFP), Paris.

\subsubsection{Reforming the Pension Scheme}

The requirement of 37.5 years to qualify for a full 75 per cent pension will probably be raised to 40 years. Other than that no major changes are foreseen in the near future.

\subsection{Germany}

\subsubsection{Current Pension System for Civil Servants}

Federal, state and local authority servants in Germany with a special status which involves a permanent position (Beamten) are, unlike other public employees, exempt from the basic state pension schemes. The special scheme for these civil servants and military officers, included in the Beamtenversorgungsgesetz, BeamtVG, is therefore also a basic scheme.

Public employees without civil servant status are covered by the career earnings-related basic state pension scheme and, in addition a special supplementary scheme, based on a collective agreement. 
The supplementary scheme aims at finally providing the same benefits as the statutory BeamtVG scheme for civil servants, including the basic state pension.

\subsubsection{Pension Rights and Retirement Age}

It takes a civil servant at least five years of service, at the latest by retirement age, before he is qualified for BeamtVG pension benefits. If the servant does not satisfy this requirement by leaving the active service, his civil service years will be insured under the basic state pension scheme.

The general retirement age is 65 , but it is possible to stay in service until the age of 67 . Certain staff retires at the age of 60 , e.g. staff in the police and fire service.

\subsubsection{Calculation of Old-Age Pension}

The BeamtVG pension promise is defined as a benefit. The calculation basis is final salary, i.e. the last salary that has been continuously paid for at least two years before retirement.

BeamtVG pension is earned from the age of 17 at the rate of 1.875 per cent of final salary per service year up to a maximum of 40 years. That makes a full old-age pension benefit at age 65 of 75 per cent of final salary. In case the civil servant is working part-time the years are counted in proportion to that.

It is to some extent possible to take years from outside the civil service sector into account for a BeamtVG pension. Generally speaking, to be considered the years must have had some significance to the civil service employment. benefits.

To avoid overcompensation there are rules about upper limits for the civil servant's total pension

Since the civil service scheme is a basic scheme, it contains provisions for a minimum pension. The benefit amount is DEM 2200 per month or, if higher, 35 per cent of final salary.

\subsubsection{Invalidity Pension and Survivor's Pension}

The civil servant is entitled to an invalidity pension if, after his discharge, he is unable to fulfil his employment and it is not possible to find him another one. The servant must be prepared to submit himself to rehabilitation measures. The benefit is calculated on the basis of the servant's final salary and service years earned plus, at a rate of $2 / 3$, remaining years until age 60 .

The BeamtVG pension scheme also provides a survivor's pension to the widow/widower and to the children of a scheme participant. The widow/widower's benefit amounts to 60 per cent of the old-age pension or, if death occurs while still employed, 60 per cent of the invalidity pension which the civil servant could have claimed. The orphan's benefit amounts to 12 per cent of the deceased's pension or, if both parents die, 20 per cent. 


\subsubsection{Termination and Change of Employment}

If the employment terminates without the civil servant being entitled to an old-age or invalidity pension, he will be retroactively insured in the appropriate basic state pension scheme. There is no such thing as a deferred BeamtVG pension.

\subsubsection{Payment of Benefits and Early Retirement}

Civil servants may retire from age 62 at their own choice, for no special reason. The old-age pension will in such a case be reduced at the rate of 3.6 per cent per year of early retirement. This age-limit will soon be raised to 63. Handicapped may at their own option retire at the age of 60 .

All retirement pension benefits are revalued in line with the cost-of-living index and wage rises in the public sector. The adjustment is not automatic but granted by means of a special law.

\subsubsection{Legislation, Financing and Administration}

The BeamtVG is issued by law and based on the notion that the public employers assume responsibility for supporting their civil servants up to the end of their lives.

The scheme is financed directly by the federal and state budgets by taxes, with no funding for future benefit payments. The civil servant pays no contribution other than that, when his salary is fixed the costs of his BeamtVG pension rights are taken into account. On the rest of the labour market the employees pay a contribution of approximately 9 per cent for their state basic pension.

The pensions of civil servants are managed by the federal administration (Bundesverwaltung) and the administration of each state (Landesverwaltung). The responsibility for rules and regulations lies with the Ministry of the Interior (Bundesministerium des Innern), Bonn.

\subsubsection{Reforming the Pension Scheme}

In 1992 some modifications were implemented, to some extent in order to keep down the heavy costs of the BeamtVG pension scheme. At present the Government is looking into the effects of a changing age structure. One can expect further changes of the BeamtVG in the future in order to soften the effects the mounting pension burden.

\subsection{Netherlands}

\subsubsection{Current Pension System for Civil Servants}

Civil servants in the Netherlands are entitled to a basic state flat-rate pension from the AOW, General Law on Retirement Pension. The pension is based on the minimum wage and calculated in proportion to years between 15 and 65 that the person has been a resident in the Netherlands. For single people the old-age pension is 70 per cent of the minimum wage; for a couple, each is entitled to 50 per cent of the minimum wage. 
The special scheme for civil servants and other employees in the Dutch public sector is supplementary to the AOW. Starting in January 1996, the scheme is to be called Pensionenreglement Stichting Pensionenfonds ABP. Participation is compulsory for all public employees except for military personnel and higher public officials who are subject to other supplementary pension schemes.

\subsubsection{Pension Rights and Retirement Age}

There are no minimum requirements to become a member of the pension scheme for public employees or to be eligible for benefits under the scheme.

The general retirement age for old-age benefits from the basic AOW as well as the supplementary ABP is 65 years. It is possible, though, to retire later than at that age.

\subsubsection{Calculation of Old-Age Pension}

The pension promise that is given to civil servants is benefit-defined. The calculation basis is final salary, i.e. the salary in the calendar-year prior to the date of retirement. In case of a part-time job the basis is the salary which the servant would have had if he had been in a full-time position.

To make allowance for the fact that the servant is entitled also to a basic state pension, the so-called franchise is deducted from the pensionable salary. The franchise is derived from the right to AOW pension.

ABP pension is earned at the rate of 1.75 per cent of final salary per full-time service year from age 25. That makes a maximum pension benefit at the age of 65 of 70 per cent of final salary, including AOW pension. In case the civil servant is working part-time, the pensionable years are counted in proportion to actual salary related to full-time salary.

The number of years may be increased by the individual giving up pension benefits earned in another employment in return for a transfer payment to the ABP fund. The fund determines the extra years to be credited from the transferred capital amount.

If there has been a substantial change in the civil service career, the final salary principle will be modified. In case of an interruption of the service time by more than one year, an increase of the salary by more than 25 per cent or a decrease of the salary by more than five per cent, a separate pension is calculated as of that date. The separated pension is indexed according to the development of the salaries for public employees.

\subsubsection{Invalidity Pension and Survivor's Pension}

The civil servant is entitled to an invalidity pension if, after his discharge, he is permanently unable to fulfil his employment owing to disease or infirmity. The benefit is calculated on the basis of the servant's final salary and degree of disablement, irrespective of his pensionable years.

The ABP pension scheme also provides a survivor's pension to the widow/widower and to the children of a scheme participant. The widow/widower's benefit amounts to 5/7th part of the old-age pension to which the participant is entitled or would have become entitled to upon reaching the age of 65 . 
The orphan's benefit, which is paid until the age of 21 , amounts to $1 / 7$ th or $2 / 7$ th part of the old-age pension, depending on if the orphan has a parent who is entitled to a widow/widower's pension or not.

In determining the survivor's pension, the dependant's possible entitlement to a basic allowance under the General Widows and Orphans Act, AWW, is taken into account.

\subsubsection{Termination and Change of Employment}

If the servant leaves the public sector before retirement age he becomes a "dormant" participant of the ABP pension scheme. The pension rights accrued by him are established and salary-indexed until he reaches the age of 65 and becomes entitled to an old-age pension.

If the participant enters into a new employment and thereby becomes a participant of another pension scheme, he may apply for transfer of his ABP pension rights to his new pension fund. In such a case the ABP fund calculates the transferable amount.

\subsubsection{Payment of Benefits and Early Retirement}

According to separate temporary regulations, so called VUT schemes, civil servants may retire before retirement age and receive immediate payment of a separate benefit until the age of 65 . Presently the regulations make this possible at age 61 if the employee has served for 40 years. There are plans to replace the VUT schemes with a flexible retirement age between the ages of 62 and 67.

The ABP pension benefits are value-protected by a salary index that follows the development of the salaries for public employees.

\subsubsection{Legislation, Financing and Administration}

The ABP pension scheme has this far been subject to an act by the Dutch parliament, Algemeen burgerlijke pensioenwet. Starting in January 1996, the scheme is to be based upon an agreement, Pensioenovereenkomst, between the Minister of Internal Affairs and the unions representing the public employees.

The ABP scheme is financed through pre-funding. The employer pays a contribution calculated on the basis of the pensionable salary. The percentage for 1993 was 8.8 .

Also the employee has to pay a contribution. This contribution is calculated on the pensionable salary, less a franchise amount. On the remaining amount the employee pays 10.1 per cent. Where the servant is younger than 25 , he only pays a risk premium of 0.6 per cent against disablement and decease.

Pension liabilities of the ABP fund are fully funded. The total assets under management of the fund, which covers about 1 million public servants, was 1992 estimated to about ECU 82 billion. That makes $\mathrm{ABP}$ one of the largest pension funds in Europe.

The implementation and the administration of the ABP pension scheme is handled by the fund, located in Heerlen. Beginning in January 1996, the fund is to be changed from being a public legal institution to being a private legal body. The board of the ABP fund will then consist of members appointed by the governmental employers and by the unions. 
No substantial changes are being planned other than the transition of the ABP pension scheme from a public to a private legal setting.

\subsection{Sweden}

\subsubsection{Current Pension System for Civil Servants}

Civil servants in Sweden are covered by the statutory state pension scheme, which covers the entire population. The scheme is presently being radically reformed. The reformed pension scheme will enter into force January 1997 and have bearing on pension payments from January 2000. The younger the person is, a progressively greater part of his pension will be calculated in accordance with the reform.

The special scheme for civil servants and other employees in the public sector is supplementary to the state pension scheme. The scheme is called Pensionsplan för arbetstagare hos staten $\mathrm{m} f \mathrm{fl}$, PA-91. Participation is compulsory for all public employees except for military personnel and employees in the local government sector, who are subject to other supplementary pension schemes. PA-91 is designed as a supplement to the old state pension scheme, which means that it has to be transformed in line with the reformed scheme within a couple of years.

The substantial part of the total pension comes from the state pension scheme. That is why this outline will cover both that scheme and the PA-91 scheme.

\subsubsection{Pension Rights and Retirement Age}

Civil servants become members of the supplementary PA-91 scheme from the beginning of their service as long as they are 18 years or older and the working basis of the employment is not less than 40 per cent.

Retirement age for the purposes of full PA-91 benefits is age 65. It is possible to retire, with the consent of the employer, after the age of 65 and before that age, at the earliest from the age of 60, with a reduced old-age benefit. The public service pension scheme prior to PA-91 had ages 60 and 63 as retirement ages for certain employments, covering roughly 50 per cent of all employees. According to transitionary rules, those who had the right to retire at that age in 1991 will keep that right as long as they remain in the same employment.

There is no specific retirement age under the reformed state pension scheme, but the earliest possible age to have an old-age pension paid out is from age 61. For the purpose of calculating a "normal" old-age pension benefit amount, age 65 is used as a commencement age.

\subsubsection{Calculation of Old-Age Pension}

The reformed state pension scheme is contribution-defined. The old-age pension will reflect a person's earnings throughout his working life.

18.5 per cent of all pensionable earnings from 16 years of age and upwards will be paid into the old-age pension system as contributions. Earnings up to a certain ceiling, presently SEK 270000 per year, 
will carry pension rights. (Slightly more than 10 per cent of the working population has an income above the ceiling.) Social security benefits, such as sickness and unemployment benefits will also carry pension rights as will years of taking care of small children and time spent in national military service.

Each individual will have two pension accounts, one fictitious where the major part, 16.5 percentage units, of the contributions will be registered and one real account for the remaining 2 percentage units. The balance of the fictitious account is revalued each year according to a wage-index and the real account accrues yield on the capital according to the performance of the fund that the individual has chosen.

On retirement the pension from the fictitious account will be calculated primarily on the basis of the average life expectancy at the time of retirement. The funded pension will be calculated on strictly actuarial grounds, although on the same conditions for men and women. The two pensions may both be taken out as a whole or partially and earliest from age 61. The later they are taken out, the greater the annual pension will be.

Persons who for some reason have not been employed or have had small incomes are guaranteed a minimum state pension of presently SEK 75600 per year.

The major part of the supplementary PA-91 pension is benefit-defined. It should be observed that it has not been adapted to the reformed state pension scheme yet. The calculation is based on final salary, i.e. the average pensionable salary during the five years proceeding the year of retirement, and the co-ordination with the basic state pension is done according to the net model.

Old-age pension is earned at the rate of 0.33 per cent of final salary for each year of pensionable service from the age of 28 , up to a maximum of 30 years. On pensionable salary above the previously mentioned ceiling of SEK 270000 , the rate is 2.17 per cent per year. The full pension level is thus 10 and 65 per cent respectively. The two levels are of course due to the earnings-related state pension that is considered to provide the failing 55 per cent of the salary up to said ceiling.

Pension rights from earlier employments under other occupational pension schemes will be transferred to the PA-91 scheme in accordance with agreements with the other sectors of the labour market.

A minor part of the PA-91 pension is contribution-defined. The servant earns a contribution of presently 1.7 per cent of the salary that he has drawn, which is paid to a pension fund. The benefit amount depends on the funded contributions, the yield and the person's share of inherited gains.

The civil servant can also pay his own voluntary contribution to the pension fund in order to raise his individual pension. This pension is however not classified as an occupational pension, which means that it comes under the same tax-regulations as private pensions.

\subsubsection{Invalidity Pension and Survivor's Pension}

The supplementary PA-91 scheme covers invalidity when the civil servant is permanently unable to fulfil his employment. The invalidity pension is calculated on the basis of the servant's final salary, the same five years as are the basis for the old-age pension. The benefit is however calculated as a gross amount that includes the servant's state pension. The pension level is approximately 80 per cent and will be reduced if the servant would not have earned 30 pensionable years if he had stayed in service until the age of 65 . 
The pension benefits to survivors of a civil servant represent a split picture. The basic state pension scheme only provides the widow/widower with a one year so-called adaptation pension, apart from certain transitionary benefits. There are two PA-91 pensions, one five year flat-rate pension and one life-long pension calculated only as 50 per cent of the old age pension above the state pension ceiling. The reason why these benefits are so minor is that the widow (widower) is supposed to be able to support herself by her own employment.

Orphans are entitled to pension benefits calculated in the same way as the widow's/widower's, but paid out until the age of 20 .

A special group life insurance policy ensures a certain level of economic protection to survivors, should the civil servant die during his term of employment. The insurance amount, at its maximum somewhat more than an average annual salary, is paid out as a lump sum free of tax.

\subsubsection{Termination and Change of Employment}

A civil servant who leaves the service before retirement age with three or more years of service is entitled to his accrued PA-91 pension benefits from the age of 65 . Without the three years qualification requirement, the same goes for the servant's pension rights under the state basic pension scheme, accumulated on his two state pension accounts.

If the former civil servant enters into a new employment and thereby becomes a member of another supplementary pension scheme, his PA-91 pension rights will be transferred to that scheme. His pensionable years will be accounted for under the new scheme and the benefit amounts will be deducted from the pension benefit he receives from the new scheme. This co-ordination is compulsory and considered possible since the design and the value of the schemes are practically the same.

\subsubsection{Payment of Benefits and Early Retirement}

Civil servants may retire from the age of 60 and receive immediate payment of PA-91 old-age pensions after actuarial reduction, to some extent, for the early payment.

According to a separate employment security agreement, state employees who are dismissed at the age of 60 or later because of redundancy are entitled to a special benefit until their retirement age. The benefit is calculated as an old-age pension of approximately 70 per cent of final salary, provided the employee would have earned at least 30 years by retirement age had he not been dismissed. Otherwise the benefit will be proportionally reduced.

A civil servant who wants to retire before the age of 65 can choose to have his basic state old-age pension paid out from, at the earliest, age 61 . The benefit amount will strictly depend on life expectancy (same for men and women) at that age and other actuarial factors.

PA-91 pension benefits financed by the pay-as-you-go system are inflation protected by a consumer price index that is uprated annually by means of a special law. Basic state pension benefits financed in the same way will during payment be revalued according to an index reflecting both prices and the real growth in the economy. If the growth is less than a fixed norm the benefits will not be raised as much as prices. 


\subsubsection{Legislation, Financing and Administration}

The PA-91 pension scheme is based on a collective agreement between the Agency for Government Employers and trade unions in the public sector, as are salaries and other conditions of employment for public employees. The state basic pension scheme is of course decided by the Swedish parliament.

Employing ministries and agencies pay contributions both to the basic scheme and to the supplementary scheme. To the reformed state scheme the contribution for old-age pension is planned to be 9.25 per cent of the salary and to the PA-91 scheme the contribution is individually calculated according to the real costs of the employees. On the average it amounts to 9 per cent of the salary.

The employee only contributes to the state scheme. As a matter of fact he does not pay any contribution yet. According to how the reform is planned, in a couple of years he too will pay 9.25 per cent, provided that it is possible to convert employers' payroll tax into employees' wages.

Both schemes are mainly financed on a pay-as-you-go basis, but a minor part of the contributions go to pre-funding systems. The basic state pension scheme leaves it to the individual to decide which fund to entrust his pension capital. The PA-91 scheme stipulates a form of pension fund, a private legal body, set up by the parties behind the collective agreement.

The implementation and the administration of the PA-91 pension scheme, including contribution calculations and benefit payments, is handled by a state agency, SPV, Sundsvall.

\subsubsection{Reforming the Pension Scheme}

As has been said, the basic state scheme is currently being reformed. In order to match, the PA-91 scheme will also have to be reformed. The career earnings principle will probably be adopted.

\subsection{United Kingdom}

\subsubsection{Current Pension System for Civil Servants}

Civil servants in the United Kingdom are entitled to the State Retirement Pension. It is a basic flat-rate pension, subject to contributions record.

On top of that the main part of the pension provision is by means of a supplementary occupational pension scheme, the Principal Civil Service Pension Scheme. In general terms the PCSPS applies to Crown servants employed in the central Departments of State. Employees in other parts of the public service, for example teachers, armed forces personnel, staff in the fire, police and health service, and staff in local authorities are covered by separate occupational pension schemes.

Membership of the PCSPS is not compulsory. Staff may opt for membership of the State Earnings-Related Pension Scheme, SERPS, or for a Personal Pension, operated by life insurance offices. Both options are, in principle, career earnings-related schemes, the Personal Pension being based on the contributions made and the investment returns achieved on the accumulated funds. The PCSPS offers benefits which are considerably less valuable than SERPS or a Personal Pension. Opting out therefore normally represents no value to Civil Servants. 


\subsubsection{Pension Rights and Retirement Age}

Membership of the PCSPS applies from commencement of employment in the Civil Service. No minimum length of service is required where the person retires at, or after, the retirement age.

Retirement age for the purposes of entitlement to full PCSPS benefits is age 60. It is possible to stay in service until an upper age limit of 70 .

The basic State Retirement Pension is payable from age 65 for men and 60 for women. The state pension age is, however, to be equalised at age 65 for both men and women by 2020 .

\subsubsection{Calculation of Old-Age Pension}

The state's pension promise to its civil servants is benefit-defined. The calculation basis is final salary, i.e. the best 12-month period of basic pay, including some other emoluments, during the last three years. The pension is co-ordinated with the state basic pension according to the net model.

Pension is earned at the rate of 1.25 per cent for each year, or part year, of pensionable service up to a maximum of 40 years. The full pension level is thus 50 per cent of final salary. Where the servant retires at age 65 , the maximum is 45 years and the pension level 56.25 per cent. There is no minimum amount of pension prescribed, except that it cannot be less than that which would have been due under the SERPS.

In addition, a tax-free lump sum benefit is paid on retirement. The lump sum is calculated as three times the annual old-age pension.

As from state pension age the basic State Retirement Pension of UK£ $3060(1995 / 96)$ is payable in addition to the PCSPS pension.

With few exceptions, all service time in the Civil Service is taken into account for pensionable years and there is no restriction for part-time service. Service reckoning may be increased, at full cost to the individual, by the purchase of added pensionable years. Service years may also be increased by the individual giving up pension benefits earned in a previous employment in return for a transfer payment to the PCSPS.

\subsubsection{Invalidity Pension and Survivor's Pension}

The PCSPS provides benefits in the event of ill health retirement and death. The qualifying time of service for invalidity pension is two years, but there is no qualifying period for survivor's pension.

The calculation is basically the same as that of an old-age pension. If years of service are between five and ten, the effective years of service for invalidity pension are doubled within the limits of what an old-age pension would have been if the person had stayed in service. If years of service are ten or more, the effective years of service are extended to 20 or, if more favourable, increased by 6 and 2/3 years.

The survivor's pension (payable to legally married spouses) is normally half of the old-age pension or half of what an invalidity pension would have been, had he or she not died. In addition, there is a tax-free lump sum of two years's salary if the servant dies in service. 


\subsubsection{Termination and Change of Employment}

Where the servant leaves before retirement age with two or more years of service, accrued pension benefits may be deferred for payment by the scheme at the retirement age. The deferred benefits are revalued each year in line with the Retail Prices Index up to retirement.

Regardless of years of service accrued pension benefits may be transferred to another employer's occupational scheme or transferred to a Personal Pension arrangement.

\subsubsection{Payment of Benefits and Early Retirement}

Civil servants may retire from age 50 and receive immediate payment of accrued pension benefits after actuarial reduction for the early payment.

Civil servants over the age of 50 may also receive early payment of accrued, or enhanced, pension benefits where the departure is for management reasons, for example redundancy. These benefits are not provided by the PCSPS, but by a separate scheme, the Civil Service Compensation Scheme.

All retirement pension benefits are fully inflation protected. They are uprated each year in line with the Retail Prices Index.

\subsubsection{Legislation, Financing and Administration}

The PCSPS and the Civil Service Compensation Scheme are schemes made and amended under the provisions of the Superannuation Act 1972. They are unfunded schemes with no assets. Benefit expenditure is met each year on a pay-as-you-go basis from general government revenue.

Cost of pension provision forms part of the overall remuneration package of employees. There is a direct employee contribution of 1.5 per cent of pay mainly in respect of dependants benefits. Employing departments pay a contribution representing the notional employer charge for a funded PCSPS. Employer and employee contributions are appropriated in aid of benefit expenditure.

The payment of PCSPS benefits is administered by Paymaster General's Office, a branch of the civil service located in Crawley.

\subsubsection{Reforming the Pension Scheme}

Minor changes to the provisions are on-going. As has been mentioned the retirement age for women will be raised from age 60 to 65 within 25 years.

No substantial changes in benefit structure are envisaged in the immediate future. 


\section{THE IDEAL PENSION SYSTEM}

Obviously, there is no such thing as an "ideal" pension system. It is a matter of value judgements and priorities. Nevertheless, an attempt will be made to describe such a system on the basis of the above discussion on the design of a pension system for civil servants. In some respects the system outlined here presents a contrast to the actual systems in force in Western Europe.

\subsection{Assumptions}

A pension scheme does not operate in a vacuum, but is (all too) dependent on the current economic, social and political situation. This situation is constantly changing. The pension scheme outlined here is therefore envisaged as one that should function reasonably well regardless of such changes.

Two assumptions are made. First, it is assumed that the Government and the civil servants agree on the need to use a reasonable share of the employees' earnings for future pensions. Second, it is assumed that the state social security system provides a flat-rate basic pension.

The following principles are applied. The pension scheme must be stable, secure and sufficiently flexible to adjust to economic, demographic and other changes in the state sector. It must be easy to understand and to administer. It must be perceived as fair and there must be a clear relationship between performance, as measured by earnings, and pensions. Benefits and costs must be reasonable and predictable, and costs must be charged to the appropriate cost centre.

Labour markets are becoming increasingly mobile, which makes it necessary for employees to take responsibility for their own pensions. To make this possible, the pensions they earn must be regarded as deferred earnings. This is the most reasonable view of what an occupational pension constitutes.

\section{$9.2 \quad$ Proposals}

A consequence of this basic view of occupational pensions is that old-age pensions should be based on employees' career earnings. The state's promise to its employees consists of two old-age pensions, one benefit-defined and one contribution-defined, the qualifying period for which starts at the age of 20 .

The benefit-defined old-age pension should be designed in such a way that for each calendar year the employee earns a pension amounting to 1 per cent of that year's pensionable earnings, which is payable from the age of 65 . Each year's pension amount is registered and indexed by reference to a wage index based on the development of the average pension accruals throughout the civil service. The result of 40 years' employment will thus be a pension corresponding to 40 per cent of average pensionable earnings throughout the employee's career.

The contribution-defined old-age pension should be designed in such a way that 7 per cent, say, of pensionable earnings are paid into a pension fund for civil servants. The pension capital is raised each year by the surplus generated by investment. The size of the pension will depend on how much has been paid in over the years and on the profits generated by fund management. 
Co-ordination with the state basic pension should take place in accordance with the net co-ordination model, whereby pensionable earnings are calculated as the salary paid out during one year, less the basic pension for that year. If the basic pension is raised substantially at some time in the future, it may be necessary to adjust the benefit-defined pension amount accordingly. All pension rights should be vested in all respects. Termination of employment should not involve the loss of any pension rights, nor should accrued pension rights be inadequately revalued during the interval between termination and commencement of pension payments.

Apart from old-age pensions the scheme should also include invalidity pensions and survivors' pensions. Invalidity pensions should be calculated as 175 per cent of the benefit-defined old-age pension that the individual employee would have been entitled to if he had remained in employment up to pensionable age. While he is receiving an invalidity pension he should continue to qualify for both old-age pensions on the basis of his pensionable earnings at the time of retirement. Survivor's pensions should, for sole beneficiaries, amount to 50 per cent of the benefit-defined old-age pension received by the deceased or, if the latter died before reaching pensionable age, the pension that he would have been entitled to if he had remained in service up to that age.

The contribution-defined old-age pension offers flexibility in various respects. Part of the contributions can be used for supplementary survivor's protection, in which case the amount saved for the old-age pension will be correspondingly lower. Moreover, employees should be entitled to take out their old-age pension early, on reaching the age of 60 , at a lower rate calculated in accordance with actuarial principles. They should also be entitled to take out a pension as a temporary benefit, e.g. between the age of 60 and 65. An employee who so desires should have the option of supplementing his old-age pension savings on favourable terms by making individual contributions to the pension fund. The information supplied to him once a year on his pension status should help him to decide whether or not he wishes to improve his future pension.

During the period when the pension is paid out, benefit-defined old-age pensions, invalidity pensions and survivor's pensions should be revalued in accordance with Parliament's annual decision. These decisions should normally be adopted in accordance with the indexation principle specified in the pension scheme. Contribution-defined old-age pensions should be revalued in accordance with the decisions on bonuses adopted by the fund's board.

Employers in the state sector should pay a contribution, calculated in accordance with actuarial principles, for benefit-defined old-age pensions, invalidity pensions and survivors' pensions, which would probably amount to a little over 15 per cent of wage costs. The best system would be to invest the contribution fully for early retirement pensions, but it is probably more realistic to finance these pensions by a pay-as-you-go system. During an introductory phase, however, a buffer fund should be built up to compensate for future imbalances between contributions payments and pension payments.

The 7 per cent old-age pension contribution to the civil servants' pension fund should be an individual contribution paid by employees by deduction from their salaries. The pension fund should be completely independent of the state. Appointing the majority of the members of its board would give the employees controlling influence over both the insurance operation and capital management. 
Administration should be the responsibility of a central state body. The same body should also administer the contribution-defined old-age pension if the fund opts for such an arrangement.

It is not possible to generalise about how such a pension scheme should be introduced, since that would depend entirely on where and under what circumstances this took place. However, it may be said in conclusion that if the pension scheme outlined here could be introduced without any modification of its essential principles, it would be a sound, sustainable and secure pension system for civil servants. 


\section{CHAPTER 2 PROTECTING THE EARLY LEAVER BY DOUGLAS ANDERSON ${ }^{3}$}

\section{Introduction}

This paper discusses a variety of issues relating to pension scheme design for "early leavers", that is individuals who leave employment, either voluntarily or on compulsory severance grounds, before attaining their normal retirement age. Pension schemes may provide for certain benefit entitlements on resigning to take up employment elsewhere, on voluntary early retirement, on cessation of work due to incapacity and on redundancy. In designing arrangements, it is necessary to balance the conflicting demands of employers and employees when targeting limited resources at areas of greatest need. Whilst discussing the issues in general terms, this paper is illustrated by examples of the types of approaches adopted in the United Kingdom.

Issues of general social and economic policy are also relevant in this area. For example, an employer may not wish to be particularly generous to an individual who is moving to a job with another employer, perhaps to a competitor. However, the national Government may see advantages in encouraging the mobility of labour, and so may pass laws to prevent the early leaver being penalised. Various issues relating to the financial control of pension costs are also important, these include ensuring the terms on which any voluntary options (e.g. transfer values or early retirement) are offered do not have an adverse impact on public finances.

\section{Benefits on Voluntarily Leaving Employment Before Retirement}

Practices vary from one country to another, and even within countries from one type of industry or employer to another. A variety of factors will impact upon the polices adopted by individual countries; for example, the requirement to protect individuals' "rights", the availability of resources and the extent to which the society or a particular employer wishes to encourage or discourage job mobility. One consideration will be the disproportionately high costs of administering small benefits arising from short periods of employment.

In earlier times, it was common for a resigning employee to forfeit all pension benefits on resignation. Given the increasing degree of social protection in Western Europe, this practice is no longer regarded as acceptable. However, pension arrangements should be tailored to meet the needs of the employer, having regard to the aspirations of his current and potential workforce. An employer with a "jobs for life" culture, as was prevalent in many countries until relatively recently, may regard the targeting of resources to those who offer long service as the best way to reward loyal staff. Some employers may wish to provide a disincentive for staff to leave their employment by offering relatively poor retirement benefits on resignation.

The author is Actuary at the Government Actuary's Department, London, United Kingdom. 
In areas of high staff turnover, the absence of any benefit on early departure would be particularly inappropriate as only those individuals in post on retirement would receive benefits and these might be based on only a short period of service. The United Kingdom Civil Service has been affected by a variety of Government initiatives in recent years. These have included the adoption of fixed-term rather than open-ended contractual terms, the desire to encourage the movement of individual staff between the private sector and the civil service to engender a cross-fertilisation of views and the wish to transfer, on a compulsory basis, the employment of groups of civil servants to the private sector. Such reforms have highlighted the need for the employer to offer "fair" benefits to those leaving early.

For these reasons, it is common practice to provide benefits on leaving voluntarily before retirement. However, in order to reduce the cost of administering small pensions, it is not normal for benefits to be offered until a pre-determined qualifying period has been completed. This is called a vesting period. On leaving a defined benefit pension scheme after this minimum period has elapsed, the individual's benefits would be calculated at the point of leaving and preserved in the scheme until normal retirement age had been attained. The length of this period varies considerably, from only one year in the Netherlands up to ten years in Germany. In the United Kingdom, the maximum period before Civil Servants' benefits must be vesting was reduced in successive pieces of legislation in the 1970s and 1980s from ten years to five years and most recently to two years.

\section{Refunds of Contributions}

For pension schemes which require a contribution from the member, it is common for a member who leaves before the vesting period has been completed to be offered a refund of their contributions, perhaps with interest. One reasonably attractive way of going some way towards protecting the benefits of the early leaver whilst establishing a scheme which is relatively simple to administer, would be to set up a scheme where the members contributed perhaps one-third of the total cost, but had a vesting period of say five years and refunds of contributions were given to those who left before completing five years' service.

It is sometimes argued that one of the attractions of defined contribution arrangements is that they offer full accrued benefits to members irrespective of when the member leaves and thereby the early leaver is not penalised. However, the cost of administering individual pensions is largely independent of their size (or the quantum of assets in an individual pension fund) and therefore the length of time an individual had been a member. It is therefore often found that the fixed expense deductions which fund mangers charge quickly eat away at these small accumulated funds leaving members' aspirations deflated when they come to retire.

\section{Revaluation of Vested Benefits}

The following table summarises the linkage of benefits in each of the three main types of occupational pension scheme and in each of the three types of membership: as a contribution member, as a deferred pensioner with vested benefits following resignation and as a pensioner with a benefit in payment. In the case of the early leaver, the rate of increase, or revaluation, up to retirement age is of great importance to protect the real value of the benefits.

At present, very few countries provide defined-contribution arrangements for civil servants; most are defined benefit. In a defined-contribution arrangement, benefits accumulate in accordance with the performance of the assets backing the pension promise (which may be chosen by the scheme members or on their behalf by the scheme managers). At retirement, the accumulated fund is simply converted to a 
pension normally by the purchase of an annuity. Annuities would typically be available which would allow the individual to decide the rate of revaluation they wished: the higher the rates of indexation, the lower the initial rate of pension. The terms on which this conversion takes place are not generally guaranteed in advance of actual retirement and so a member of a defined contribution arrangement is exposed to the vagaries of the investment markets both during the accumulation period and at the point of retirement.

Table 1. Options for revaluing benefits

\begin{tabular}{|l|l|l|l|}
\hline \multirow{2}{*}{ In Service } & \multicolumn{1}{c|}{$\begin{array}{c}\text { Defined } \\
\text { Contribution }\end{array}$} & \multicolumn{1}{c|}{ Final Salary } & \multicolumn{1}{c|}{$\begin{array}{c}\text { Defined Benefit } \\
\text { Earning }\end{array}$} \\
\cline { 3 - 4 } & $\begin{array}{l}\text { Contributions paid on } \\
\text { individual earnings } \\
\text { during employment }\end{array}$ & $\begin{array}{l}\text { Individuals' earnings at } \\
\text { retirement } \\
\text { (or leaving if earlier) }\end{array}$ & $\begin{array}{l}\text { Individuals' earning } \\
\text { during employment } \\
\text { (normally revalued by } \\
\text { General Earnings Index) }\end{array}$ \\
\hline In Deferment & $\begin{array}{l}\text { Fund accumulated with } \\
\text { investment returns }\end{array}$ & Choices as below \\
\hline In Payment & $\begin{array}{l}\text { Variety of Choices: } \\
\text { No indexation; } \\
\text { Fixed rate of indexation e.g. 3\%, 5\% a year; } \\
\text { Increase in line with Consumer Price Index; } \\
\text { Increase in line with Earnings Index; } \\
\text { Index increase up to pre-determined maximum e.g. 3\%, 5\% a year; } \\
\text { Guaranteed or Discretionary? }\end{array}$ \\
\hline
\end{tabular}

In a defined benefit arrangement, the increases to the vested pension benefits during the period from departure up to normal retirement could follow a variety of forms. Given the length of this period perhaps up to 40 years - there is considerable potential for the real value of benefits to be substantially eroded if no (or limited) increases are provided. Looked at from the employer's point of view, few organisations would relish the prospect of an open-ended long-term liability from linkage to price or earnings inflation.

Practices depend on the prevailing economic climate and the extent to which it is felt desirable to target moneys at protecting the value of vested benefits. In countries of low inflation, or where there is a general desire to target the limited moneys available for providing pensions to those who remain in employment there may be no need, or little inclination, to provide increases during the period of deferral.

However, in many Western European countries there have been trends towards increased labour mobility and claims for better value for money from scheme members on early departure. Not only has this led to reductions in vesting periods but also to demands for improved revaluation of benefits, particularly in countries with high inflation. It would be relatively easy to link increases in deferred benefits to price or earnings inflation to maintain purchasing power. Employers, especially in the private 
sector, express concern about entering into such open ended liabilities. Alternative possibilities include a system of fixed increases during the period from departure to retirement, which might be reviewed every few years in the light of the changing economic environment, or offering an inflation link subject to a maximum level - so called "Limited Price Indexation".

In the United Kingdom prior to the early 1970s increases to Civil Servants' benefits, both during the period of deferral and in payment, were on an ad-hoc, or discretionary, basis. Increasing wage and price inflation led to demands from scheme members which were met with the introduction of legalisation which provided a guaranteed link to the consumer prices index. Although the civil service has offered fully inflation-proofed benefits since the early 1970s, the practice in private industry is to offer less protection against the effects of inflation. Legislation now requires pension schemes to increase vested benefits in the period up to retirement by at least the increase in the consumer prices index, but subject to a maximum increase of five per cent a year. Preserved benefits guaranteed to increase fully in line with the rise in the consumer prices index are virtually unknown in the private sector.

If preserved benefits increase at a lower level than the member's salary might have been expected to rise, the transferring member is arguably penalised. Defined-benefit arrangement are often criticised, especially where vesting and revaluation arrangements are relatively poor, for reducing labour mobility. On moving to a new employer, the transferred member is either left with less valuable benefits in the preceding scheme or possibly with a lower level of transferred benefits on joining his new employer. Theoretically, this issue should be addressed in the labour market with some employers willing to offer generous terms for transferring past service in order to attract staff of sufficient calibre. However, in the United Kingdom, such a "golden hello" approach with individual employees negotiating their own pension terms on transfer remains relatively unusual and generally restricted to more senior appointments.

\section{Transferability of Pension Rights}

Another way of protecting the early leaver is to allow individuals to transfer the value of their pension rights to another pension scheme, possibly with a new employer or an individual arrangement if no longer directly employed. This approach is often given as a voluntary option, rather than a compulsory alternative, to scheme members whose benefits would otherwise be preserved. The option need not necessarily be taken at the point of departure but would normally be available at any point up to retirement.

Whenever a voluntary option is given in a pension scheme careful consideration must be given to the possibility of adverse selection by the scheme member, in order to protect the financial interests of the other pension scheme members and, of course, the sponsoring employer. Transfer values are an important example. If the terms offered are more valuable to the individual than the benefits which would otherwise be payable, financially astute members will take up the option at the expense of the pension scheme and ultimately its sponsors (in the case of Civil Service Pension Schemes, the tax-payer).

Such adverse selection may happen, for example, if the terms offered by the pension scheme are out of line with the financial markets, or if the terms do not reflect the circumstances of the scheme members likely to transfer. Transfer values should therefore be calculated as of equivalent value to the preserved benefits which would otherwise be payable. A number of actuarial issues will need to be considered in setting the terms e.g. life expectancy of those transferring, and the appropriate allowance for investment returns. 


\section{Transfer Clubs}

One of the ways of assisting job mobility is for like-minded employers to enter into a mutually binding agreement which allows employees joining from another employer whose pension scheme participates in the transfer club to transfer their pension rights on enhanced terms. Such arrangements are referred to as Transfer Clubs. In the United Kingdom, such an arrangement has been developed to cover the whole of the Public Sector. Similar arrangements have also developed in private industries where retirement from competitors is important. One such arrangement has developed in the electricity industry.

\section{Early Retirement}

By the very nature of a pension, it is more expensive to pay a monthly allowance to an individual who survives for a long period in retirement than for a pensioner who dies a short period after retirement. With trends towards increased longevity in Western Europe, this issue has led to many private employers and state pension schemes increasing their retirement ages. With regard to early retirement, it can be seen that the earlier an individual retires the more costly it is to pay the same amount of pension. There is not only a cost arising from paying the pension for longer, but also from the fact that the investments, whether real or notional, have not been allowed to accumulate for as long a period.

As in any other area of scheme design, the early retirement provisions should be developed to meet the needs of a particular employer's business, in this case the Civil Service, having regard to the aspirations of the scheme members. It is common practice to offer more generous benefits to those who are forced to retire early on ground of ill-health and, depending on the nature of the condition, who may not survive in retirement for particularly long. But, because of the cost issues, it is not common to offer favourable treatment to those who wish to retire voluntarily.

\section{Ill-Health Retirement}

Benefits may be provided in a variety of ways for those who suffer from long-term incapacity which prevents a return to work. In a defined benefit scheme, the pension might be paid immediately, possibly with some enhancement to allow for the pension which would have been accrued if the individual had remained employed up to the pension scheme's normal retirement age. Such an approach would be expensive to provide, especially to young members, those whose life expectancy is not reduced, or where generous benefits are also payable to dependants on the death of the member.

One of the key disadvantages of defined-contribution arrangements is that they generally provide poor benefits to the member and any dependants if an individual is forced to retire early or dies in service. For young and short-service individuals, the accumulated fund of assets may well be too small to buy pension benefits which are sufficient to maintain the desired standard of living. This issue might be addressed by the employer providing an additional injection of capital into the individual's fund at the time of retirement, or more commonly providing extra top-up benefits, possibly through separate insurance arrangements. The commercial insurance market is attractive to small employers, or those with limited resources, but the extent to which such a route offers value for money to large employer such as the Civil Service is questionable. 


\section{Other Ill-Health Issues}

Difficulties commonly arise when determining whether an individual is sufficiently incapacitated to meet the scheme's definition. Some schemes review the health of incapacity pensioners every few years and may reduce or stop benefits if an individual has taken up paid employment or is now deemed to have improved sufficiently to permit a return to employment. If such mechanisms are to be considered fair by scheme members, it is desirable for such reviews to be conducted by a body which is independent of the sponsoring employer and which is required to take proper medical advice.

Other issues would include the way in which employers should be able to deny access to the pension scheme to any member who is known to have a pre-existing health condition. Thus, if a scheme is to offer generous benefits on ill-health retirement, it is prudent to medically underwrite any new members before admitting to membership. In designing their schemes, employers should also take account of any incapacity benefits paid from elsewhere.

\section{Voluntary Early Retirement}

In a defined-contribution arrangement, the age, and possibly sex, of the individual at the time the annuity is purchased will determine the level of benefits. The longer an individual delays retiring, the longer contributions will be made, the greater the effect of the investment returns on the accumulated funds and the more favourable the annuity terms offered are likely to be (as these reflect the individual's expected remaining lifetime). Thus, an individual who wishes to retire early may find that the resulting pension is considerably lower than they had expected on retiring at normal retirement age. In order to allow employers to plan their workforces it may be advisable to restrict the early retirement option to those who have attained a specified minimum age or completed a minimum length of service. Special enhanced terms might be offered to staff whom the employer wished to encourage to retire early, perhaps by the purchase of additional pensions.

Early retirement benefits from defined-benefit arrangements require slightly more complex rules, but unlike defined contribution arrangements the individual member interested in early retirement is aware of the rules which will apply and the level of benefits that can be expected. It is therefore easier for members of defined-benefit arrangements to plan for their retirement without being exposed to the vagaries of the investment markets in the period up to retirement.

The additional costs of paying pensions early means that it is not common for benefits to be paid immediately without any reduction simply at the request of the member. Like transfers, such terms are normally a voluntary option of the member (although perhaps requiring the consent of the employer) and therefore the pension scheme must ensure that the terms offered have regard to the cost of paying the accrued benefits from normal retirement age. The terms will vary from one scheme to another depending upon retirement age, indexation provisions, the typical life expectancy of the scheme members and the investment returns which would be achieved if the scheme were funded.

In the United Kingdom, a typical reduction to the accrued benefits might be 5 per cent for each year early. Thus, an individual who retired five years early might see a 25 per cent reduction in benefits, but an individual who retired ten years early might lose half their accrued pension in order to bring it into payment ten years early. Such reductions, when combined with the loss of accrual of further benefits means that voluntary early retirement is only affordable for those close to retirement, or by those who have made separate provision for income in retirement, possibly by paying additional contributions. 


\section{1. “Compulsory” Early Retirement}

From time to time, any employer, including the Civil Service, may wish to encourage staff to leave. This must be done within the confines of the relevant employment legislation in the particular country. There may, for example, be certain minimum redundancy payments which must be paid on making an individual compulsorily redundant. Nevertheless, most employers would aim to keep additional costs to a minimum. If the statutory minimum redundancy benefits are set at a high level, it may be that few staff are made compulsorily redundant and that instead employers will try to induce staff to leave voluntarily through offers of less expensive compensation.

So called down-sizing is often achieved by allowing older and longer serving members to retire early on voluntary grounds, perhaps with the offer of a smaller reduction to their accrued pension than would otherwise apply to or even the offer of an enhancement to cover part or all of the outstanding service. The cost of such enhancement is not always apparent. Actuarial advice should be sought on the cost of such augmentations so that the sponsoring employer is aware of the true consequences both in funded and unfunded pension schemes. The United Kingdom Civil Service has made wide use of such schemes in recent years.

\section{Conclusion}

In designing arrangements for early leavers, a balance will need to be struck between the aims of the employer and the demands of the workforce. Limited resources must be targeted at areas of greatest need though a careful consideration of the strategic aims of the employer. Care must be taken when offering voluntary options, or more valuable benefits on ill-health retirement, to ensure that such facilities are not abused to the financial detriment of the sponsoring employer. 


\section{CHAPTER 3 THE TRUE COST OF EARLY RETIREMENT SCHEMES BY DOUGLAS ANDERSON ${ }^{4}$}

\section{INTRODUCTION}

Enhanced early retirement terms are commonly offered by employers as a means of reducing staff numbers. Personnel managers often regard early retirement schemes as a simple solution to the difficult question of how to persuade older staff to give up employment before normal pension age. The true cost of such arrangements is rarely appreciated by those who operate them. This paper dispels some of the myths surrounding the deceptive attractiveness of early retirement schemes.

Many employers regard offering improved early retirement arrangements as a 'cost effective' way of reducing staff numbers. Such arrangements are perhaps seen as a way of rewarding long serving staff, who may be under-performing, rather than trying to motivate them. As the cost of paying a pension is generally considerably less than the amount of the salary, finance officers see the opportunity to make 'efficiency savings' in the short term. But what about the cost to the sponsor of the pension scheme in the long term?

This paper concentrates on some often overlooked financial issues. Of course, there may be other relevant staffing issues involved in the decision to shed older staff rather than looking to reduce the numbers of younger staff or to cut back on recruitment, but these are not considered in this paper. The issues considered in this paper relate to early retirement arrangements in general and not the experience of the United Kingdom. 


\section{EARLY RETIREMENTS VERSUS LUMP SUM COMPENSATION: CASH FLOW IMPLICATIONS FOR EMPLOYERS}

\subsection{Pay-As-You-Go Pension Arrangements}

Most pension arrangements for civil servants offer pensions which are expressed in terms of the individual's final salary. Typically, these arrangements are operated on a so called pay-as-you-go basis. That is, the pensions of civil servants are simply paid from Government revenues as the benefits fall due for payment, rather than being funded in advance. For simplicity, this paper assumes that no money has been set aside, in advance, to pay for either the accrued pension or the extra pension which would be payable on early retirement. Of course, the amounts of extra benefits granted on an early retirement are precisely the same whether or not they are paid from an existing fund.

\subsection{So Why Are Early Retirement Schemes So Popular?}

Possibly the most important reason is that reducing staff numbers through early retirement is cheap in the short term. If a lump sum payment is offered to an employee being made redundant, all the cost of the compensation is incurred immediately -- often meaning that it is some time before the salary savings build up to offset the initial lump sum cost. However, if older employees are eased out of an organisation by offering improved early retirement terms, savings start to occur immediately.

To illustrate this point, consider a simple example. A civil service employer is considering making a long serving employee, currently aged 55, redundant. The employer may award a lump sum compensation payment of, say, three years' pay. Alternatively, the employer could allow the civil servant to retire early. The employer operates a pension arrangement with a normal retirement age of 60 , but may offer the civil servant the opportunity to retire immediately with the same pension as he would have earned had he remained in employment until his 60th birthday. What are the cost implications for the employer of the two possible arrangements?

\subsection{Option 1. Lump Sum Compensation Payment}

If the civil servant remained in employment until his normal retirement age the employer would have to meet his salary plus any other employment-related costs for the next five years. Figure 1.1 compares the employer's expenditure pattern on either keeping the individual in employment or allowing the civil servant to depart. Figure 1.2 shows the net costs or savings arising each year from age 55 and cumulative totals. It is three years before the employer recoups the cost of the redundancy payment and starts to make savings. 
Figure 1.1 Illustrative redundancy cash flows -Lump sum compensation payment

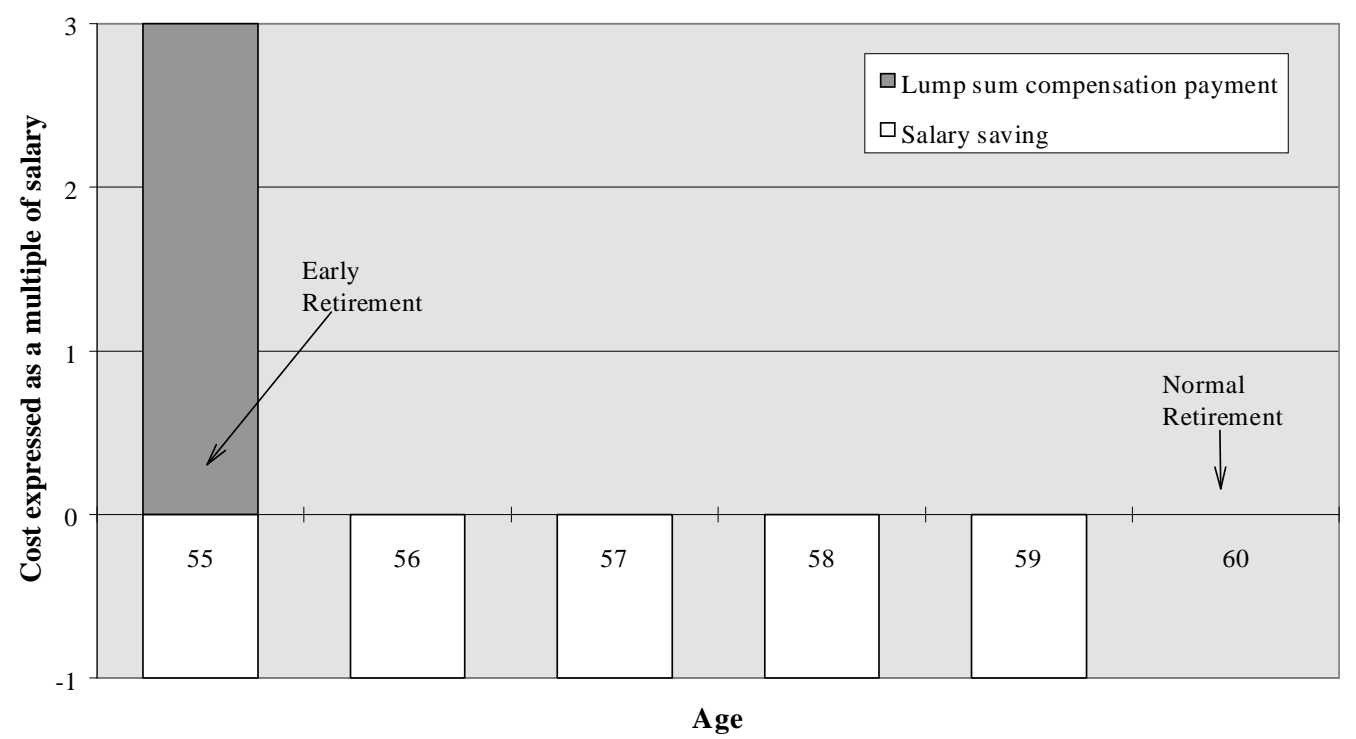

Figure 1.2 Build up of costs/(savings)*

\begin{tabular}{|c|c|c|c|c|c|}
\hline \multirow{2}{*}{ Net Costs/(Savings) } & \multicolumn{5}{|c|}{ Age } \\
\cline { 2 - 6 } & $\mathbf{5 5}$ & $\mathbf{5 6}$ & $\mathbf{5 7}$ & $\mathbf{5 8}$ & $\mathbf{5 9}$ \\
\hline Each Year & 2.0 & $(1.0)$ & $(1.0)$ & $(1.0)$ & $(1.0)$ \\
\hline Cumulative & 2.0 & 1.0 & nil & $(1.0)$ & $(2.0)$ \\
\hline
\end{tabular}

* Expressed in terms of multiples of annual salary. Ignores pay rises, pension increases and interest.

\subsection{Option 2. Enhanced Early Retirement}

If the individual is allowed to retire with the same pension as he would have built up by age 60 , two extra costs arise. First, there is the cost of paying the pension that the civil servant had earned to date -- his "accrued" pension -- five years earlier than would normally be the case. Secondly, there is the extra cost of providing the civil servant with the extra pension he would have earned had he remained in employment for the remainder of his life. Assume that the civil servant has built up a pension of 52.5 per cent of pay after 35 years' service, but this is enhanced to 60 per cent of final salary. These pension costs are illustrated in Figure 2.1 and Figure 2.2. 
Figure 2.1 Illustrative early retirement cash flows --

Enhanced early retirement

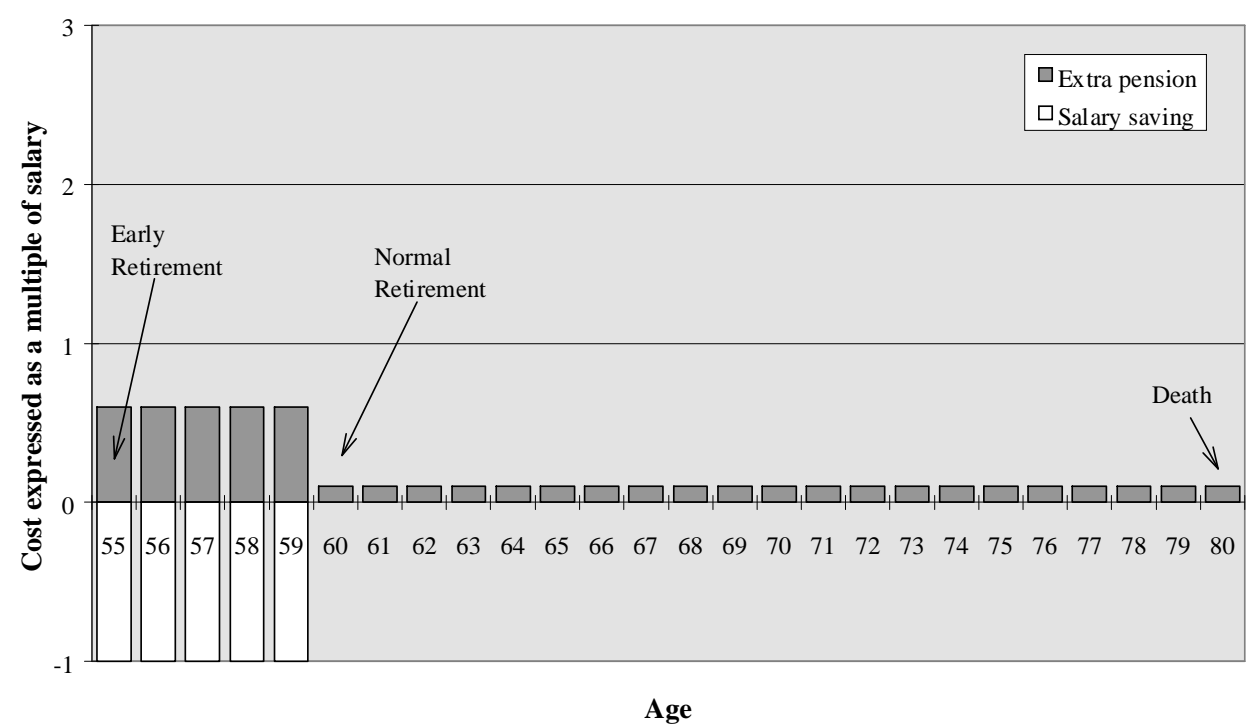

Figure 2.2 Build up of costs/(savings)*

\begin{tabular}{|c|c|c|c|c|c|c|c|c|}
\hline & \multicolumn{7}{|c|}{ Age } \\
\cline { 2 - 10 } Net Costs/(Savings) & $\mathbf{5 5}$ & $\mathbf{5 6}$ & $\mathbf{5 7}$ & $\mathbf{5 8}$ & $\mathbf{5 9}$ & $\mathbf{6 0}$ & $\mathbf{6 1}$ & $\ldots$ \\
\hline Each Year & $(0.4)$ & $(0.4)$ & $(0.4)$ & $(0.4)$ & $(0.4)$ & 0.1 & 0.1 & $\ldots$ \\
\hline Cumulative & $(0.4)$ & $(0.8)$ & $(1.2)$ & $(1.6)$ & $(2.0)$ & $(1.9)$ & $(1.8)$ & $\ldots$ \\
\hline
\end{tabular}

* Expressed in terms of multiples of annual salary. Ignores pay rises, pension increases and interest.

Under the early retirement arrangement (Option 2), the employer will reduce expenditure immediately, making this approach appear much more attractive to employers with scarce resources than Option 1. But which option is likely to offer the best value for money in the long term? This paper considers this fundamental question. 


\section{CAPITALISED COST OF EARLY RETIREMENTS: METHODOLOGY AND ASSUMPTIONS}

\subsection{Capitalised Costs}

Instead of simply noting that offering attractive early retirement terms provides the greater opportunity for making expenditure savings in the short term, the long term position should also be considered. The capitalised cost, or net present value, of the extra benefits payable on early retirement may be calculated using actuarial techniques. This quantity may be considered to be the amount of money, or capital, which would have to be invested at the outset to meet the cost of the extra retirement benefits. The capitalised cost allows a direct comparison to be made with the amount of lump sum compensation payments which might be offered to other staff on redundancy. Thus, value for money to the employer can be considered for the long term as well as the short term.

\subsection{Model Pension Scheme}

Let us consider a hypothetical pension arrangement -- typical of the types of occupational pension arrangement which operate in the United Kingdom and other western European countries. The arrangement offers a pension based on the individual's salary on retirement. The pension is calculated as 1.5 per cent of pay for each year of service. The pension is normally payable on retirement at the age of 60 and is increased each year in retirement in line with Price Inflation. On the death of the member, a pension of half ( 50 per cent) of the member's pension is payable to a surviving spouse.

Under this arrangement an individual retiring at the age of 60, having joined at the age of 20 , would have 40 years' service by retirement, giving a pension of

$$
\text { or } 60 \text { per cent of final salary, payable immediately. }
$$

If the same individual had left voluntarily at the age of 50, he would have built up, or accrued, a pension of 45 per cent of his final pay, but it would not payable for a further ten years. Some pension schemes allow individuals who wish to retire early the option of bringing their pensions into payment immediately, in return for a reduction in the amount of the pension. If the capitalised cost of the reduced pension paid early is the same as the capitalised cost of the accrued pension which would be paid at normal retirement age, the arrangement is cost neutral.

Such schemes are often called actuarially reduced retirement. A typical reduction in the accrued pension might be around 5 per cent for every year early, so that 95 per cent of the accrued pension at age 59 would be payable from age 59. In broad terms, the reduction in the level of pension pays for the extra year of pension paid between age 59 and age 60 . The employer's consent would not normally be required if the terms are cost neutral. However, in this example, a 5 per cent reduction in the pension for ten years would only leave a pension of 22.5 per cent of the individual's final pay. Few civil servants would be able to afford to retire ten years early unless they had built up substantial savings. 


\subsection{Enhanced Early Retirement Arrangements}

So what other options are available to an employer wishing to encourage individuals to retire early? Enhancements or augmentations above the level of actuarially reduced pension are commonly offered. It is rare for the enhancement to increase the pension above the level which would have been earned by normal retirement age. Theoretically, an employer could negotiate separate arrangements with each civil servant being considered for early retirement. In large organisations looking to shed a number of staff, it is perhaps more common to offer a standard set of terms. To illustrate the costs three possible early retirement options are considered:

- Accrued Pension: Immediate payment of accrued pension, with no reduction for early retirement;

- Half Prospective: Pension is enhanced to take account of half the extra service that would have been earned by normal retirement age;

- Full Prospective: Immediate payment of pension, enhanced to take account of full prospective service to normal retirement age.

The three early retirement options are considered against a fourth option of simply paying a lump sum.

- Lump Sum: A lump sum payment of one month's pay for each year of accrued service at date of severance. The retirement pension accrued by the point of departure is preserved and paid from age 60 as normal. (In practice, the lump sum would normally be cut back for those very close to normal retirement.). The total service, including any enhancement, is assumed to be subject to a maximum of 40 years' in the model pension scheme. A small lump sum might also be paid on retirement, but is ignored in this paper.

\subsection{Factors Underlying the Cost of Early Retirement}

The precise cost of an early retirement will not be known for certain until the retiree, and any surviving dependants, have died -- perhaps in 30 or more years time. A number of factors will determine the cost. The most important of which are the length of time that the extra pension is in payment and the rate at which the pension is increased during payment. Other lessor factors include the proportion of civil servants who are married at death and the age differences between husbands and wives. In order to estimate the cost of the early retirements it is possible to make assumptions for these quantities, based on past mortality and economic experience.

A further key assumption is the rate of return on the assets backing the pension. This assumption may appear unnecessary if the pension scheme is operated on a pay-as-you-go basis, but it is essential to assess the capitalised cost of the extra benefits. It is common for there to be some discussion on the discount rate as it is a critical assumption. As the extra pension will be paid for many years, it is appropriate to use a very long term rate of interest. The long term rate of return which might be expected to be achieved on the assets of funded pension schemes could be used as a reference. Alternatively, the rate of interest which the Government has to pay on its long term borrowings may be used as a guide. 


\subsection{Actual Assumptions}

For the illustrative numbers produced in this paper, assumptions have been used which are typical of those which might be adopted in the United Kingdom.

\subsection{Real Rate of Return}

As many Government retirement schemes increase pensions in line with inflation each year it is often easier to consider the real rate of return, net of price increases, rather than making separate assumptions for the gross rate of return and the rate of pension increases. The strong link between inflation and investment returns in the long term in most economies makes the real rates of return a more stable criterion than either the rate of inflation or the rate of investment returns. A real rate of return of 4 per cent a year has been assumed. This would be consistent with Price Inflation of 4 per cent a year and gross investment returns of 8 per cent a year in the long term.

\subsection{Life Expectancy}

In the United Kingdom, investigations are carried out by the actuarial profession on the mortality experienced by various demographic groups. Members of occupational pension schemes are found to have slightly longer life expectancy than the population as a whole. Women also tend to live slightly longer in retirement than men. To give a guide to how the costs may change in countries experiencing longer or shorter life expectancy, Figure 3 sets out the number of years that members of occupational pension schemes who have attained the ages of 50,55,60 and 65 are expected to survive on average.

Figure 3. Life expectation (years)

\begin{tabular}{|c|c|c|}
\hline Age Attained & Men & Women \\
\hline 50 & 31.5 & 35.9 \\
\hline 55 & 26.8 & 31.2 \\
\hline 60 & 22.4 & 26.6 \\
\hline 65 & 18.2 & 22.1 \\
\hline
\end{tabular}




\section{CAPITALISED COST OF EARLY RETIREMENTS: RESULTS}

Using the assumptions and methodology described in Section 3 above, the capitalised cost of the extra benefits payable under the different early retirement schemes have been calculated using standard actuarial techniques. The results are illustrated in the graphs below. To give a feel for the variation of the results according to age and length of service, the calculations have been carried out for a variety of different values for these parameters. The graphs show early retirement from the age of 45, assuming that the civil servant joined at ages 20,30 and 40 . It is assumed that the civil servant was in continuous employment from the age of entry to the age of early retirement.

As the model retirement scheme provides pensions which are related to the civil servant's final pay, the capitalised costs may be expressed as a multiple of the individual's annual salary on retirement. These figures may be simply adjusted according to the salary rates and currencies of each of the different SIGMA countries. Figures 4.1, 4.2 and 4.3 show the results for a pension scheme with a normal retirement age of 60. To indicate how the costs change with a higher retirement age, Figures 4.4, 4.5 and 4.6 show the extra costs for a scheme with a retirement age of 65 .

\subsection{Commentary on Results} highlighting.

The graphs in Figures 4.1 to 4.6 show a number of interesting features which are worth

- Typically the costs of granting enhanced early retirement falls in the range two to four years' pay, depending on the age of the member, their length of service and the generosity of the terms on offer. In extreme cases, the costs can be over eight years' salary. These costs may appear expensive when compared with typical lump sum redundancy payments in the private sector.

- Not surprisingly, the full prospective service terms are more expensive than the half prospective service terms, which are in turn more costly than the accrued service terms.

- Capitalised costs generally reduce for individuals who are close to normal retirement. The capitalised costs for those departing a few months early are negligible compared with the cost for those staff departing ten or more years early.

- The longer the service, the higher the severance cost. It is more expensive to grant early retirement to persons of the same age in an age 65 scheme than in an age 60 scheme.

- Paying a lump sum of 1 month's pay for every year of service tends to be considerably cheaper in the long term. Only at the ages close to retirement is the lump sum option more expensive. (The lump sum may be reduced for those close to retirement.)

Returning to the example in Section 2, it can be seen from Figures 4.1 to 4.3 that, in either of the enhanced options, the capitalised cost of the retirement benefits for a 55 year old exceeds three years' pay. For an individual who joined at 20 and retires at 55, the capitalised cost of enhancing his pension up to age 60 is 3.6 years' pay. So while the lump sum compensation payment of three years' pay may have appeared generous at first (and expensive for the employer), it may well be the cheaper option in the long term. 


\subsection{Capitalised Cost of Early Retirement Terms -- Normal Retirement Age 60}

Figure 4.1 Assuming entry age of 20

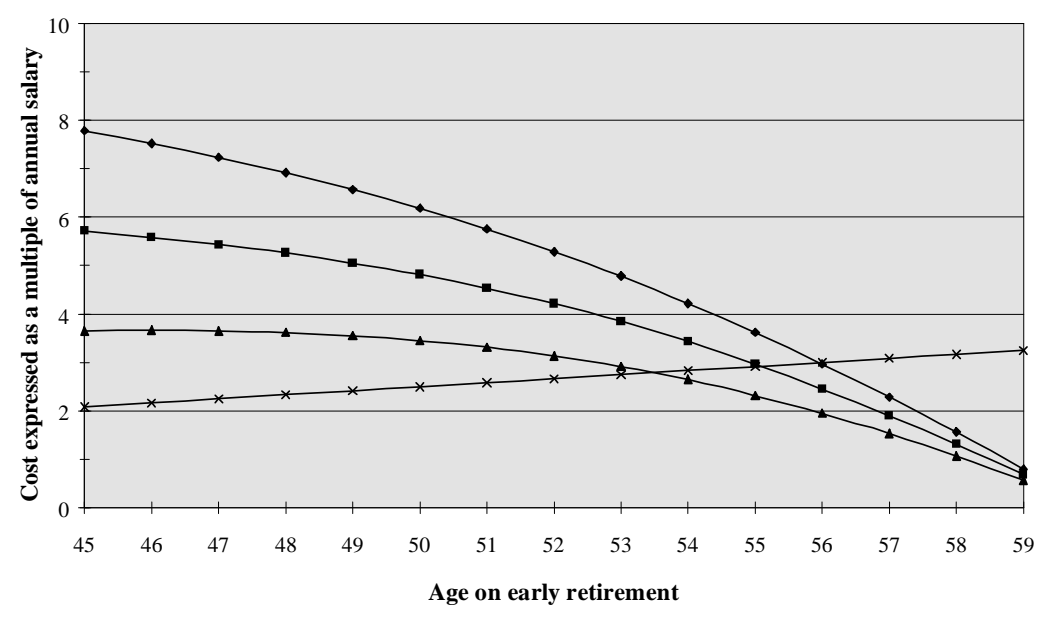

Figure 4.2 Assuming entry age of 30

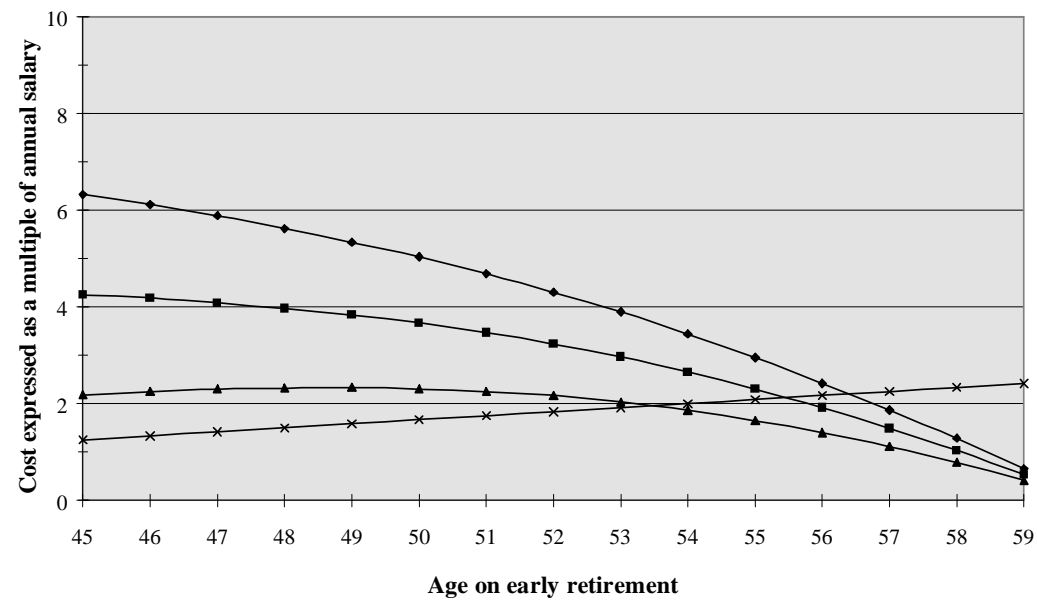


Figure 4.3 Assuming entry age of 40

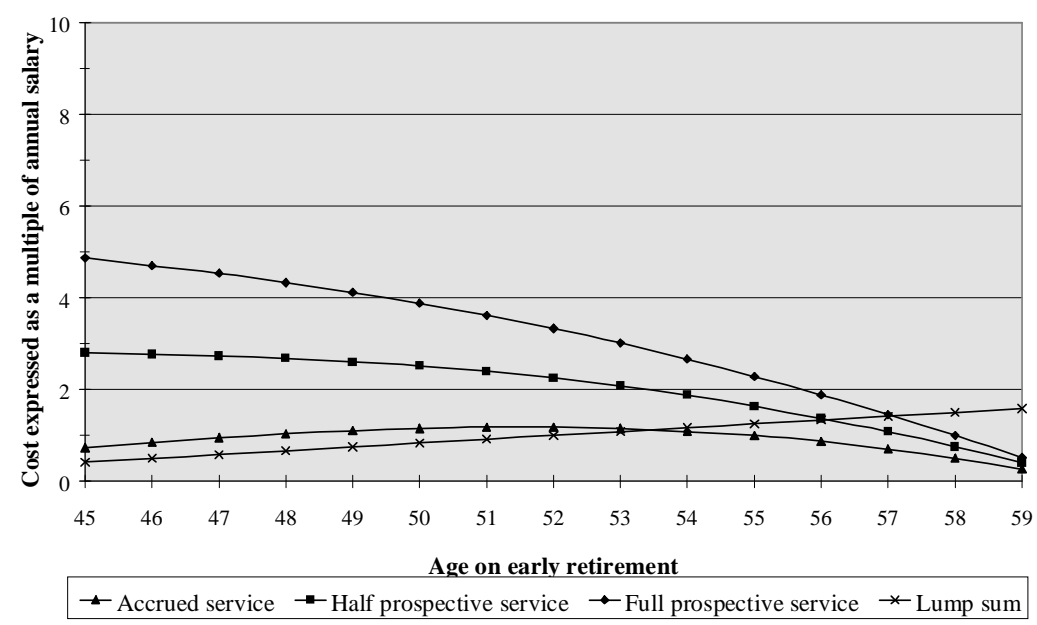

4.3 Capitalised Cost of Early Retirement Terms -- Normal Retirement Age 65

Figure 4.4 Assuming entry age of 20

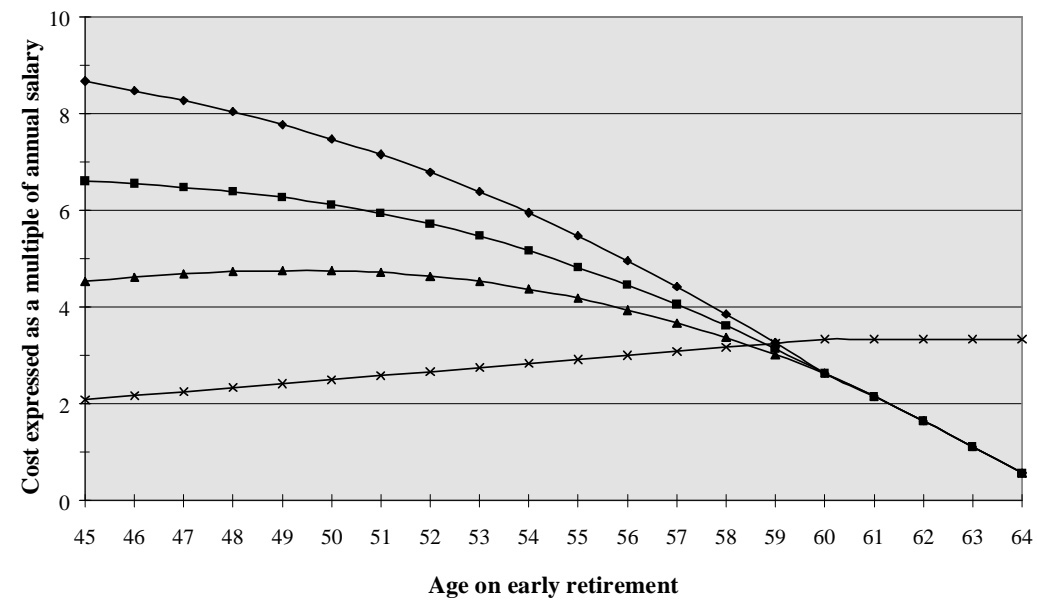


Figure 4.5 Assuming entry age of 30

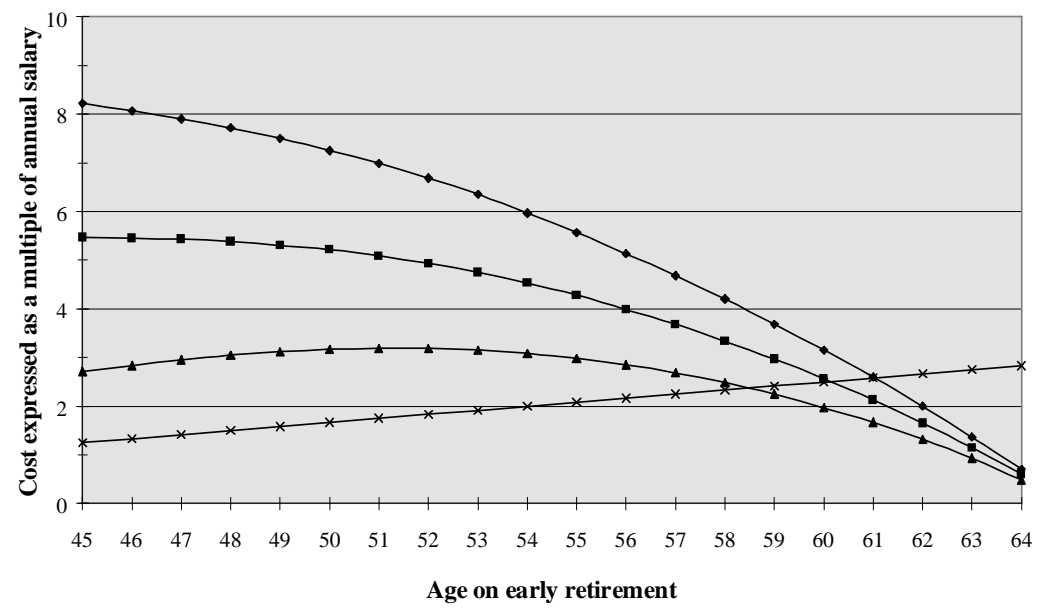

Figure 4.6 Assuming entry age of 40 


\section{RECOMMENDED CONTROL MECHANISMS}

The results in Section 4 show that the capitalised costs of augmenting retirement benefits can be very significant - especially for longer serving staff. If early retirement schemes are to be used prudently, these figures indicate that great care needs to be taken to ensure that the schemes are not abused - either knowingly or unwittingly - by managers. Experience from other public service organisations suggests that potential abuses are likely to be more common where pensions are paid centrally, rather than by the individual departments operating within the public service who would normally have the management initiative for declaring redundancies.

This section suggests some ways to assist in the control of long term public expenditure. The same principles may be applied either to an individual departure or to a one-off down-sizing exercise involving thousands of staff. An important principle is to ensure that those who have responsibility for meeting the costs have an effective input into the decision making process on premature retirements.

\section{1 “Enhanced" Early Retirements Only a Last Resort?}

In order to limit costs, personnel managers might be encouraged to make use of all other possible avenues for reducing staff through "natural wastage" before offering enhanced early retirement terms. Perhaps to state the obvious, organisations which are looking to reduce staff numbers should not normally be recruiting staff. Civil service departments should consider redeploying staff where-ever possible, either to another post in the same department or another department elsewhere in the Civil Service. Any staff who remain in employment above normal retirement age may be asked to leave at nil cost.

\subsection{Introduce a Minimum Age}

Figures 4.1 to 4.6 illustrate that the costs are significantly higher for staff who retire with a longer period to complete until normal retirement. The introduction of an appropriate minimum age for consideration for early retirement may help to contain costs. A minimum age of five to ten years below the pension scheme's normal retirement age might be considered.

\subsection{Early Retirement Costs borne by Organisation's Own Budget}

Those managers who have the power to authorise early retirements must be aware of the long term cost implications. Local personnel managers will have the greatest incentive to control costs if the extra cost of the enhanced early retirements are met out of their own budget. 


\subsection{Consider Cost to Taxpayer}

Even if local managers do not bear the full cost of early retirements from their own budgets, the true cost to the taxpayer can still be used as one of the key criteria in selecting candidates. The capitalised cost of each redundancy can be used as a measure to allow a direct comparison to be made between lump sum costs and augmented pensions. Value for money must be considered not only in respect of the employer's own budget, but for the future expenditure of the country's Exchequer as a whole. More sophisticated systems may make allowance for the impact of tax and social security.

\subsection{Consider Last-In-First-Out}

Some employers operate redundancy schemes on a Last-In-First-Out (LIFO) basis. Personnel managers criticise such arrangements as too restrictive. Indirectly LIFO schemes have the benefit of helping to minimise severance costs. However, they tend to target younger staff. There may be some longer serving older staff with similar redundancy costs who would be happy to retire and who are overlooked under LIFO.

\subsection{Compulsory Schemes}

Making such schemes compulsory allows the employer to choose who to shed - normally the cheapest. Offering early retirement terms to volunteers will encourage those with the longest service and the most expensive benefits - to volunteer. Besides having the largest retirement benefits, they may be the staff who are most expensive to allow to retire, except if they are very close to retirement.

\section{$5.7 \quad$ Voluntary Schemes}

While enhanced early retirement terms should only be offered with the consent of the employer, inviting volunteers for early retirement may be a helpful way of minimising costs. Start by inviting volunteers for "cheap" terms. Select the cheapest candidates who also meet the local managers' requirements. If necessary, gradually improve the terms on offer until sufficient volunteers are obtained.

\subsection{Avoid Building Up Expectations}

One of the key problems in operating voluntary schemes may be avoiding developing an expectation in younger staff that enhanced retirement terms will be offered indefinitely. Such expectations should be avoided, as the cost of effectively reducing the retirement age of all civil servants would be very considerable.

Various ways of deflating expectations might be considered. For example, if the Civil Service pension arrangements do not have a mechanism for allowing older individuals to resign and retire early on a cost neutral basis, then one should be introduced. This should be regarded by both the employer and the employee as the benchmark against which improved early retirement terms are considered. Furthermore, younger staff may be encouraged to make their own provision for their retirement, possibly through tax incentives. Such tax efficient savings schemes allow younger civil servants to plan to offset part of the cost of voluntary early retirement. 


\subsection{Avoid Developing an Imbalanced Workforce}

As early retirement schemes target older staff, it is possible to end up with an imbalanced, as well as inexperienced, workforce. Instead of employing a broadly even number of staff by age, the civil service could be left employing a disproportionately large number of younger staff. In time, this may have a negative effect. It may, for example, lead to a reduction in staff morale, if unable to secure promotion. (Rather ironically, early retirement schemes are often seen by personnel managers as a mechanism for removing promotion blockages. Whilst this may help to motivate younger staff in the short term, the cost of the associated pay rise is incurred on top of the early retirement costs. Moreover, if widely adopted it will simply perpetuate the uneven age distribution.) 


\section{CONCLUSION}

This paper demonstrates the high long term cost of early retirement schemes. Early retirements are probably used far more extensively than is justifiable solely on financial criteria. Civil Service organisations operating pay-as-you-go pension schemes, should take particular care when considering offering early retirement arrangements to ensure that the long term implications for the sponsors - the Government and its taxpayers - are well understood. Managers with responsibility for selecting candidates for redundancy or early retirement should be aware of these costs. Perhaps the challenge for the finance manager of the future is to ensure that any early retirements can be justified on strict value for money grounds. 


\section{CHAPTER 4 REFORMING PENSION SCHEMES, IMPLEMENTATION AND TRANSITIONAL ARRANGEMENTS BY DAGMAR KNIEP-TAHA}

Against the background of an increasing life expectancy, a reduced birth rate and a decreasing economically active population, long-term changes in the age structure of the population begin to emerge which will result in increasing financial burdens for all old-age pension systems. The growing difficulty to fund these systems is not a problem specific to the area of public service law. All systems providing old-age pensions - such as general statutory pension insurance in Germany - will be confronted with considerable problems if the percentage of persons over 60 in the total population will further rise in the future.

Global studies relating to provision for old-age show that the problem is not confined to Germany, but I will limit myself here to experiences made in our country.

The "pensions report", which the German federal government is presently preparing, will not only constitute a current inventory, but will also be a survey of the expenses for personnel, benefits and pensions in the past and in the future. Henceforth, the report will have to be submitted every four years.

The report will show for the first time personnel development since 1970 and include a forecast up to the year 2008. It will contain a multitude of detailed information on the development of active personnel, the number of recipients of benefits and the amount spent on benefits.

Since increases in the number of personnel result in a corresponding increase in the number of recipients of benefits and thus in the expenses for pensions 30 to 40 years later, the period for which the prognosis is made reflects the personnel increases of the sixties and above all the seventies. These increases were primarily due to the new demands society placed on the State and the resulting additional tasks that had to be performed by the public service. There are therefore particularly high growth rates in the fields of education (schools, universities) and internal security (law enforcement services). It should also be mentioned that not only the number of civil servants, but also of employees and workers in the public service, has risen markedly between 1970 and today.

This rise in the number of personnel entitled to pensions will in the future lead to a considerable increase in funds that have to be made available for pensions.

Another cost factor which must not be underestimated is the total length of the period during which benefits have to be paid to the individual recipients. The earlier retirement begins, the longer is the total period during which benefits have to be paid and the higher the total amount of benefits that have to be paid during the period of retirement.

The author is Legal Advisor at the German Federal Ministry of Interior, Bonn, Germany. 
According to studies of the German Federal Statistical Office, on average a pensioner receives benefits for 16 years, and a survivors' pension is subsequently paid to the widow and children for another seven years.

In this context, the average retirement age is of decisive importance. Factors influencing this average age not only include special age limits for specific categories of civil servants and the military, but also the many cases of early retirement. They are attributable to early retirement schemes provided for by law, early retirement owing to invalidity and to many civil servants making use of the possibility of retirement on application. For the time being, this is at the age of 62 .

With the exception of soldiers, the average retirement age of German civil servants and judges, as well as contractual employees in the public service, is around 59 years. This is not very different from the situation in the private sector: the average retirement age of employees in the statutory pension insurance was 59.4 years.

What is striking is that in both the public service and private sector the retirement age of women, on the whole, is lower than that of men: female civil servants on average retired a few years earlier than their male colleagues. A disproportionately high percentage retired from active service because of the inability to work - i.e. disability - certified by a doctor. Comparing the number of female employees who have retired because of disability in the public sector to those in the private sector would not be useful since private sector cases in which the inability to work (or disability) has resulted in retirement often occur before the legal retirement age for women (60 years). In contrast, no specific lower age limit for women is laid down in the public service law.

The reason for the relatively low retirement age, however, cannot be attributed solely to women as the percentage of female workers in the civil service is still relatively low. In the federal administration, for instance, the percentage of female staff - i.e. female civil servants and employees - is not even 20 per cent.

It remains to be seen whether the longer life expectancy of women observed in the past also applies to those who have been gainfully employed all their lives - or at least during a major part of it. The results of demographic studies have been based to date on surveys of women who, for the most part, had not been gainfully employed.

In light of the generally increasing life expectancy and the resulting longer period during which pensions have to be paid, it is possible to conclude, however, that retiring earlier and earlier from the civil service will be difficult to accept.

Pessimistic estimates in some publications assume that the total amount of pension payments to civil servants in Germany may double by the year 2010 if all these factors are taken into account and one presumes that pensions will be annually adjusted in an adequate way. Whether this estimate is correct will be shown by the findings of the "pensions report".

Nevertheless, public budget expenditure on pensions must not be considered without proper context. Within the framework of the civil servants' relationship of life-long service and loyalty to the public employer, their pensions are in fact a form of continued support in the form of old-age benefits. Public budgets in Germany, therefore, show pensions as only a part of personnel expenditure on the whole. 
As regards the burden on the taxpayer, it is the overall development rather than the relative weight of individual factors within total personnel expenditure that plays a decisive role. This approach differs from that of insurance institutions specifically set up for pensions purposes and financed on the basis of solidarity. Since here the ratio of the number of contributors and the number of recipients of benefits determines the amount of the contribution, these insurance institutions strive for the largest possible number of contributors.

When looking at Germany's state budgets, it is possible to see that from 1970 to today the share of personnel costs and pensions of the total budget expenditure did not change significantly despite a strong rise in absolute figures. In the final analysis this means that public budgets have grown to the same extent as personnel and pension expenses have increased.

Even more important than the total amount of pensions expenditure in public budgets is their relation to macroeconomic values for comparison. Measured against the long-term development of the gross national product or gross domestic product or the total volume of the social budget, respectively, the following statements can be made concerning pensions:

- From 1970 (179.2 billion DM) to 1993 (859.4 billion DM) the total social budget comprising all social expenditure, from old-age pension schemes, unemployment benefits and social assistance, to sickness benefits - grew by 380 per cent. Compared to this increase, the 266 per cent growth of public service pensions expenditure - over the same period - clearly lags behind. The expenditure on statutory pensions, however, increased by 391 per cent;

- Part of the gross national product, which has to be made available for pensions, has slightly decreased from 1970 to now. This is primarily due to the continued decrease in the number of pensions for the war-disabled;

- In the future, the development of public budgets will be parallel to macroeconomic comparative values.

Although future economic trends cannot be precisely forecast, in March 1996 the German research institute PROGNOS presented a study commissioned by the Federal Ministry of Labour, which takes into account past experience and much national and international reference data - e.g. development of the age structure of the population, percentage of economically active population, effects of increasing number of gainfully employed women and migrants, technological progress, development of the labour market and the sales markets - and draws up alternative scenarios (best and worst possible) for potential future developments. Inter alia, it includes a long-term forecast of the gross national product (GNP) and the expenditure of both public service pensions and the statutory pension system.

According to these estimates, the expenditure on public service pensions for civil servants and soldiers, in terms of percentage of the GNP, will not increase as dramatically — by about one fifth - as the costs of the statutory pension system, which will rise by about one third. Whether and to what extent these PROGNOS assumptions will turn out to be correct will be shown by the "pensions report".

On the whole, experiences in Germany have lead to the following conclusion: preventing a marked increase in total personnel expenditure — including public service pensions - in public budgets requires a wise and sound recruitment policy and more reductions in the number of active staff. First steps in this direction have already been taken under the catchword "lean government".

In line with the reform of the statutory pension system, important measures have also been taken in the field of public service pensions, notably by the amendment of 1992. The principal item of the 
reform was the extension and linear graduation of the pension scale. The existing degressive pension scale was replaced by a linear fixed rate increase of 1.875 per cent of the pensionable pay for every year of pensionable service.

This means that the maximum pension rate ( 75 per cent of final remuneration) is reached after 40 - and no longer 35 - years of service. In addition, the new law now provides for measures to curb early retirement, giving priority to rehabilitation and new assignment rather than retirement. Pensions will also be reduced by 3.6 per cent for every year of early retirement from 2002 onwards.

These amendments will gradually take effect and will go into full effect during the period when demographic growth will be such that the highest increase in pension expenditure has to be expected.

Civil servants who are already in service at the time when the new law goes into force will be subject to transitional regulations with regard to acquired rights for future pensions. These regulations aim to preserve the entitlements already acquired under the old pension scale. Until the next millennium, comparative calculations both under the old and new law will be made whenever a civil servant retires, who will then benefit from the more favourable solution.

Following the model of pensions for civil servants, the extended and linearized scale as well as the pension reduction have been incorporated into the overall scheme of supplementary occupational pension for contractual employees in the civil service.

After a thorough analysis of the pensions report, it will be necessary to see how the existing civil service pensions law might best be amended. It will also be up to the employees' and employers' representatives in collective bargaining to implement these amendments in the collective agreements for the contractual staff.

As the amount that has to be made available for civil service pensions is determined by the period during which benefits have to be paid, it is now clear that future legislation in this field should primarily aim to stop the current trend towards early retirement and, instead, aim to make the average working life in the public sector longer. For this reason, additional measures designed to extend the period of gainful employment have been included in the Draft Service Law Reform Act. Inter alia, it envisages:

- raising the age limit for retirement (on application) from 62 to 63 years;

- introducing, step by step, a pension reduction of 3.6 per cent for every year that a civil servant (on application) retires earlier than the standard age limit of 65, beginning as early as 1998 and no later than 2002; and

- setting more rigid standards for determining disability for service, and promoting the principle "rehabilitation and new assignment has priority over retirement".

If we succeed in raising the average retirement age of civil servants by one year, several billion Deutschmarks could be saved every year.

The pensions report will also help determine whether or not the legal provisions for lower retirement age limits applying to the law enforcement sector (60 years) and the military (from 53 years onwards) will have to be scrutinised.

One thing, however, is already obvious: legislators can only get a clear sense of the financial consequences of a measure if they take into account not only remuneration of active personnel but also the 
pensions incurring many years later and — what is more important - calculate accordingly all measures in the personnel sector.

On the other hand, it is counterproductive to try to reduce pension costs by promoting early retirement for surplus personnel through specific legal regulations. It may initially appear more favourable to pay 75 per cent of benefit payments instead of 100 per cent of remuneration. However, it should not be overlooked that this is associated with a surge in pension payments that is not matched by a consideration for service rendered.

The current situation in Berlin is instructive in this regard. There are huge administrative machines in both parts of reunified Berlin, and the neighbouring city of Potsdam, which is the capital of the Land Brandenburg, also employs a large number of government officials. Should the planned amalgamation of the city of Berlin and Land Brandenburg be put into practice, staff will have to be reduced at a much higher rate than that of decreases for reasons of old-age.

Another idea is to replace, in the long run, a large number of civil servants by employees under contract, but from a cost perspective this does not seem appropriate. As numerous studies have shown the latest being a survey (August 1995) of the Ministry of Finance of Land Lower Saxony - it is on the whole not only more expensive (by about 5-15 per cent) to employ contractual employees instead of civil servants, but paying employer's contributions to the statutory pension insurance would also considerably aggravate the already tight financial situation of public budgets. Higher personnel expenditure for contractual employees during their active service would be added over the next few decades to the growing costs of pensions for existing pensioners.

Besides this direct comparison of costs, there are two other factors which should be taken into account when considering public finances: the tax revenue from the civil servants' pensions and the federal grants to co-finance statutory pensions which, in 1994, amounted to 64 billion DM , or about one-fifth of the overall expenditure on statutory pensions.

As long as budgets continue to be restrained, no relief can be expected from establishing establishment pension funds now. It is not possible to save money by paying pension benefits in the future from a separate pension fund rather than from the current budget. Building reserves for such funds will also be uneconomical as long as the budget situation remains tight because it does not make sense to pay money into a fund with low deposit rates while at the same time considerable parts of the current budget have to be financed by expensive credits.

To sum up: in the final analysis, all old-age pension systems are actually different forms of pay-as-you-go systems. To base them on a capital-cover insurance system would mean to build up enormous reserves which would go far beyond the scope of any public budget. The State, however, is normally not free to choose a form of investment for this enormously large amount of money which is actually due to its citizens - we all remember that the private US pension fund once fell victim to the crash of the stock exchange.

All that remains seems to be the traditional and proven system of the inter-generation contract, i.e. benefits are financed from the current revenues. According to the systems in Germany, these consist of tax revenues made available for the public service pensions on the one hand, and current contributions plus federal grants for the statutory pension system on the other hand.

Just like all other benefits exchanged between generations, this system is generally susceptible to demographic imbalances. Although we now all face a population decrease - for instance, fewer bakers 
will in the future have to bake more bread, just to give you one example - we can have recourse to past experience:

In a dynamic economy, it is not so much the number of people that is important for the capacity of an old-age pension system, but rather how many of them have jobs and how productive their work is. Let me prove this by two figures: in the period from 1950 to 1990, Germany's gross national product increased by 47.3 per cent, while the number of economically active persons rose by only 42 per cent over the same period. This means that an increase in national prosperity and, in this context, the capacity to finance old-age pensions is more dependent on the productivity of a country's economy in general than on the total number of employed persons. 


\section{CHAPTER 5 NATIONAL PENSION SCHEMES IN TEN CENTRAL AND EASTERN EUROPEAN COUNTRIES}

\section{Albania}

Social security rights in Albania are guaranteed by the following main laws: the Law on "The Main Constitutional Provisions" and the Social Insurance Act. no. 7703 of May 11, 1993.

According to the above legislation, all economically active Albanian citizens and their families are insured for illness, maternity (including birth grants), employment injuries, and unemployment, and there are pensions for old-age, invalidity and survivors (death grants included).

Before going on about the insurance arrangements, here is a brief introduction to Albania and its social problems.

Albania is a European country with about 29000 sq. km of land. Nearly 3.3 million Albanians live within the country and about the same number, or a bit more, abroad. Nearly 60 per cent of our population lives in the countryside and more than 70 per cent of Albania is high rural.

The population is relatively young, with an average age of 28 , structured as follows:

- up to 4 years old: 11 per cent;

- from 5-15 years old: 21.6 per cent;

- from 16-24 years old: 19.2 per cent;

- from 25-60 years old: 40 per cent; and

- over 60 years old: 8.2 per cent.

The life expectancy for Albanians is 71.4 years; 68.5 for men and 74.3 for women.

After the Second World War, Albania remained with the "red" part of the European map and followed the Russian model of socialism. For 50 years, Albania experienced the failure of socialist principles, especially the total collapse of its own "resources development principle" which forced the country into tremendous self-isolation.

During that period very little, if anything, was done to reconstruct the economy, which was extremely centralised, leading to high economic and social differences. The differences were so evident that the communist regime could hardly hide them.

In December 1990, the democratic movement started in Albania and in March 1992 a democratic government came into power through free and democratic elections. Albania has started reforms to transform the economic and social life of the country. The overall reform programme includes reform in the social area, which aims to establish the solid basis for a modern social safety net and welfare state development. 
A social insurance system, dating from 1947, existed previously. It must be stressed that policies developed in the past were conditioned by centralised economic development, a high rate of a fictive employment and state-guaranteed salaries. About 90 per cent of employees used to receive comparable wages, at the minimum level, that could hardly provide for a minimum living standard. That is why the old social insurance system was considered very inadequate, and a set of reforms was badly needed to meet new demands. In addition, only three insurance programmes had been developed under the old system: temporary incapacity, maternity and pension insurance.

In the past a very irrational policy was applied in the social sector, a policy that aimed to solve the immediate problems without considering future impacts and further developments.

Favoured by demographic growth, liberal legislation had been introduced that led to abuse of the pension insurance. This legal framework made it easy for citizens to retire, even for those with a very poor employment record. The retirement conditions, such as the retirement age and length of service, were closely related to the job categories, or degree of job difficulty.

The old pension scheme anticipated three job categories:

- The first category comprised the most difficult occupations (mines, metallurgy, chemical and textile industries, etc.). A man in this occupation could retire at age 50, with only 20 years of employment, and a woman at 45 , with 15 years of employment;

- The second category comprised the less difficult jobs and the retirement age was 55 years for men, with 25 years of employment, and 50 years for women, with 20 years of employment;

- The third category comprised the ordinary occupations and the retirement age was 60 for a man, with 25 years of service, and 55 years for a woman with 20 years of service.

Besides these "facilities", other special provisions were introduced early in 1990 to encourage early retirement and create new vacancies for younger people. As a result, from 1990 until the end of 1993, each employee who had acquired the necessary years of service could become eligible to retire five years earlier than the respective ages prescribed in the above-mentioned categories.

It is easy to see that these provisions encouraged a very rapid increase in the non-active population and in the number of social insurance beneficiaries. Compared to the year 1960, the increase in beneficiaries was:

- 8.5 times more in 1970 ;

- 8.5 times more in 1980;

- 2.0 times more in 1985; and

- 26.1 times more in 1993.

For the period 1979-1990, the annual average increase in the number of pensioners was 7-8 per cent, in spite of the 2 per cent natural annual increase of the population. This is mainly due to the impact of the rapid increase in retirement in the favourable occupations and the early retirements (before the age of 60 for men, and 55 for women). Early retirements in 1993 reached 42 per cent of the total old-age pensions compared to 18.7 per cent of the total in 1975. This increase was also followed by a reduction in the average retirement age which, by the end of 1993, was 53.1 years compared to 57.6 years in 1975 . Thus the benefits period rose to an average of 19.5 years per beneficiary. 
The statistical data on demography, compiled by the National Institute of Statistics, showed a new and different trend, indicating that:

- the birth-rate was decreasing quickly — from 79000 deliveries in 1990 to nearly 65000 a year, calculated for 1995-2000;

- the active population at working age (15-59 years), which was relatively high in the period 1969-1989, was going to fall considerably in 1989-1994 due to the decrease in birth-rate and to emigration;

- the elderly group (people over 60 years old) is going to increase. It was estimated that in 2000 this group should increase by 42 per cent compared to 1989 .

Adjusting the social security schemes to these new developments was a very difficult job, which necessitated great improvements and big changes in the existing legal framework. In an attempt to find new solutions and meet the needs of recent developments, new social security legislation was adopted.

The new social security scheme in Albania provides both pay-related and non-pay-related benefits. Pay-related benefits are guaranteed under the Social Insurance Act of May 11, 1993. This Act provides insurance benefits in five insurance branches:

- sickness;

- maternity;

- employment accidents/occupational hazard;

- pensions (old-age, disability and survivors); and

- unemployment.

The financing of such benefits is through contributions, payable to the social insurance fund by the employees and their employers.

Another law guarantees the distribution of non-pay-related benefits. The Act "On Economic Aids and Social Protection in the Albanian Republic", provides social assistance for people with low family income. These are minimal and earnings-tested benefits, providing at least for a minimum living standard. The scheme is financed out of the state budget through general taxes.

The social insurance law has been the basis for reconstructing the entire social insurance system; the new system was founded on a completely new model and designed to meet the demands of the free market economy.

The new system comprises the following schemes:

\section{- The General (basic) Insurance Scheme}

This is a pay-as-you-go mandatory scheme, where all economically active people (employees and self-employed) have compulsory insurance. The scheme covers the entire population, urban and rural, providing insurance benefits in the five branches listed above.

The scheme is financed from contributions paid by the insured persons and their employers. The scheme is also guaranteed against insolvency by the state budget. 
- The Voluntary Insurance Scheme

This consists of an extension of the general scheme to protect some categories of people who:

- are not compulsorily insured;

- for acceptable reasons have given up the compulsory insurance and may continue with insurance under voluntary arrangements; or

- self-employed people, who wish to have higher benefits.

- Supplementary Insurance Schemes

- State supplementary benefits

The Social Insurance Act allows for a supplementary arrangement in addition to compulsory insurance. The Parliament or Government has the right to introduce the supplementary schemes for civil servants and military personnel.

These supplementary benefits are to be financed out of the state budget.

\section{- Private Supplementary Scheme}

This scheme, which is private, applies to both private-sector and public-sector employees. It enables those who are insured to benefit from early retirement (at 40 years of age) or higher benefits, provided they have paid at least five years of contributions. The scheme is financed by individual contributions made by the insured and their employers. The benefits are closely related to the amount of contributions that the insured people pay.

The administration of private supplementary insurance can be commissioned to legal bodies, or specialised organisations. These funds are always founded and managed by the shareholders. There is no minimum or maximum for the benefits provided by the private insurance; these are subject to the individual and/or collective contracts. It is a pre-funded scheme.

- Special State Pensions

Under this scheme, the Council of Ministers has the right to award special state pensions, or supplements, to people who have distinguished themselves in national liberation movements, democracy and politics, scientific research, culture, economy, etc. Special pensions are also available to people who were politically persecuted under the communist regime. All special schemes are financed out of the state budget.

\section{Legal Arrangements}

Under the new legislation, the general social insurance system protects the entire economically active population on a compulsory basis. The employed and self-employed, resident in Albania as well as Albanians employed abroad, are covered against a loss in earnings due to temporary incapacity, maternity, occupational injury, unemployment, old-age, disability and the breadwinner's death. The entire former legal framework has been completely revised and the greatest improvements have been made in pension insurance. One of the biggest changes consists of eliminating the job categories and excessively favourable retirement ages. The retirement age has become standard and the insurance period considerably longer.

The conditions for eligibility now are: 
- retirement from economic activity;

- after 35 years of contribution (for both men and women); and

- at age 60 for men, 55 for women.

A transitional period is foreseen for applying the new measures. By 2004, the new legislation will become fully effective; retirement ages related to different job categories and the contribution period will be gradually increased step by step.

The pension insurance also has provisions for social fairness; new measures have been introduced to calculate benefits, taking into account the insurance periods and the contribution rates.

The three types of pension benefits (old-age, survivors and invalidity) are calculated in the same way. The formula utilised to calculate the pension amount has two tiers. The first one introduces the minimum benefit principle. Everyone is entitled to the minimum guaranteed amount, providing at least for a minimum living standard, to be set by the government. The second tier represents an increment based on the participation of individuals in the insurance scheme; it is proportional to the years and amounts the insured persons have contributed.

\section{The Cost of the Scheme and the Financial Arrangements}

The new scheme has also modified financial arrangements. The social insurance schemes are foreseen to be a non-profit activity. The income from the contributions will cover the total expenditure of the scheme (insurance costs plus administrative costs). The state will finance only the special programmes, such as merit pensions, allowances and those categories of personnel that government has decided to support, e.g. soldiers under compulsory service, unemployment beneficiaries, etc.). Employees will also pay a contribution out of their gross salaries.

The compulsory contribution is shared by the employee and his employer, with the employee's share representing 10 per cent and the employer's 26 per cent of the salary. In addition, the employer will also pay 6.5 per cent of the salary for occupational injury insurance $(0.5$ per cent $)$ and unemployment insurance ( 06 per cent). The employer is obligated to deduct and transfer the total contribution to the social insurance funds.

Fundamental changes are also being made in the social insurance administration. Social insurance management has been entrusted to an independent public institute, the Social Insurance Institute. This Institute is run by its Administrative Council, where representatives of the three social spheres government, employers and trade unions - participate.

The new system is now complete. Besides compulsory social insurance, which provides support to the whole economically active population (regardless of type of employment), the system also allows for voluntary insurance. Another law has been adopted - the Law on Supplementary Insurance and Private Pensions Institutions - and became effective to implement Article 4 of the Social Insurance Act. Work is going also well with preparing supplementary benefits for civil servants and the military personnel.

The new scheme has now been in force for two years. The social insurance system has proved it is economically sustainable because, for the first time, the budget met its projections. We may consider the system effective in guaranteeing the existence and delivery of the promised benefits. The experience also provides evidence that organisations independent of the State can run the insurance business. 


\section{The Major Problems Ahead}

We cannot yet pretend that we have constructed a complete social security system; much remains to be done in this respect. Only the legal framework is actually in place and its implementation will require much effort. It is important that the legislation we have adopted is based on the most modern approaches. This I would like to emphasise. Parallel to legal transformation, we are also working to reorganise the scheme's administration. New administrative units are to be established, both at the centre and in localities.

To be realistic, we must accept that the transitional period our country is passing through has generated many problems related to the limited experience we have in dealing with new social matters and the financial difficulties of a transitional economy.

The difficult economic situation that Albania is experiencing does greatly influence the social sphere by overburdening the social security schemes and making their financing very difficult.

The current unemployment rate of 13 per cent has greatly reduced the number of contributors and has decreased the dependency ratios (contributors/beneficiaries), making it very difficult for the scheme to survive. Regardless of the many difficulties we have, I do believe that the scheme is well conceived and that the major problems are due to its implementation in a transitional period, and that progress belongs to the future.

\section{Bulgaria}

The social security system has a long tradition in Bulgaria. The first law on the social assistance of disabled persons was passed in 1881. In 1885, the Law on the Retirement of Civil Servants was adopted. The period 1900-1920 saw coverage of a considerable number of hired workers with social security for illness, accident, old-age and maternity. In 1924, the Social Security Law created a universal and mandatory social security system. In 1949, the new Law on Social Security brought together various types of social security into a single fund managed by the State Social Security Institute. The budget of the Social Security Institute became part and parcel of the integrated state budget.

In 1957, the Pension Benefits Law was passed to establish a general pension system for all categories of secured persons, except for co-operative and private farmers whose social security benefits were regulated by a special law. The latter was in force from 1961 to 1975. Afterwards farmers were also included in the scope of the Pension Benefits Law.

In terms of social security, government employees come under the provisions of the Pension Benefits Law. No privileges exist and government employees are placed on equal footing with employees of the public and co-operative sector.

The social security system is financed through social security contributions paid by employers only. The system operates on a pay-as-you-go basis. The amount of benefits is different for each of the three categories of occupation based on the extent of strenuousness and harmfulness to health. The social security contributions paid are equal to 50 per cent of the gross compensation for Category I, 45 per cent for Category II, and 35 per cent for Category III. Only self-employed sole proprietors and free-lance professionals pay social security contributions at their own expense.

The social-security system (except for health care) is managed by the Chief Division Social Security at the Ministry of Labour and Social Affairs and its regional social security subdivisions. 
The Pension Benefits Law provides for the following types of personal and inherited pension benefits:

- old-age pension benefits;

- illness-related disability pension benefits;

- disability pension benefits due to labour accident and occupational disease;

- old-age pension benefits for private craftsmen and private farmers; and

- death-related pension benefits of the above types.

The requirements for persons to qualify for old-age pension are as follows: 60 years of age for men and 55 years for women, and 25 years of service for men, and 20 years for women. If the length of service is shorter than required by at least one half of it, the pension is reduced on a pro rata basis.

The early retirement option was introduced as of April 1990 for men who are 57 and for women who are 52, provided they were eligible on the basis of several additional conditions. That amendment to the Pension Benefits Law was repealed in June 1992. The pension under the early retirement option was reduced (20 per cent) compared to the normal old-age pension.

In addition, the early retirement option applies to persons who have worked under conditions qualifying for Categories I and II.

Military servicemen and those with equivalent jobs, as well as teachers, may qualify for early retirement provided they have the required length of service.

The service record includes the periods covered by social security contributions and several other cases recognised as equivalent (maternity, regular army service). The length of service is calculated on a consolidated basis, regardless of the sector of employment. The periods in which the person had no employment contract or no social security contributions were paid do not count for the calculation of the length of service.

The replacement rate is 55 per cent of the average monthly gross wage or salary in three consecutive years of work over the last 15 years of employment at the choice of the retired person. Two per cent are added to the amount of the pension for each year of service above the required minimum level but these further allowances cannot exceed 12 per cent or six years altogether.

As all other secured persons, government employees are entitled to disability pension benefits due to general illness, labour accident or occupational disease, as well as to death-related pensions of the above types.

The requirements for illness-related disability pension benefits are as follows: permanent or long-term disability and length of service of at least five years for persons above the age of 25 , and three years for persons in the 20-25 age bracket. No length of service is required for persons below the age of 20.

The degree of disability is determined by a medical board. There are three groups of disability: Group I for persons unfit for any type of occupation; Group II for persons unfit for professional work; and Group III for persons who need to change their occupation or working conditions.

Replacement rates are 55 per cent of the gross wage or salary over the last 12 months of service prior to the disability date for disability of Group I, 40 per cent for Group II, and 25 per cent for Group III. 
The illness-related disability pension for Group I can be increased by 75 per cent of the benefit when support of another person is required. Accident-related disability pensions are paid out under similar conditions, although no length of service is required for them.

The Pension Benefits Law provides for the possibility to receive two pensions at a time. The first benefit is paid out in full, while the second one is limited to one-half of the established amount.

Death-related benefits are equal to 50 per cent of the personal pension benefits of the deceased person when there is only one heir, 75 per cent for two heirs and 100 per cent for three or more heirs.

If a person is dismissed from the institution, company or organisation, or the employment contract is terminated due to expiration of its term, unemployment benefits are paid out depending on age and duration of employment, but they cannot exceed 12 months.

Social security benefits are not automatically adjusted. They are adjusted or updated by a decision of the government on the basis of an inflation index it has established.

Prior to the retirement age under the Pension Benefits Law, persons may qualify for disability benefits or receive death-related benefits.

Old-age pensions are life benefits, while disability pensions are granted for a specific term established by the medical board.

All pension benefits are exempted from taxation. Pensioners receive their benefits through the post offices or the State Savings Bank.

Economic conditions have changed considerably in the Republic of Bulgaria since 1990. The change has had disastrous effects on the social security system. At the end of 1991, there were 2374418 pensioners and 4108598 secured persons, and the entire population was 8993310 . Inflation rates were very high but the increase of social security benefits lagged behind considerably. Furthermore, pensions were the only source of income for this large group of the population. In 1991, the spending on pension benefits accounted for some 14 per cent of the gross domestic product of the country.

In addition, demographic indicators are extremely unfavourable for the social security system, with a continuing tendency to deteriorate.

Over the last few years, several public debates have been conducted in connection with the reform process. Consensus has been reached on the major aspects of the reform.

The reform has already started with the Law on the Establishment of a Social Security Fund. After the institutional reform, in 1996, the National Assembly of the Republic of Bulgaria will discuss a package of laws related to all aspects of social protection.

Hopefully, a new Government Employees Law will make it possible to have this group of employees covered by a separate pension scheme. 


\section{The Czech Republic}

In the Czech Republic, no special civil service pension scheme exists. There is no special pension system for any category of employees. However, there is supplementary pension insurance open to all citizens or residents of the Republic.

In 1994, a Law came into force on supplementary pension insurance with a state contribution. By this Law, supplementary pension insurance was introduced as a superstructure over and above the basic system of pension security, expanding the possibilities for citizens to play an active role in safeguarding their future according to their individual situations. The Law stipulates only the basic rules which every pension fund must adhere to, but it also permits the offering of more advantageous conditions. This should enable competition among pension funds and lead to advantages for participants in supplementary pension insurance.

Supplementary pension insurance with a state contribution (hereafter referred to as supplementary pension insurance) is consistently based on a civic and individualistic principle, not on an employer (branch, profession), corporatist principle. This decision was taken with regard to the present circumstances and expected development of the Czech economy, the situation of the labour market (increased mobility of labour forces during the transition period) and the structure of employer organisations (transition to medium-size and smaller enterprises). Supplementary pension insurance rests consistently on the relationship between the pension fund and the citizen, not on the relationship of pension fund/employer/employee. The insurance comes into force exclusively on the basis of the participant's choice, on the basis of the competitive offers of the pension funds and with direct support from the State. The insurance concept here stresses that insurance is first and foremost the concern of the participant himself and his ability to plan for his future.

Supplementary pension insurance is administered by pension funds which are joint-stock companies with a minimum basic capital of 20 million Kc. The fund manages the contributions from participants and the State, and attempts to valorise further these contributions through suitable investments. Unlike traditional commercial insurance companies, the pension funds are institutions where the major part of the profits from the economic activity of the fund must be used only to the benefit of the participants in supplementary pension insurance (shareholders are entitled to a maximum of 10 per cent of the profits). The type of investments is restricted by Law so as to exclude those which are risky. On its establishment, each pension fund must declare the bank which is entitled to execute the function of depository. This also guarantees a certain control over the financial activity of the fund. According to the Law, it is the responsibility of the pension fund to inform participants regularly concerning the financial state of the fund.

A participant may contribute to a fund any amount payable by the end of each month, eventually for several months at a time in advance. He is entitled to the state contribution only if he pays in time. The State provides contributions for every participant according to the following scheme: 
Amount contributed by participant in Ke (KZK)

\author{
100 to 199 \\ 200 to 299 \\ 300 to 399 \\ 400 to 499 \\ 500 and over
}

Amount of State contribution in Kc (KZK)
$40+32 \%$ of the amount over 100
$72+24 \%$ of the amount over 200
$96+16 \%$ of the amount over 300
$112+8 \%$ of the amount over 400
120

Note: The average wage in the Czech Republic in 1994 was 6790 Kc.

The minimum contribution by a participant to which a state contribution is made is $100 \mathrm{Kc}$. In the first two years of participation in the system, the state contribution is raised by 25 per cent. The aim of this increase is to encourage the interest of citizens in supplementary pension insurance.

In lieu of or apart from the participant himself, contributions may also be sent to a fund to his "benefit by a third party", but an employer may do so only from profit after taxation. It is not possible, however, for contributions to be paid into several funds simultaneously to the benefit of a single person. To check on this regulation, a central register of participants in supplementary pension insurance has been established, which is maintained by the Ministry of Finance, the state supervisory body. This body also has a number of other functions which are intended to ensure the protection of participants and the greatest possible security of the system. Together with the Ministry of Labour and Social Affairs, it approves pension plans and also gives its opinion on the personnel composition of the management bodies of funds. It regularly sends reports on business activity, and it may also request special information on the activity of a fund, impose fines or corrective measures and, in extreme cases, withdraw the activity permit of the pension fund.

An individual account is kept for each participant recording the contributions paid (by the participant and the State) and shares in profit.

In case a participant decides to transfer to another pension fund, the original fund is required by Law to enable him to make this transfer with all the financial means recorded in his account (in other words, the contributions of the participant, the contributions of the State and the yields from investments corresponding to the contributions both of the participant and of the State).

The participant has the possibility of selecting the contingency (obligatory age and also disability or death), the period of time and the level of the complementary income. This selection is made possible by the variously conceived pension plans of the individual pension funds.

The Law permits only defined contribution pension plans with the sole exception of disability pensions. If, however, a pension fund offers a defined benefit disability pension a separate account must be kept for this and no state contribution is provided for contributions to this type of pension.

\section{Estonia}

In Estonia, state employees are subject to the common general pension scheme, which covers all categories of employees. 
The common scheme is regulated by the Law on State Allowances (17 March 1993) and operates on a pay-as-you-go basis. It is financed by the social security budget, which derives from social contributions (social tax) paid by the employers at the rate of 20 per cent of the salary. Employers in the public sector pay social tax on equal terms with employers in the private sector. Social contributions of public institutions are included as separate items in the state and local budgets.

The general retirement age in 1995 was 61 for men and 56 for women. Since 1994, the retirement age is gradually rising by 6 months each year, until it will reach 65 for men and 60 for women in 2003. In Estonia, eligibility criteria for the common old-age pension is 15 years of employment.. Although there is no general early retirement, early retirement is possible for those working in hazardous conditions, and in some other prescribed cases.

The common old-age pension scheme currently depends on two factors: the amount of national pension and the length of employment (or equivalent activity). The amount of national pension is determined by the government, depending on financial constraints of the social security budget, and can be increased twice a year. The employment period component of pension rises progressively along with the years of employment. For an employment period of 15-19 years, 1.7 per cent of national pension is added to the amount of national pension for each year of employment. For a period of 20-24 years, 1.8 per cent; for 25-29 years, 1.9 per cent; for 30-34 years, 2.2 per cent; for 35-39 years, 2.3 per cent, and for an employment period of over 40 years, 2.5 per cent of national pension is added for each year. When defining the length of service, periods of military service, studies at institutions of higher education, periods of registered unemployment etc., are equalised with employment. Periods of unlawful detention account threefold. The pension has no upper limit.

As stated above, the amount of national pension and, thus, the total pension payments, are determined by the government. Currently, there is no automatic adjustment mechanism or indexation of pensions. The pension is defined as a benefit, not as a contribution, and its payment is life-long.

According to the Law on Civil Service, which was adopted for implementation after 1 January 1996, civil servants are entitled to pension supplements. The amount of supplement depends on length of service in civil duties and on the amount of old-age pension: 10-15 years of civil service should increase the normal old-age pension by 10 per cent, $16-20$ years by 20 per cent, $21-25$ years by 25 per cent, 26-30 years by 40 per cent and over 30 years by 50 per cent. These supplements will be financed from the state budget. However, the Law on Civil Service does not cover pension rights for certain categories of civil servants, such as the President, Parliament Members, Ministers, the State Controller, Chancellor of Justice, the President of the Estonian Bank, judges, police and military officers and border-guards.

Police officers, detectives, judges, prosecutors and some other categories of workers in the field of criminal justice, but also military officers, rescue workers and firemen have pension rights on preferential conditions, regulated by the Law on Superannuated Pensions. Eligibility requirement here is generally 25 years of service (at least 15 years in Estonia) in prescribed positions without any minimum age limit. Periods of part-time employment in given positions are excluded when defining the length of service. The superannuation pension for the mentioned categories of civil servants is the amount of national pension augmented by 1.5 per cent of national pension for each year of service in prescribed position, plus 20 per cent of national pension for some professions. Thus, the superannuation pension is generally lower than normal old-age pension. After completing the common retirement age, persons on superannuation pension can switch to the normal old-age pension. 
The pension rights of the President and the Members of the Parliament are regulated by a separate law. Old-age parliament pensions may be awarded to 60 year-old men with 25 years of service and to 55 year-old women with 20 years of service, if he/she has been a Member of the Parliament for at least two years up to the end of Parliament's mandate. There is also a possibility for earlier retirement on prescribed conditions. The pension amounts to 75 per cent of the Parliamentarian's salary, and is paid from the state budget.

The overall administration and financial management of social security lies with the Estonian National Social Insurance Board. The payment of pensions (with the exception of parliament pensions) is carried out by the regional pension departments. The Social Insurance Board also drafts new legislation.

\section{Hungary \\ The Current Pension System for Civil Servants}

There is a national pension system in Hungary. All employees in all sectors should be covered by this scheme. There is no special provision for state employees or any other specially defined groups.

The Act on Mutual Insurance Funds in 1993 brought changes to the system, and Mutual pension funds came into force. The role of these funds is still marginal compared to the national scheme, but more and more employers and employees find these schemes attractive, both in the state and private sectors.

\section{Pension Rights and Retirement Age}

The retirement age in Hungary is 60 for men and 55 for women. Those who have reached this retirement age and have 20 years of service are entitled to full pension. Those who do not have 20 years of service but have more than ten years are entitled to partial pension. People in specific occupations mainly with high risk to health - are entitled to early retirement. The retirement age for state employees is the same as for other categories of employees.

\section{Calculation of Old-Age Pension}

The old-age pension in Hungary is benefit-defined with the amount based on the length of service and the final salary. The amount of the pension after ten years of service is 33 per cent of the average net salary in the last seven years. The replacement ratio after 30 years of service is 68 per cent.

The following periods are taken into account in defining the length of service:

- employment (also self-employment);

- membership in a corporative body;

- military service;

- period with sick pay, child care allowance, child care benefit; and

- one course at University or college.

Leave of absence is defined as part of the service when this leave has a specific reason (care for sick family member, house building). 


\section{Invalidity Pension and Survivors Pension}

Civil servants are covered by the national invalidity pension scheme. The entitlement is conditioned by a certain period of service, which varies by age group. The amount of the invalidity pension is defined by the degree of invalidity, the length of service, the age and the final salary. The maximum amount is 63 per cent of the final salary.

The widow's pension is provided to a husband/wife if his/her deceased spouse has attained the service period required for old-age (or invalidity) pension or was entitled to old-age (or invalidity) pension. The widow's pension is permanent if the survivor has reached the retirement age or is invalid or has at least two dependent children. Otherwise, the benefit is temporary, provided for one year. The amount of the widow's pension is half of the deceased's old-age or invalidity pension. The entitlement conditions for the orphan's benefit is similar to the widow's pension, but the amount is half.

\section{Termination and Change of Employment}

Because of the general nature of the national pension, entitlements are transferable between institutions, branches and sectors.

In case of termination of civil service, the employee is entitled to severance pay equivalent to 12 months of salary after 20 years of service.

\section{Payment of Benefits and Early Retirement}

There is a possibility of early retirement - especially in the state sector - for people who are no more than five years from their retirement age. The condition for benefit entitlement is 30 years of service for men, and 25 years for women.

The Social Insurance Act declares that the pensions should follow the growth of the average net wages, but the actual figures and details of the indexation are to be decided by the Parliament.

\section{Legislation, Financing and Administration}

The 1975 Act on Social Insurance and its modifications define the pension scheme. The details are regulated by government decrees.

The employer pays 44 per cent of wages as social insurance contribution. Out of the 44 per cent, 24.5 per cent go to the pension fund, and 19.5 per cent go to the health fund. The employee should pay 6 per cent for pension, 4 per cent for health insurance. Altogether the pension system is financed 30.5 per cent by contributions, the rest by taxes.

\section{Reforming the Pension Scheme}

Recently there have been changes in the rules of calculation but not in the basic structure of the system. There are proposals to introduce major changes in the whole structure of the pension system. The main points of the reform ideas are: 
- decreasing the contribution rate (25 per cent instead of 30.5$)$;

- channelling part of contribution to a fully funded scheme;

- cutting pension expenses by increasing the retirement age (with the goal of 62 years for men and women alike); and revising the assessment procedure for invalidity pensions.

The planned pension would contain an earnings-related basic pension, financed by employer contributions. The amount of this pension would be less than the recent old-age pension and would be contribution defined. There would be a compulsory fully funded part, financed by individuals' contributions, proposed at 10 per cent of the gross earnings. Voluntary pension savings could be paid into special funds besides the compulsory schemes.

The proposed pension reform is subject to political debate. The government itself has not yet decided what kind of changes it will support and how these can be implemented. The autonomous pension fund management does not agree with the ministries on certain questions. It seems that the lack of political agreement is slowing down the reform of the pension system.

\section{Latvia}

\section{Current Pension Scheme}

There is a common national pension scheme in Latvia. Employees in all sectors are subject to one scheme without any special provisions for specific groups. The current pension scheme covers all kinds of staff and all categories in the state administration.

In accordance with the current pension scheme, there are the following kinds of pensions:

- labour pensions (old-age, invalidity, survivors, seniority); and

- social pensions.

Soldiers and officers of Interior Ministry institutions and retired soldiers of National Armed Forces are subject to a special occupational pension scheme.

\section{Pension Rights and Retirement Age}

The right to a pension is based on the official retirement age and on length of service. The general retirement age is:

- 60 years for men (if the length of service is at least 25 years); and

- 55 years for women (if the length of service is at least 20 years).

There is no maximum retirement age. Retirement age can be lower and length of service can be shorter for special groups of people, such as invalids, women who have more than five children or whose children are invalids, blind people, and people who have seniority pensions.

\section{Calculation of Old-Age Pension}

The calculation of pensions is based on the length of service and average salary per month of state employees during the last quarter prior to retirement. The pension promise is defined as a benefit. 
The required length of service to become eligible for a full pension is different for different groups of people.

The pension consists of a basic pension plus a supplementary pension. The basic pension is 30 per cent of average salary. The supplementary pension is 10 per cent of average salary divided by 25 and then multiplied by the length of service of a pensioner. The maximum length of service that can be taken into account when calculating a supplementary pension is 38 years.

For example:

The length of service is 38 years.

The average salary is Ls 82.35 (lats).

1)30 per cent of Ls $82.35=$ Ls 24.70 . The basic pension is Ls 24.70 ;

2) 10 per cent of Ls $82.35=$ Ls 8.23 . Ls $8.23 \div 25=$ Ls 0.32 .

Ls 0.32 x $38=$ Ls 12.51 . The supplementary pension is Ls 12.51;

3)The total pension is: Ls $24.70+$ Ls $12.51=$ Ls 37.21 .

\section{Invalidity Pension and Survivor's Pension}

The invalidity pension is calculated accordingly: social pension plus $20-40$ per cent of the basic pension (depending on the group of invalidity). The minimum invalidity pension is 70-100 per cent of the official minimum wage.

The survivor's pension consists of the social pension and supplementary pension. The supplementary pension is calculated as 40 per cent of the supporter's earnings for each disabled member of the family. The supplementary pension cannot exceed the survivor's average earnings.

The social pension is $50 \%-100 \%$ of the official minimum wage.

\section{Termination and Change of Employment}

A state employee is not entitled to any benefits if his/her employment is terminated before retirement age. The value of pension benefits defined by legislation remains intact before payment at retirement age and depends on average salary.

\section{Payment of Benefits and Early Retirement}

In accordance with legislation, pensions are assigned and paid by social maintenance institutions.

Special occupational groups have different retirement ages and it is impossible to draw an old-age pension before retirement age. Not all pension benefits are lifelong. Some of them can be revised, as, for example, a survivor's pension.

\section{Legislation, Finance and Administration}

The existing pension scheme is Latvia is defined by the Law On State Pensions, by the Law On Temporary Procedure of Calculation of State Pensions, by the Cabinet Regulations On Seniority Pension and by regular orders of the Ministry of Welfare On Increasing the Value of Pensions. 
The current pension scheme is financed by the annual state budget. Income from a social tax constitutes the basis of social benefits payment. The rate of social tax is 38 per cent of earnings, with 37 per cent paid by the employer and 1 per cent by the employee.

The pension scheme is administrated by the Ministry of Welfare.

\section{Problems of Creating a New Civil Service Pension Scheme}

The Law On Civil Service stipulates that civil service pensions are calculated by the Law On State Pensions. This Law also states that a person has rights to other pensions (employer's pension, personal pension insurance, etc.), that are not state pensions.

In February and March of 1995, the Institute of Labour Research and Science of Latvia carried out a study on "Non-governmental Pension Funds and Accumulations of Supplementary Pensions", ordered by the State Civil Service Administration.

On the basis of 830 responses to this study, the following conclusions were made:

- The majority of civil servants are not satisfied with the current scheme;

- 20 per cent of civil servants are willing to start contributing to supplementary pensions this year. Another half of the respondents agree to develop contributions to supplementary pensions, depending on additional information;

- Civil servants would like to receive information either by mail or in the mass media. They would not refuse the opportunity to participate in seminars;

- The majority of respondents would not like to make contributions to supplementary pension independently from the employer;

- Approximately one half of employees would like to receive credit based on supplementary pension accumulations to buy homes, cars, furniture or other necessities. One third would like to pay a part of the contributions themselves, with the other part to be paid by the employer;

- Civil servants would be willing to pay one-third of monthly contributions each month; and

- As a main precondition for security of the pension fund and deposited money, civil servants would accept supervision by the State Control Office, backed by equity capital of the pension fund.

\section{Lithuania}

\section{Current Pension Schemes}

State employees are subject to general (common) social insurance pension schemes. Special pension schemes exist for military, police, security and prosecution services:

- The general social insurance scheme is common for all employees;

- The "military" scheme is complementary to the common national pension scheme; 
- There are no special provisions in the common national scheme for state employees;

- The general scheme covers all kinds of staff and occupations;

- There are no special pension schemes for employees, except for one (temporary), which is for scientists employed in state scientific institutions.

\section{Pension Rights and Retirement Age}

The basic requirements under the general scheme are:

- Age of 60 years for women and 62.5 for men (steadily increasing from 55 for women and 60 for men, which was the retirement age before 1995);

- For minimal pension - 15 years of employment;

- For full pension - 30 years of employment (steadily increasing from 20 years, which was the required length of service before 1995);

- General retirement age is the same for all employees;

- Special regulation for "military" service schemes - earlier retirement by statutes of service.

\section{Calculation of Old-Age Pensions}

The calculation of the pension is based on length of employment (service) and 25 years of the highest salary. Calculation based on final salary and length of service is also applied to the complementary "military" scheme:

- The scheme is benefit defined;

- Every kind of service and employment under labour contract is taken into account;

- Periods of service outside the state administration are taken into account.

The approximate ratio between average old-age pension and average salary is 45 per cent (less for higher salaries, more for lower salaries).

\section{Invalidity Pension and Survivor's Pension}

Invalidity, orphans, and widows/widowers pensions are included in the general scheme. There are no provisions for early retirement, except for the military.

Basic requirements for disability pension are disability confirmed by a competent institution and required length of service (employment) according to the age of the disabled person. If a deceased person had required length of service (same as in the case of disability), the widow/widower is entitled to pension if she/he has children (less than 18 years old) with the deceased person, or if she/he will reach retirement age in five years or lessor less; an orphan is entitled to retirement pension if he/she is younger than 18 or was disabled before this age.

Invalidity pensions are calculated like old-age pensions, prolonging the years of service by the disabled person until his/her retirement age. Widow and orphan pensions are calculated like the invalidity pension and divided between the widow/er ( 50 per cent) and the children. 


\section{Termination and Change of Employment}

Civil servants or state employees are entitled to severance pay like any other employees.

Pension rights are transferable: employment under labour contract in every branch, sector or institution is treated in the same way.

The value of pension before payment is calculated according to "points" (coefficients) for every year. These "points" are not adjusted but collected year by year.

\section{Payment of Benefits and Early Retirement}

Pensions are paid by the Social Insurance Fund Administration. Military pensions are paid by special divisions in the Ministries of Defence, Internal Affairs, etc.

No old-age pension benefits can be received before retirement age, except for military personnel.

It is possible to get invalidity pension before retirement age.

Old-age pension is lifelong. Disability pension is paid as long as the disability lasts. Orphan pension is paid until the orphan reaches 18 years old (if he/she is a student, 24) Sickness and maternity benefits are temporary.

Pensions are periodically adjusted: the basic part is adjusted according to price index and by special Government decree, and the supplementary part is adjusted according to the average wage in the country and automatically by decision of Social Insurance Fund. Pension by "military" scheme is adjusted when salaries for military, police and other service are increased.

\section{Legislation, Financing and Administration}

The main legislation is the Law of State Social Insurance Pensions (1995).

The system is financed on a pay-as-you-go basis by the Social Insurance Fund, which is separated from the state budget. "Military" scheme is financed by State budget.

The employer pays 30 per cent and the employee 1 per cent of gross salary.

The contribution rate is calculated according to the evaluated benefit-defined expenditures for a year.

The pension scheme is administrated by Social Insurance Fund.

\section{Reforming the Pension Scheme}

The new pension system was established from 1 January 1995.

A scheme for supplementary pension insurance (voluntary pension funds) is in preparation. Professional pensions are also on the agenda. 
The main obstacle to supplementary (funded) pension insurance is the high level of taxation and the low incomes of the majority of the population. It leaves little possibility for saving.

\section{8. $\quad$ Poland}

\section{Current Pension Schemes}

Three main national pension schemes exist in Poland. They are for:

- employees, covering all kinds of employees, both in the public and private sectors;

- farmers (benefits in this scheme are financed from a separate fund administered by the Agricultural Social Insurance Bank); and

- uniformed services (police and military officers); their benefits are paid on the whole from the state budget.

State employees are subject to the common employees scheme, as there is no special regulation for them. However, special rules regulate the situation of some professional groups, such as miners or railwaymen. The description of the common employees pension system contains regulations concerning state employees.

\section{Organisation and Financing of Pensions in the Employees System}

Benefits are financed from the FUS (Social Insurance Fund). Its income comes from compulsory contributions paid solely by employers at the level of 45 per cent of wages and from state transfers. Social benefits payments of all kinds are guaranteed by the state budget. Currently state transfers cover about 15-20 per cent of total FUS expenses.

The ZUS (Social Insurance Institute), which is an organ of the central state administration, manages the FUS, collects contributions, makes decisions on individual pension benefits and pays them.

\section{Pension Rights}

An employee is entitled to the old-age pension if he/she meets two requirements:

- retirement age (generally 60 years for women and 65 for men); and

- insurance period (at least 20 qualifying years for women or 25 for men).

Because there is one central Social Insurance Fund, changes in place of employment do not affect rights to a pension or its level.

\section{Calculation of Old-Age Pension}

The old-age pension is composed of two parts:

The first part depends neither on the length of the insurance period, nor on the earnings (income) from which social insurance contribution is to be paid; each retiree is entitled to 24 per cent of the base amount. The insurance period includes all periods covered by the obligation of paying social insurance 
contributions (contributory periods) and other periods envisaged in legal provisions and not covered by the obligation to pay social insurance contributions and which affect the right to or the rate of benefits ("non-contributory" periods). Some exceptions exist in calculating the level of pension concerning professional groups mentioned above.

The second part is proportional to the insurance period (1.3 per cent of the calculation base for each contributory period and 0.7 per cent of the calculation base for the non-contributory period). The calculation base of the benefit may not be higher than 250 per cent of the average wage, despite payment of contributions on higher earnings.

\section{Invalidity Pension and Survivor's Pension}

Apart from old-age pensions, the pension system includes other benefits such as the invalidity pension, widow's/widower's pension, orphan's pension and early retirement.

Basic requirements for acquiring the right to the invalidity pension are:

- one of three groups of invalidity, granted by the medical board for disability and employment;

- length of insurance period (depending on age); and

- invalidity must occur during employment or 18 months after the end of employment.

This pension is paid according to the same regulations as the old-age pension.

The widow's/widower's pension and orphan's pension can be granted upon death of insured employees, who fulfil the conditions required for an old-age pension or disability pension.

A widow/widower is entitled to a pension if:

- he/she is at least 50 (women) or 65 years old (men);

- he/she is an invalid; or

- takes care of children who are under the age of 16.

An orphan or dependent has the right to a pension if:

- he/she is up to 16 years old or until graduation (but not older than 25); or

- he/she is an invalid.

The amount of these two pensions is a fixed percentage of the benefit calculated for the insured employee as if he/she were alive.

Many groups may claim early retirement. In most cases the right to early retirement is treated as an equivalent for the conditions of work and loss of health in the course of economic activity.

Base amount: in 1991-1992, the average wage in the national economy in the quarter for which the remuneration was the basis for benefit indexation.

From 1 January 1993 to the end of May 1994 it amounted to 91 per cent of the above mentioned wage, and from 1 June 1994 to 93 per cent of this wage. 
Calculation base of benefits: in 1995, the average wage or the calculation base of contributions of six consecutive years selected by the person concerned from 15 years preceding the year of applying for the benefit.

In future years the period of today's six years is increased by one year each year, up to ten consecutive years in 2000. At the same time, the period from which this wage is selected is extended gradually to 20 years.

\section{Indexation of Old-Age and Disability Pensions}

Old-age and disability pensions are increased in relation to the growth rate. Every quarter the increase in the average wage is determined in relation to the quarter preceding the last indexation. If wages rise by at least 10 per cent, indexation of benefits takes place according to actual wage growth.

At the end of 1994, in order to reduce the Social Insurance Fund deficit, a different method of indexation was proposed, based on the principles of maintaining the purchasing power of a benefit (price related indexation).

\section{Payment of Benefits}

Most pension benefits are paid until death but in certain circumstances they may be suspended. Orphan's/dependant's pensions are usually temporary.

Legal provisions allow for combining old-age pensions with limited income from work. Incomes not exceeding 60 per cent of the average wage do not affect old-age pension payment. When this limit is exceeded, the old-age pension is decreased by the "social part" (24 per cent of the base amount), and when earned income is 120 per cent of the average wage, the old-age pension is suspended entirely.

\section{Reforming the Pension Scheme}

The Ministry of Labour and Social Policy is working on a project of reform of the Social Insurance System. Basic assumptions of the reform follow:

\section{The Minimum: The State Pension}

Each citizen, who has fulfilled specified conditions, receives the state pension, paid out from the state budget. In the beginning, this is equal to not more than 30 per cent of the average wage, and in future years the pension will retain the purchasing power of the initial level.

The state pension will make up the first level of the pension benefit, which will contain all the current non-insurance components (the "social" part and the non-contributory periods).

The state pension will replace the following existing benefits:

- exceptional pensions;

- fixed benefits (social pension) from social assistance;

- family allowances and other non-insurance benefits. 


\section{More: Social Insurance Pension}

Each person who has worked for at least 15 years (and has paid social insurance contributions during this time), will receive, in addition to the state pension, a social insurance pension. The amount of this pension is directly proportional to the number of years a contribution has been paid and the level of income covered by the contribution, with a rate for each insurance year of 1.1 to 1.25 per cent of the insured person's remuneration. The specific amount of this index will depend on the self-financing capacity of the system.

The new old-age pensions will be paid out only from funds derived from contributions within the self-financing system,

After the reform, non-contributory periods, which are currently taken into account, will disappear. They will be replaced with the state pension, which will also replace the "social part" of the current old-age pension. Non-contributory periods include vacation leave and higher education.

\section{Still More: Supplementary Old-Age Pension}

Apart from the compulsory insurance, organised by the State, opportunities for supplementary social insurance schemes will be created. Whoever can afford to pay a supplementary contribution will be able to secure himself higher income during retirement later on. Individual establishments or entire branches would also be able to benefit from such a system. The supplementary contribution would be invested to generate income. Specialised insurance firms and institutions would deal with investment of contributions, under state supervision. Everyone would be able to select the firm that suits him best.

In the beginning, the more affluent citizens could benefit from these social insurance schemes.

The State will create legal provisions defining the principles of the funds' functioning, and define tax relief for participants of supplementary insurance schemes. The funds would be obliged to establish guaranteed funds for themselves against insolvency (reinsurance).

At present, many firms have appeared on the Polish insurance market, both Polish and foreign, and many people invest their savings there. However, with the exception of a few, these firms are not certified by the Ministry of Finance and in case of bankruptcy, there is no guarantee of recovering money that has been invested. The law also does not prohibit the creation of pension funds by individual branches and enterprises. Without a system of supervision and guarantees, supplementary insurance schemes may prove risky.

Supplementary old-age pensions can be serviced by institutions with various organisational-legal structures. Depending on the adopted legal regulations, these can be large enterprises which would not entrust servicing of a supplementary pension scheme to an external institution, but would manage this fund themselves through a system of book reserves. This system offers the best possibilities - with supervision - for making use of accumulated capital for investing in the firm itself. However, it also creates the risk of capital loss in case of the enterprise's bankruptcy.

Decisions concerning the principles of investing resources (assets) on the capital market would be supported by special regulation. This would apply to the share of state securities, or limitation of fund resources investment in investment projects of the enterprise which is the founder of such a fund.

Pension funds may also be serviced by external institutions, e.g., enterprises, mutual insurance societies, non-profit foundations. 
Pension investment funds will also be created on the basis of some of the privatised state-owned enterprises, contributing to social insurance finances.

\section{Implementing the New System}

The elements of the new system will be introduced gradually, yet as a cohesive whole, and in a manner so that today's pensioner's will not be at a disadvantage. This cannot be carried out without new rules for the current benefits indexation.

Old-age pensions will continue to rise in relation to wages, but they will be modified in two ways. In per cent, the indexation will be lower than the average wage increase, but the index of the base amount will rise by one percentage point with each indexation - from the current 93 per cent of the average wage to 100 per cent. This process will begin with the first indexation in 1996. There will also be a comparison with the rise of prices; in order for old-age pensions to maintain real purchasing power, they cannot rise more slowly than prices.

The pace of transition to the new system will depend on the growth rate of real wages.

\section{Indexation After the Reform}

The real value of the state pension should be guaranteed in order to accentuate the influence of rising income from work on the benefit rate, to lower the share of the state budget in financing social insurance, and to deepen the insurance character of the system.

For this purpose, the state pension should be adjusted according to the index of price increase laid down in the budget act for the given year. Any difference in the index between the plan and its execution would be corrected in the following year. The universal state pension will be a benefit paid out from state budget resources (the current subsidy to social insurance and part of resources collected in the form of a contribution to the Social Insurance Fund) and a benefit fully guaranteed by the State. With economic growth, the proposed price indexation of this benefit will lead to reduced encumbrance of the budget.

It is proposed that benefits paid out from insurance systems or provision systems be adjusted according to a suitably modified growth rate of the average calculation base of social insurance contributions. This modification should depend on the fluctuations of the number of insured persons and the number of beneficiaries. The mechanism, based on these parameters, will create conditions for maintaining the principle of self-financing of the insurance fund.

\section{The Basic Principles of Social Insurance}

The social insurance will remain compulsory and universal. As before, irrespective of how much a person has been earning or how long he has worked, his old-age pension may not be calculated on a base higher than 250 per cent of the average wage. Even if a person has earned three times the national average wage, the old-age pension would be calculated on 2.5 times the average wage.

The highest amount on which a contribution will have to be paid will be 250 per cent of the national average wage. If someone earns more, he will not have to pay a contribution on the amount over 250 per cent. Even though a person pays the contribution today, it will not effect the level of his old-age pension later on. 
In the future this threshold will be lowered, so that more people can have additional insurance and labour costs are reduced.

A floor for the lowest income on which the compulsory contribution can be collected will be established. This will be the amount of the minimum wage (currently z1.280).

If someone is not covered by social insurance but would like to arrange a pension scheme, he can be insured at his own request so that insurance period continuity can be maintained. This can apply to women caring for children up to the age of four, persons who have taken unpaid leave or who are unemployed without the right to an unemployment benefit.

\section{Pension Rights and Retirement Age}

A person who has reached retirement age and has worked for at least 15 years will be eligible for a pension.

Earlier retirement and other privileges for branches will be maintained, but only when they have been "bought out" through a raised contribution. The new pension fund will not additionally pay, as is the case now, from the pool of all contributions. Similarly, if a non-contributory period is to be included in the period of employment - e.g. general military service or a combat period - then the contribution will have to be paid by an appropriate institution. Gradually, over ten years, the retirement age of women may be extended from 60 to 65 years.

Women, who have completed a 20-year insurance (contributory) period when the new regulations become effective, will be eligible for retirement after reaching the age of 55, on the condition that they have completed a 30-year insurance period.

\section{Benefits Calculation}

It is already known that the new old-age pension scheme will consist of the state pension and a benefit that will depend on the employment period and income covered by the contribution. At present, for the purposes of the old-age pension calculation, six consecutive years can be chosen from the last 15 years before retirement. Next year this will be seven from 16 years, up to ten years from 20 in the year 2000 . After the reform, however, earnings from the 20 most favourable years of the entire employment period can be chosen. If, however, in any year the retiree had been insured for less than 6 months, that year will not be counted for him. Naturally, if someone has not worked a 20 -year period, his old-age pension will be calculated on the earnings from the entire insurance period.

\section{$\underline{\text { Work During Retirement }}$}

After the reform, if a retiree, takes up work, he will lose the right to a state pension, and the old-age pension would be decreased depending on the income level. ZUS will suspend the pension if together with the income from work it exceeded 100 per cent of the calculation base of the old-age pension. If, then, the base of calculation is zl. 1500 and the old-age pension zl. 1000 , the retiree may earn an additional zl. 500.

Because people earn little and benefits are low, a principle might be introduced for a limited period which would allow retirees to earn additional income - but not more than the minimum wage without suffering any consequences. 
Work during retirement will continue to be covered by the insurance obligation, that is, it will be included in the employment period and therefore will affect the old-age pension amount. The principle may be introduced that after 40 years of work, employment during retirement has no influence on the amount of the old-age pension.

\section{Old-Age Pension Like a Puzzle}

The old-age pension can be constituted from employment with different employers, and will "link together" the different parts. For example, if someone were a policeman for ten years, worked on a farm for ten years, and for ten years held a position at the Ministry of Finance, he would receive the state pension and partial benefits from each of these systems corresponding to the 10-year insurance period, adding up to a 30-year insurance period in total.

However, the old-age pension could not be received simultaneously from several systems for the same years of employment. If someone is a farmer and at the same time works in a factory, he has to choose whether he is to be insured as a farmer or as a factory worker.

\section{Disability Pensions}

The principles of granting disability pensions will be changed. At the moment the right to these depends first of all on the damage to health and not on the ability to acquire income from work.

After the reform, a pension would essentially be granted to people who are incapable of performing work in previous conditions. This means that these persons would be able to perform work in conditions specially adapted to their disability. Those who show hope of improvement will receive a pension only for a definite time. At the same time, patients would undergo rehabilitation as early as possible.

\section{New Way of ZUS}

ZUS will acquire public-legal status and the attributes of an insurance institution. To a broader extent than now it will acquire the capacity to make decisions concerning revenues from contributions and payment of benefits.

Its supervisory board will consist of representatives of employers, the insured and the state administration in equal shares.

It will be necessary to introduce individual records of the insured, as the new tasks are based on individual information on each insured person (accounts of the individual record of insurance).

\section{Slovak Republic}

\section{Current Pension Scheme}

The pension scheme, like virtually all other national social security schemes, provides old-age, invalidity and survivor's pensions. State employees are subject to this general pension scheme.

Current pension conditions vary according to type of work and are split into three categories:

- category I - mainly miners, but also aircraft personnel and some other professions; 
- category II - mainly those exposed to contagious diseases, radioactive or toxic materials or other health endangering environments;

- category III - all other occupations; about 90 per cent of employees are in this category.

\section{Pension Rights and Retirement Age}

Normal pension age is 60 for men. Persons having worked a defined number of years in particularly hazardous jobs can retire one to five years earlier, depending on the type of work (this concerns mainly professions listed as category I). For women it varies depending on the number of children raised and decreases one year per child from 57 (with no children raised) to 53 (five children or more raised).

Employees (men and women) are eligible for a full pension after 25 years of service.

Partial pension can be granted to persons with less than 25 years of service, to men at age 65 with a minimum of ten years of service, and to women at age 60 with minimum of 20 years of service.

\section{Calculation of Old-Age Pension}

Full pension of 50 per cent of the reference incomes is due after 25 years of service. The replacement rate is increased by one percentage point for each year of service after 25 up to a maximum pension.

Partial pension is calculated as 2 per cent of the reference income per each year of employment.

Reference income is defined as the average of the highest five of the last ten annual earnings of a beneficiary. Monthly reference earnings are defined as the sum of percentages of three income bands: i.e. 100 per cent of the first $2500 \mathrm{Sk}, 33.33$ per cent of income between 2501 and $6000 \mathrm{Sk}$ and 10 per cent between 6001 and $10000 \mathrm{Sk}$. Income in excess of $10000 \mathrm{Sk}$ is not taken into account.

Certain professions (pilots, artists) are eligible for special, higher pensions.

\section{Invalidity Pension and Survivor's Pension}

Invalidity pensions are paid at two different rates depending on the degree of incapacity, i.e. at a rate of full old-age pension (calculation includes credited insurance years covering period between event of invalidity and normal retirement age) or at a rate of 50 per cent for partial invalidity.

Widows' pensions are paid at a rate of 60 per cent and orphans' pensions at a rate of 30 per cent of the pension entitlement of the deceased breadwinner per dependent. A widow is entitled to receive a widow's pension for one year after the death of her husband unless she is disabled or has at least one dependent child or at least raised three children, or is older than 45 and raised two children, or is older than 50 .

A widower is eligible for a widower's pension if he has at least one dependent child. 


\section{Termination and Change of Employment}

Employees are not entitled to any immediate benefits if his/her employment is terminated before retirement age. They are entitled to receive benefits from another system like the unemployment benefit system, social and family benefits, and so on.

Pensions should be adjusted when the cost of living increases by ten per cent or the average wage increases by five per cent since the last adjustment of pensions, but not earlier than three months after the last pension adjustment.

\section{Payment of Benefits and Early Retirement}

The administration of the pension has been separated from the state and commissioned to the Social Insurance Company, which was largely built on the administrative infrastructure of the former Slovak Pension Office.

There are some special conditions for drawing old-age pension benefits before retirement age, such cases of bankruptcy, but the maximum is two years before.

\section{Legislation, Financing and Administration}

The majority of social protection benefits, including social security pension benefits, are still regulated by the Law on Social Security passed by Parliament on 16 June 1988 (Law 100/1988 with complements).

Until 1992 the financing system was the classical payroll system. Contributions were booked on a separate account but the account had a direct link to the general state budget. Since then, social security has been separated from the state budget.

The following contribution allocation was introduced in January 1993:

- contribution of employers 20 per cent of payroll/income and of employees 5.9 per cent;

- reference income for contribution of wage and salary earners is previous month's sum;

- pension insurance contributions are not paid for persons employed in the Ministry of Defence, Ministry of Interior, Ministry of Justice and Slovak Information Service;

- for employees of all budgetary organisations, social insurance contributions are paid only in the total amount assumed each year within the state budget.

The pension scheme is funded.

The SIC is governed by a tripartite Board of Representatives composed of representatives of the government, representatives of employers and representatives of insured persons (trade unions). Members of the Board of Representatives are nominated by Parliament out of the list of candidates proposed by respective organisations. 
The Pension scheme is administered by the Social Insurance Company, the Ministry of Defence and the Ministry of Interior.

\section{Reforming the Pension Schemes} pension schemes.

There are plans in Slovakia for further reforms concerning the creation of complementary

\section{Slovenia}

The pension and disability insurance in Slovenia is regulated by the law on pension and disability insurance (Official gazette of the Republic of Slovenia No. 12/92) which has been applied since 1 April 1992. This law represents the first entirely independent legal regulation of the insurance system in Slovenia as an independent state. However, it should be stressed that this regulation is not entirely new because the specifics and the long-term character of the pension and disability insurance system were taken into consideration by the legislator so that continuity of the system has been preserved. of Slovenia.

The bearer and implementer of this insurance is the Institute for Pension and Disability Insurance

The resources for pension and disability insurance are provided by insurees and employers through the contributions of salaries or insurance bases in the ratio 50:50.

The contribution rates for insurees and employers are defined by the Parliament of Slovenia. At the moment, the contribution rate for the entire range of rights is the same for insurees and employers and totals 15.5 per cent of wages for each side.

The forms of pension and disability insurance are laid down by law:

- compulsory insurance based on work and the principles of mutuality and solidarity;

- voluntary joining the scheme of compulsory insurance; insurance.

- supplementary voluntary insurance for an additional range of rights within compulsory

The rights arising from compulsory insurance are: old-age pensions, disability pensions, survivors' pensions, early benefits, part benefits, supplementary allowances to a benefit, disability grants, dependent allowances, refund of travel and furniture removal expenses, indemnity and maintenance grants for a widow/widower, pensioners' recreation grants, active rehabilitation of the disabled, assignment to another appropriate position or employment in part-time job and corresponding allowances from disability insurance.

A Civil Service Pension Scheme does not exist in our pension system and there is no special scheme for state employees.

The main characteristics of our pension and disability insurance system are as shown in the following tables: 


\begin{tabular}{|c|c|c|}
\hline \multicolumn{3}{|l|}{ System Parameters: } \\
\hline \multicolumn{3}{|l|}{ NORMAL RETIREMENT PENSIONS } \\
\hline PENSION TEMPLATE & YEAR 1995 & CHANGES SINCE 1987 \\
\hline \multicolumn{3}{|l|}{ Males } \\
\hline Retirement age & $\begin{array}{l}\text { 1. Age } 62 \text { - min. } 20 \text { years of insurance period; } \\
\text { 2. Age } 65 \text { - min. } 15 \text { years of insurance period; } \\
\text { 3. Age } 56.5 \text { years for } 40 \text { years of insurance period. } \\
\text { (Age limits are lower for extremely difficult work conditions) } \\
\text { (Age limit for category } 1 . \text { will increase for one year during ' } 96 \text { and '97) }\end{array}$ & $\begin{array}{l}\text { 1st category: } 60 \text { years. } \\
\text { 3rd category: } 40 \text { years of insurance } \\
\text { without age limit. }\end{array}$ \\
\hline Minimum insurance periods & 15 years. & \\
\hline \multicolumn{3}{|l|}{ Females } \\
\hline Retirement age & $\begin{array}{l}\text { 1. Age } 57 \text { - min. } 20 \text { years of insurance period; } \\
\text { 2. Age } 60 \text { - min. } 15 \text { years of insurance period; } \\
\text { 3. Age } 51.5 \text { - } 35 \text { years of insurance period. }\end{array}$ & $\begin{array}{l}\text { 1st category: } 55 \text { years. } \\
\text { 3rd category: } 35 \text { years of insurance } \\
\text { period without age limit. }\end{array}$ \\
\hline Minimum insurance periods & 15 years. & \\
\hline $\begin{array}{l}\text { Other criteria (i.e. specify special pension } \\
\text { categories) }\end{array}$ & Military servants, policemen, war veterans, miners. & $\begin{array}{l}\text { After } 1987 \text { for a short period special } \\
\text { pension treatment was provided also } \\
\text { for ministers and members of } \\
\text { parliament. }\end{array}$ \\
\hline \multicolumn{3}{|l|}{$\begin{array}{l}\text { Benefits } \\
\text { Males and Females }\end{array}$} \\
\hline \multicolumn{3}{|l|}{$\begin{array}{l}\text { Formula or schedule for calculation of } \\
\text { benefits }\end{array}$} \\
\hline Checklist: Accrual rates & $0.85 \%$ of pension base. & \\
\hline $\begin{array}{l}\text { Pension base (net or gross wages, } \\
\text { contribution periods) }\end{array}$ & $\begin{array}{l}\text { Net wage: } 10 \text { best years, recalculated to the average of the last completed } \\
\text { year of insurance. }\end{array}$ & \\
\hline $\begin{array}{l}\text { Indexation of base (price or wage } \\
\text { growth) }\end{array}$ & Recalculated wage growth (from gross to net). & \\
\hline $\begin{array}{l}\text { Indexation of benefits (price or wage, or } \\
\text { none) }\end{array}$ & Wage growth. & \\
\hline Maximum pension & $310 \%$ of average wage $+/-0.85$. & $350 \%$ of average wage $+/-0.85$ \\
\hline Minimum pension & $64 \%$ of average wage $+/-0.35$ (female), $+/-0.40$ (male). & \\
\hline $\begin{array}{l}\text { Supplementary pension (means tested } \\
\text { income supplement for pensioners) }\end{array}$ & $\begin{array}{l}\text { Supplement if pension is lower than minimum pension for } 40(35 \mathrm{~F}) \text { years } \\
\text { of insurance period. }\end{array}$ & \\
\hline $\begin{array}{l}\text { Tax on Benefits } \\
\text { (if yes, specify type and rate) }\end{array}$ & $\begin{array}{l}\text { The sum of already allocated monthly income tax is subtracted from the } \\
\text { income tax, calculated for the annual gross pension and incomes. The } \\
\text { difference is paid as real income tax. }\end{array}$ & $\begin{array}{l}\text { There was no taxation on pensions } \\
\text { until income tax system was } \\
\text { established in } 1991 .\end{array}$ \\
\hline Other Benefits & Holiday bonus. & \\
\hline \multicolumn{3}{|l|}{ Duration of Benefits } \\
\hline Length of time benefits can be received & No limit. & \\
\hline $\begin{array}{l}\text { Can pensioners work? (yes, no) - if yes, } \\
\text { how are benefits reduced? }\end{array}$ & $\begin{array}{l}\text { No, if employment relation is tied to compulsory insurance. Exception: } \\
\text { registered inventors, artists and farmers. }\end{array}$ & \\
\hline $\begin{array}{l}\text { Can pensioners postpone pensions after } \\
\text { reaching retirement age? (yes, no) - if yes, } \\
\text { how are benefits calculated? }\end{array}$ & Yes. & \\
\hline \multicolumn{3}{|l|}{ Financing } \\
\hline \multicolumn{3}{|l|}{ Tax Type (land, payroll, etc.) } \\
\hline \multicolumn{3}{|l|}{ Tax Rate (on gross or net wages, incomes) } \\
\hline Are Contributions Tax Exempt? & Yes. & \\
\hline Payment System (monthly, yearly) & Monthly. & \\
\hline Budget Financing (yes or no) & No. & \\
\hline $\begin{array}{l}\text { Maximum Wage for Contribution } \\
\text { (contributions cap) }\end{array}$ & No. & \\
\hline $\begin{array}{l}\text { Minimum Wage for Contribution } \\
\text { (contributions floor) }\end{array}$ & Minimum wage. & \\
\hline
\end{tabular}




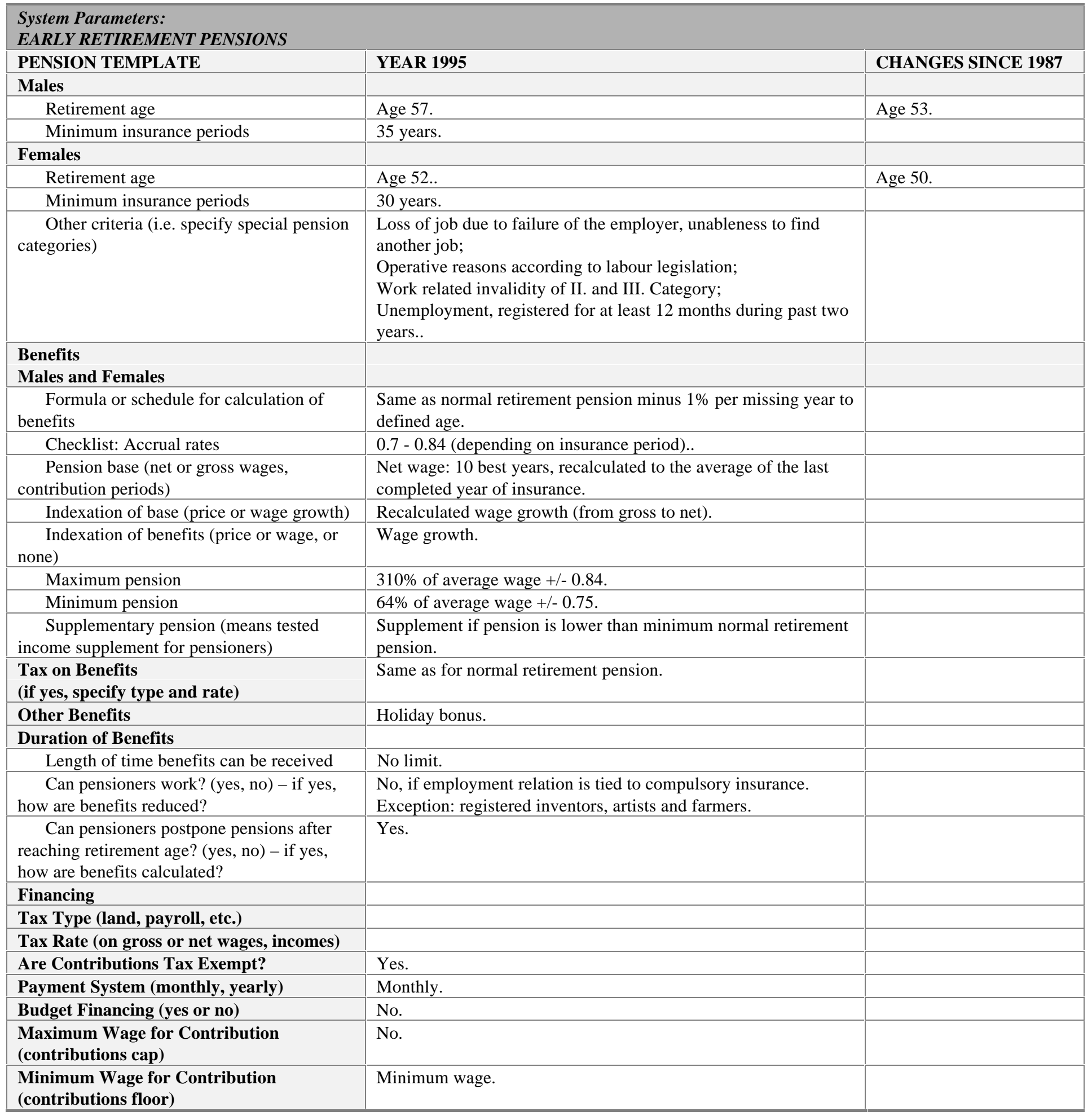




\begin{tabular}{|c|c|c|}
\hline \multicolumn{3}{|l|}{$\begin{array}{l}\text { System Parameters: } \\
\text { INVALIDITY PENSIONS }\end{array}$} \\
\hline & YEAR 1995 & CHANGES SINCE 1987 \\
\hline Eligibility & $\begin{array}{l}\text { Invalidity of category I; } \\
\text { Invalidity of category III, incapable for other adequate job } \\
\text { without vocational training, over age } 50(45 \mathrm{~F}) \text {; } \\
\text { Invalidity of category II in category III, capable for other } \\
\text { adequate job, but eligible to old-age pension; } \\
\text { Younger than age } 21 \text { if insured; } \\
\text { Between age } 21-30 \text { if employed at least } 1 / 4 \text { of working period } \\
\text { (23-30 for BD). }\end{array}$ & \\
\hline Males and Females & 26-equal & \\
\hline Retirement age & Not prescribed; depends on the age when invalidity occurred. & \\
\hline Minimum insurance periods & $\begin{array}{l}\text { Regardless to the insurance period: for work related injuries and } \\
\text { diseases; } \\
\text { one-third of working period after } 20 \text { years accomplished: for } \\
\text { other reasons and causes for invalidity. }\end{array}$ & \\
\hline $\begin{array}{l}\text { Other criteria (i.e. specify } \\
\text { special pension categories) }\end{array}$ & $\begin{array}{l}\text { Military invalidity of categories } 1 \text { to } 6 \text {, incapable of doing } \\
\text { his/her job more than one half of the daily working time. }\end{array}$ & \\
\hline \multicolumn{3}{|l|}{$\begin{array}{l}\text { Benefits } \\
\text { Males and Females }\end{array}$} \\
\hline $\begin{array}{l}\text { Formula or schedule for } \\
\text { calculation of benefits }\end{array}$ & $\begin{array}{l}\text { Same as normal retirement pension: for work related injuries and } \\
\text { diseases; } \\
\text { same as early retirement pension: other reasons and causes for } \\
\text { invalidity, but not less than } 45 \%(55 \% \mathrm{~F}) \text { of pension base before } \\
\text { reaching age } 63 \text { ( } 58 \mathrm{~F}) \text {, and not less than } 35 \%(40 \% \mathrm{~F}) \text { after } \\
\text { age } 63(58 \mathrm{~F}) \text {. }\end{array}$ & \\
\hline Checklist: Accrual rates & $0.35-0.85$ of pension base. & \\
\hline $\begin{array}{l}\text { Pension base (net or gross } \\
\text { wages, contribution periods) }\end{array}$ & Net wage. & \\
\hline $\begin{array}{l}\text { Indexation of base (price or } \\
\text { wage growth) }\end{array}$ & Recalculated wage growth. & \\
\hline $\begin{array}{l}\text { Indexation of benefits (price } \\
\text { or wage, or none) }\end{array}$ & Wage growth. & \\
\hline Maximum pension & Same as for normal retirement pension. & \\
\hline Minimum pension & Same as for normal retirement pension. & \\
\hline $\begin{array}{l}\text { Supplementary pension } \\
\text { (means tested income } \\
\text { supplement for pensioners) }\end{array}$ & $\begin{array}{l}\text { Supplement (5-20\% of pension base), depending on insurance } \\
\text { period and age. }\end{array}$ & \\
\hline $\begin{array}{l}\text { Tax on Benefits } \\
\text { (if yes, specify type and rate) }\end{array}$ & Same as for normal retirement pension.. & \\
\hline Other Benefits & $\begin{array}{l}\text { Compensation of the invalidity pension, when age conditions are } \\
\text { not fulfilled. }\end{array}$ & \\
\hline \multicolumn{3}{|l|}{ Duration of Benefits } \\
\hline $\begin{array}{l}\text { Length of time benefits can } \\
\text { be received }\end{array}$ & No limit. & \\
\hline $\begin{array}{l}\text { Can invalids work? (yes, } \\
\text { no) - if yes, how are benefits } \\
\text { reduced? }\end{array}$ & No. & \\
\hline
\end{tabular}




\begin{tabular}{|c|c|c|}
\hline \multicolumn{3}{|l|}{$\begin{array}{l}\text { System Parameters: } \\
\text { SURVIVOR PENSIONS }\end{array}$} \\
\hline PENSION TEMPLATE & YEAR 1995 & CHANGES SINCE 1987 \\
\hline \multicolumn{3}{|l|}{ Husband } \\
\hline Age of insured at time of death & Age 55 & \\
\hline $\begin{array}{l}\text { Type of pension of insured } \\
\text { (old-age, early or invalid) }\end{array}$ & $\begin{array}{l}\text { Not less than } 5 \text { years of insurance period; or } \\
\text { Not less than } 10 \text { years of pension insurance period; } \\
\text { or } \\
\text { Entitlement to retirement or invalidity pension; or } \\
\text { Entitlement to disability benefit. }\end{array}$ & \\
\hline \multicolumn{3}{|l|}{ Number of dependants } \\
\hline \multicolumn{3}{|l|}{ Wife } \\
\hline Age of insured at time of death & Age 50 (45 if not insured). & \\
\hline $\begin{array}{l}\text { Type of pension of insured } \\
\text { (old-age, early or invalid) }\end{array}$ & $\begin{array}{l}\text { Not less than } 5 \text { years of insurance period; or } \\
\text { not less than } 10 \text { years of pension insurance period; } \\
\text { or } \\
\text { entitlement to retirement or invalidity pension; or } \\
\text { entitlement to disability benefit. }\end{array}$ & \\
\hline \multicolumn{3}{|l|}{ Number of dependants } \\
\hline \multicolumn{3}{|l|}{ Children } \\
\hline Age/Education status & $\begin{array}{l}\text { Until age } 15 \text { ( } 18 \text { if registered unemployed); or } \\
\text { until the end of regular schooling (maximum up to } \\
\text { age 26). } \\
\text { If incapable for work -.as long as the incapability } \\
\text { lasts. }\end{array}$ & \\
\hline Other Relatives Eligible & $\begin{array}{l}\text { If nourished by the insured: parents, brothers and } \\
\text { sisters, grandchildren and other parentless children } \\
\text { if adopted or under tuition of the insured. }\end{array}$ & \\
\hline \multicolumn{3}{|l|}{$\begin{array}{l}\text { Benefits } \\
\text { Husband and Wife }\end{array}$} \\
\hline $\begin{array}{l}\text { Formula or schedule for } \\
\text { calculation of benefits (proportion } \\
\text { of insured's pension) }\end{array}$ & $\begin{array}{l}\text { Allotment of retirement or invalidity pension the } \\
\text { insured was entitled to, depending on the number } \\
\text { of family members: } 70-100 \% \text {. }\end{array}$ & \\
\hline $\begin{array}{l}\text { Indexation of benefits (price or } \\
\text { wage, or none) }\end{array}$ & Wage. & \\
\hline Maximum pension & $310 \%$ of average wage $+/-0.85$ & \\
\hline Minimum pension & Pension rating base for 20 years of insurance.. & \\
\hline \multicolumn{3}{|l|}{$\begin{array}{l}\text { Supplementary pension (means } \\
\text { tested income supplement for } \\
\text { pensioners) }\end{array}$} \\
\hline \multicolumn{3}{|l|}{$\begin{array}{l}\text { Tax on Benefits } \\
\text { (if yes, specify type and rate) }\end{array}$} \\
\hline Other Benefits & $\begin{array}{l}\text { Severance and provision if the widower (widow) is } \\
\text { not eligible to survivors pension and is not } \\
\text { employed or insured.. }\end{array}$ & \\
\hline Duration of Benefits & & \\
\hline
\end{tabular}

